\title{
River Protection Project Mission Analysis Waste Blending Study
}

\author{
Gary Stegen(AEM Consulting, LLC) \\ Washington River Protection Solutions \\ Richland, WA 99352 \\ U.S. Department of Energy Contract DE-AC27-08RV14800
EDT/ECN: DRF UC:
Cost Center: 2GB00 Charge Code: 200700
B\&R Code: Total Pages: 90 N.F. $4-19-10$

Key Words: RPP-RPT-42968, RPP-RPT-42577, RPP-RPT-26040, RPP-RPT-41742, SVF-1427, SVF1623, SVF-1663, SVF-1767, SVF-1768, SVF-1813, Blending, HTWOS, Hanford Tank Waste Operations Simulator.

Abstract: Preliminary evaluation for blending Hanford site waste with the objective of minimizing the amount of high-level waste (HLW) glass volumes without major changes to the overall waste retrieval and processing sequences currently planned. The evaluation utilizes simplified spreadsheet models developed to allow screening type comparisons of blending options without the need to use the Hanford Tank Waste Operations Simulator (HTWOS) model. The blending scenarios evaluated are expected to increase tank farm operation costs due to increased waste transfers. Benefit would be derived from shorter operating time period for tank waste processing facilities, reduced onsite storage of immobilized HLW, and reduced offsite transportation and disposal costs for the immobilized HLW.

TRADEMARK DISCLAIMER. Reference herein to any specific commercial product, process, or service by trade name, trademark, manufacturer, or otherwise, does not necessarily constitute or imply its endorsement, recommendation, or favoring by the United States Government or any agency thereof or its contractors or subcontractors.

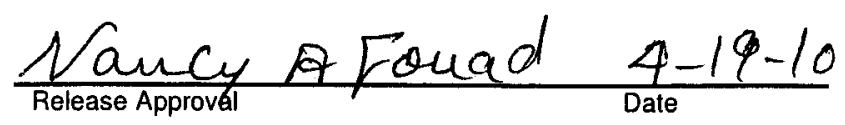

Approved For Public Release

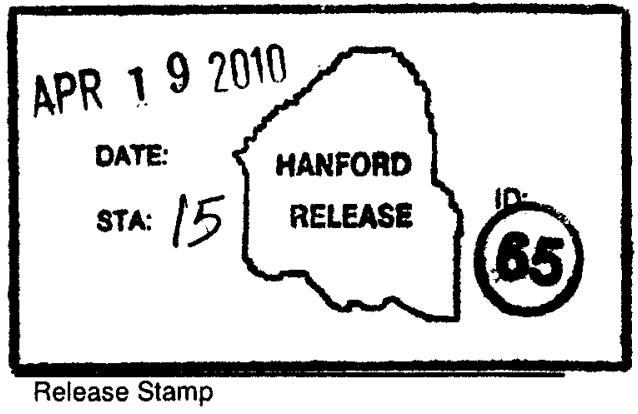

Release Stamp 


\section{River Protection Project Mission Analysis Waste Blending Study}

Prepared by:

Gary Stegen

James Baker

Robert Ferebauer

A E M Consulting, LLC

D.H. Shuford

Mission Analysis Engineering

Washington River Protection Solutions, LLC

Date Published

February 2010

Prepared for the U.S. Department of Energy

Assistant Secretary for Environmental Management

Contractor for the U.S. Department of Energy

Office of River Protection under Contract DE-AC27-08RV14800

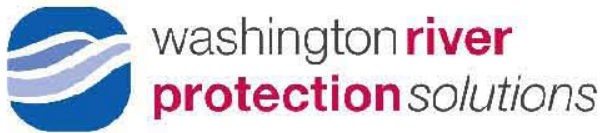

P.O. Box 850

Richland, Washington 


\section{EXECUTIVE SUMMARY}

A preliminary evaluation was performed on concepts for blending Hanford Site tank waste with the objective of minimizing high-level waste (HLW) glass volumes without major changes to the overall waste retrieval and processing sequences currently planned. The evaluation is based on the ORP-11242, River Protection Project System Plan, Revision 4 (System Plan) Unconstrained Case Waste Tank and Immobilization Project (WTP) feed batch composition and sequence. The evaluation utilized simplified spreadsheet models developed to allow screening type comparisons of blending options without the need to use the Hanford Tank Waste Operations Simulator (HTWOS) model.

A base case designed to avoid meaningful blending of feed batches was developed for comparison with blending alternatives. Leached solids washing efficiency and HLW melter sulfate retention were adjusted from the Unconstrained Case values to more closely match recent WTP performance predictions. These adjustments for the study base case resulted in a reduction in HLW glass quantity by about $10 \%$ compared to the System Plan Unconstrained Case.

Tank farm blending was evaluated based on blending selected wastes planned for delivery within a rolling 1/2- to 2 -year window. No credit was taken for blending the first four batches based on the assumption that blending would be accomplished in part during refilling of tanks initially emptied by transfers to the WTP. The tank farm blending cases resulted in about $20 \%$ reduction in estimated HLW glass volume compared to the study base case.

Blending partial batches in the tank farm tanks used for HLW transfers to WTP was evaluated based on refilling the WTP feed transfer tank with the next planned WTP feed batch each time one half of the feed tank contents have been transferred. This evaluation reduced the HLW glass quantity by about $10 \%$ compared to the base case. A side benefit of this approach is that WTP feed composition would be more consistent and predictable, which is expected to result in improved operations.

The blending scenarios evaluated are expected to increase tank farm operation costs due to increased waste transfers. The increased tank farm operation costs are a small fraction of expected savings, which result primarily from:

- A shorter operating time period for tank waste processing facilities,

- $\quad$ Reduced onsite storage for immobilized HLW, and

- $\quad$ Reduced offsite transportation and disposal costs for the immobilized HLW.

However, it should be recognized that the capacity of other waste treatment systems (e.g., waste pretreatment, low-activity waste immobilization, and secondary liquid waste treatment) must be increased to take full advantage of cost savings as sociated with a shorter operating time period. 


\section{Table of Contents}

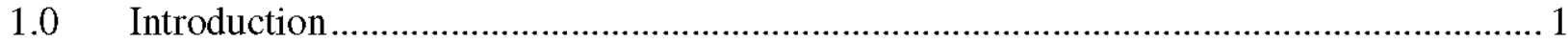

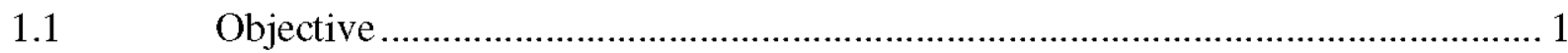

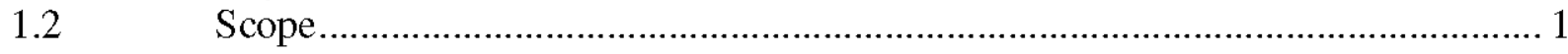

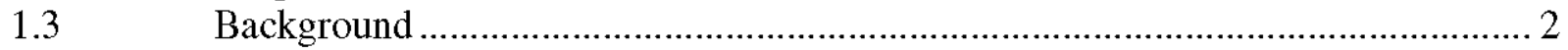

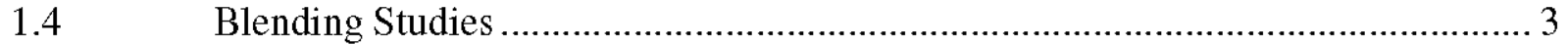

2.0 Conclusions and Recommendations ....................................................................... 3

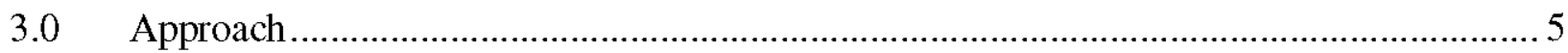

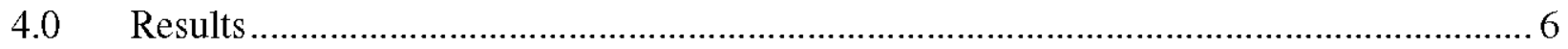

4.1 Calculation Tools and Macro Batch Definition .............................................. 6

4.2 Development of a Base Case for Blending Comparisons .................................. 8

Evaluation of Solids Washing Efficiency .......................................... 9

Melter Sulfate Retention ............................................................... 12

Initial Blending results .......................................................................... 13

4.3.1 Tank Farm Batch Blending ......................................................... 13

4.3.2 Blending of Partial Batches in Waste Feed Transfer Tanks .................... 14

4.3.3 Low-Activity Waste Glass Impacts from Blending ............................. 15

$5.0 \quad$ Functions Requirements and Objectives......................................................... 15

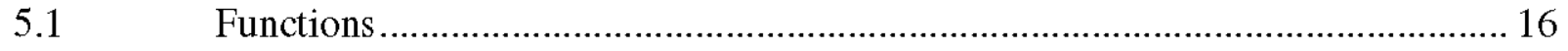

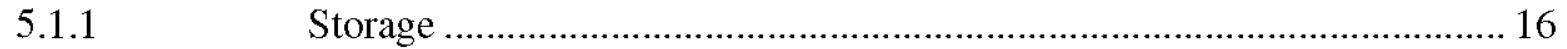

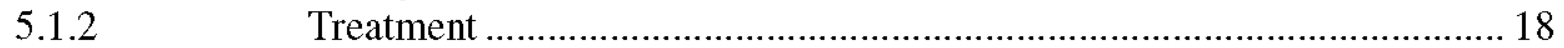

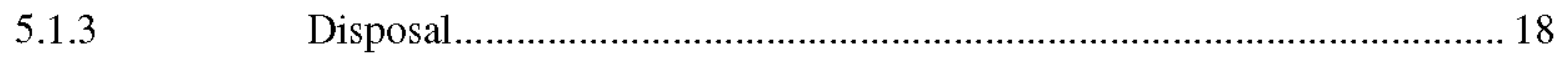

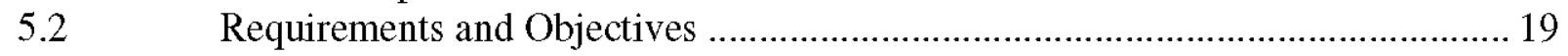

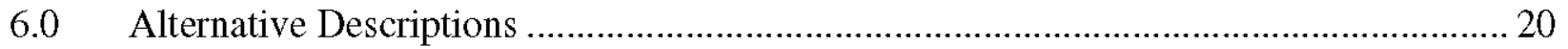

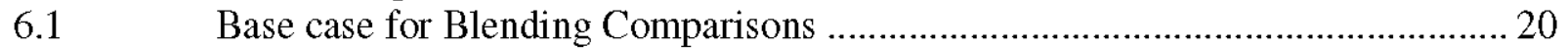

6.2 Waste Treatment and Immobilization Plant Incidental Blending ........................ 21

6.3 Blending of Waste Batches in Tank Farms..................................................... 22

6.4 Blending of Partial Batches in Waste Feed Tanks ........................................ 22

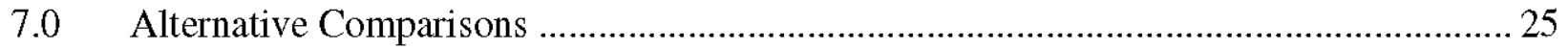

7.1 Unblended and Incidental Blending Cases .............................................2 25

Evaluation of Solids Washing Efficiency ........................................... 26

7.1.2 Melter Sulfate Retention ............................................................. 34

7.1.3 Base Case Results ....................................................................... 35

7.1.4 Waste Treatment and Immobilization Plant Incidental Blending............. 35

7.2 Blending of Waste Batches in Tank Farms ................................................... 35

7.2.1 Effect of Blending Waste Batches on High-Level Waste Quantity.......... 36

7.2.2 Potential Impacts to Tank Farm Operations ........................................... 39

7.3 Blending of Partial Batches in Waste Feed Tanks ............................................. 41

7.3.1 Blending Half Batches in the Feed Transfer Tanks ................................ 42

7.3.2 Potential Impacts to Tank Farm Operations ........................................... 43

7.4 Qualitative Assessment of Blending Alternatives ........................................... 45

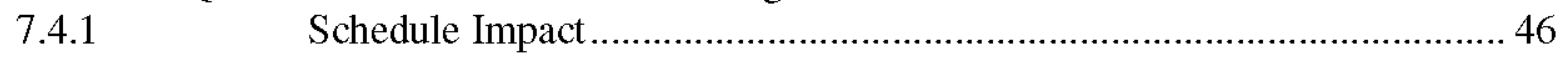

Cost Impact ............................................................................. 46

7.5 Application to Hanford Tank waste Operation Simulator Modeling.................. 49

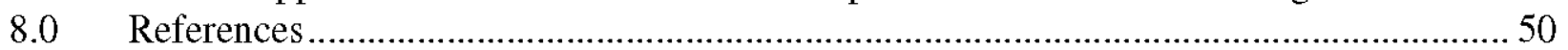


RPP-RPT-42968 Revision 0

\section{LIST OF APPENDICES}

APPENDIX A - HIGH-LEVEL WASTE GLASS RUN SUMMARIES …………................... A-1

APPENDIX B - BLENDING STUDY FEED VECTOR BATCHES AND SOURCE

TANKS

\section{LIST OF FIGURES}

Figure 1-1. System Plan Waste Process Flows for the Unconstrained Case .............................. 2

Figure 4-1. Sulfate in Stream 19 Versus Overall Washing Efficiency..................................... 10

Figure 4-2. Effect of Soluble Component Purge Efficiency on High-Level Waste Glass Quantity.

Figure 4-3. Effect of Melter Sulfate Retention and Purge Efficiency on High-Level Waste Glass.

Figure 4-4. Effect of Blending and Purge Efficiency on High-Level Waste Glass Quantity...... 14

Figure 5-1. River Protection Project System Unconstrained Case Simplified Process Flow

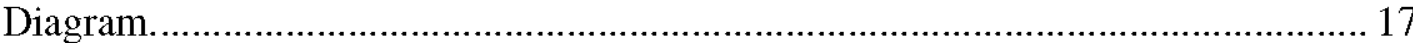

Figure 6-1. Feed Transfer Tank Blending Scheme............................................................. 24

Figure 7-1. Variation of High-Level Waste Vitrification Feed Component Mass Estimates with

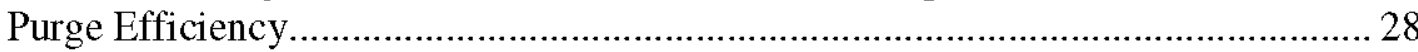

Figure 7-2. Effect of Soluble Component Purge Efficiency on High-Level Waste Glass

Quantity. 29

Figure 7-3. Effect of Melter Sulfate Retention and Purge Efficiency on High-Level Waste Glass

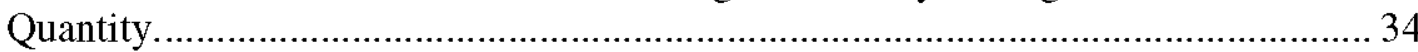

Figure 7-4. Effect of Blending and Purge Efficiency on High-Level Waste Glass...................... 38

Figure 7-5. Effect of Blending and Sulfate Retention on High-Level Waste Glass Quantity..... 38

\section{LIST OF TABLES}

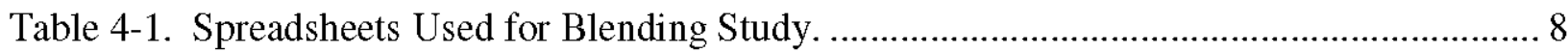

Table 4-2. Results of Solids Washing Calculations............................................................... 10

Table 4-3. Effect of Solids Washing on Total High-Level Waste Glass Quantity...................... 11

Table 4-4. Effect of Melter Sulfate Retention on High-Level Waste Glass Quantity.................. 12

Table 4-5. Summary of Initial Tank Farm Blending Results........................................................ 14

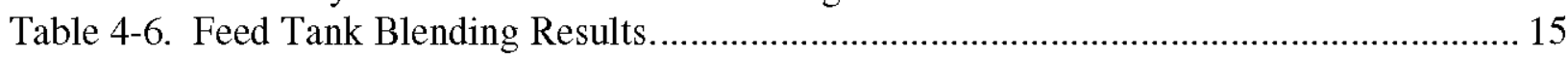

Table 6-1. System Plan Unconstrained Case Description. ......................................................... 21

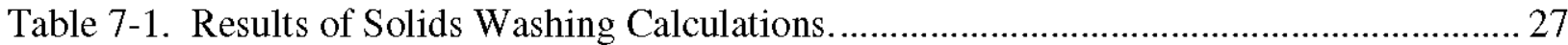

Table 7-2. Effect of Solids Washing on Total High-Level Waste Glass Quantity...................... 29

Table 7-3. Effect of Washing Efficiency on Batch by Batch Glass Quantities. (4 pages) ........... 30

Table 7-4. Effect of Melter Sulfate Retention on High-Level Waste Glass Quantity.................. 34

Table 7-5. Comparison of 56 and 116 Macro Batch Case High-Level Waste Glass Quantities. 35

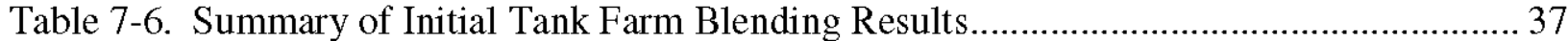

Table 7-7. Impact of Tank Farm Blending on Required Waste Transfers................................. 40

Table 7-8. Additional Tank Farm Transfers for 23 Macro Batch Blending Case. ....................... 41

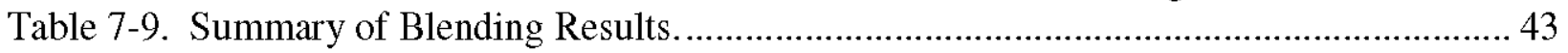

Table 7-10. Qualitative Assessments of Tank Blending Alternatives........................................ 46 
Table 7-11. Cost Savings for Blending Scenarios.

Table 7-12. Qualitative Assessment of Tank Blending against River Protection Project Mission Requirements.

\section{LIST OF TERMS}

\section{Abbreviations and Acronyms}

Al

aluminum

$\mathrm{CH}$

contact-handled

DST

FY double-shell tank

HLW fiscal year

HTWOS

high-level waste

IHLW

Hanford Tank Waste Operations Simulator

ILAW

LAW

$\mathrm{Na}$ immobilized high-level waste immobilized low-activity waste

RPP low-activity waste sodium

SBS

SST

River Protection Project submerged bed scrubber

System Plan single-shell tank

TRL

TRU River Protection Project System Plan (ORP-11242, Rev. 4)

WRPS Technology Readiness Level

WTP transuranic Washington River Protection Solutions Waste Treatment and Immobilization Plant

\section{Units}

$\mathrm{g} / \mathrm{ml}$ grams per milliliter

$\mathrm{kg} \quad$ kilogram

L liter

M molar

Mgal million gallon

MT metric ton

MTG metric ton of glass

wt\% weight percent 


\subsection{INTRODUCTION}

Material flow from tank storage through retrieval, feed staging, and treatment is modeled by the Hanford Tank Waste Operations Simulator (HTWOS) to support the River Protection Project (RPP) System Planning process. However, due to complexity of the HTWOS, simplified spreadsheet-based material balance models are used to perform preliminary alternative evaluations to reduce the number of alternatives evaluated using the HTWOS model. This study uses a simplified spreadsheet approach to evaluate waste blending and related topics to help identify potentially attractive alternatives to be further evaluated with the more detailed HTWOS model.

\subsection{OBJECTIVE}

The primary objective of this study is to perform preliminary evaluations of potentially attractive alternatives for blending/optimizing feed for the high-level waste (HLW) process as a method of reducing the total quantity of HLW glass produced by the tank waste mission. Reducing quantity of HLW glass produced has the potential to shorten the mission operating schedule and reduce life-cycle costs for process operation and for storage, transportation, and disposal of the immobilized HLW (IHLW).

\subsection{SCOPE}

The scope of work addressed by this document includes:

- Development of calculation tools (spreadsheet workbooks).

- Evaluation of the effect of solids washing and melter sulfate retention on glass quantity.

- Definition of a base case for blending comparisons, including: a set of 116 macro batches of waste feed to WTP based on the System Plan Unconstrained Case feed vector, and selected WTP process performance factors.

- $\quad$ Calculation of HLW glass quantities for the base case, several partial blending cases, and a total blend case.

Results are summarized in Section 4.0 and discussed in more detail in Section 7.0. The results described in this document (in particular, specific glass quantity estimates) should not be confused with formal predictions of the RPP material flows. Simplifications necessary to perform the spreadsheet-based calculations neglect factors that can have a significant impact on blending feasibility (e.g., logistic interferences) and must be addressed by HTWOS modeling efforts. Therefore, while glass quantity estimates were required to perform the blending study described in this report, the relative change in glass quantity as a result of blending alternatives should be considered more important than the absolute glass quantities predicted. These relative 
changes in glass quantity are used as a basis for recommending blending alternatives that could be considered in future HTWOS predictions to construct material balance estimates resulting in reduced quantities of HLW glass from the tank waste processing mission.

\subsection{BACKGROUND}

Revision 4 of ORP-11242, River Protection Project System Plan (hereafter System Plan), is used to provide a basis for alignment of program costs, scope, and schedules, from upper-tier contracts to individual facility operation plans. The System Plan also serves to define issues that must be resolved to ensure success of the cleanup mission. The predicted flow of materials through the tank waste retrieval, storage, and processing systems as a function of time is important to integrating the RPP facilities (see Figure 1-1). The material flows identify the required capacity and operating duration for individual facilities as the cleanup mission is completed, which influences program costs and schedule estimates.

Figure 1-1. System Plan Waste Process Flows for the Unconstrained Case.

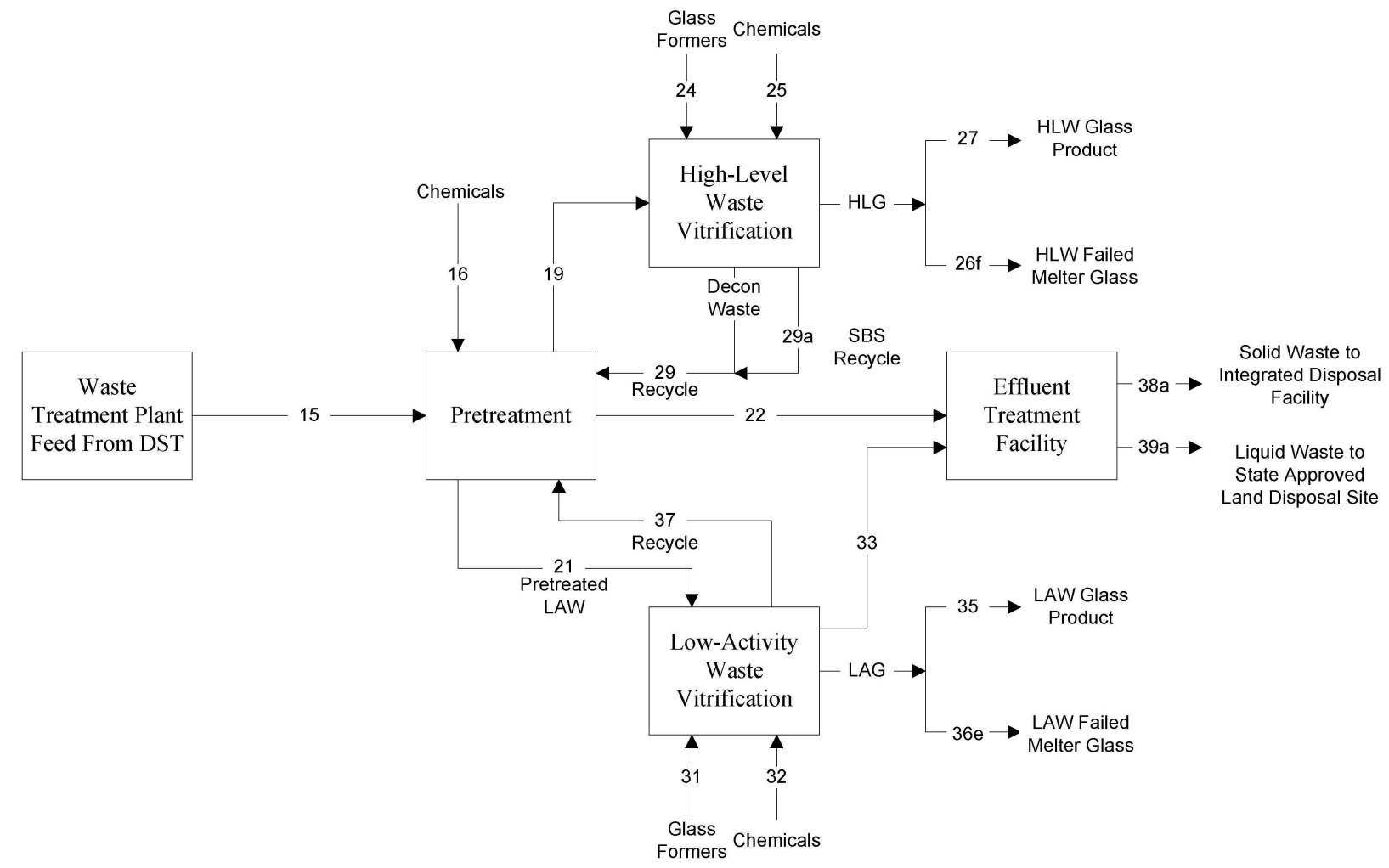

HTWOS is a complex program that models process steps and transfers between tanks and facilities over the mission life. This results in tracking thousands of waste transfers predicted during operating time periods of 20 to 40 years as waste moves through storage, retrieval, feed staging and multiple treatment processes. HTWOS predicts the outcomes of various proposed operating scenarios. Overall, the HTWOS model incorporates 670 waste treatment vessels and operations, and unenumerated transfer and routing system segments. 
Alternatives can be evaluated using the HTWOS model. However, due to complexity of the HTWOS, significant time periods can be required to incorporate code changes representing new alternatives. Therefore, simplified spreadsheet-based material balance models are used for performing preliminary alternative evaluations in order to reduce turn-around time.

\subsection{BLENDING STUDIES}

Because of substantial tank-by-tank variations in Hanford tank waste sludge compositions, separately processing waste from individual tanks is expected to result in significantly lower average glass waste loadings than could be achieved by blending wastes to provide a more uniform composition. Previous blending studies (e.g., RPP-RPT-26040, Pairwise Blending of High-Level Waste) have evaluated potential reductions of HLW glass quantity by sludge blending with the following primary conclusions:

- $\quad$ Processing tank by tank produces the largest amount of HLW.

- Blending all tanks ("Total Blend") and then processing produces the least amount of HLW.

- $\quad$ Pairwise blending of specific selected tanks results in substantial reductions in HLW.

- Incidental blending, where some blending occurs naturally during retrieval and inter-tank transfers prior to transfer to WTP, provides significant improvement over segregation of waste from each tank.

- Unconstrained intentional pairwise blending of problem wastes may yield close to the least amount of HLW.

Other factors inferred from prior work include:

- $\quad$ Blending will likely get easier later in the program as tank space is freed up.

- Known issues with intentional blending include limited tank space, tank farm retrieval logistics, and the impact of WTP feed tank waste sampling hold time and batch transfer philosophy on blending.

\subsection{CONCLUSIONS AND RECOMMENDATIONS}

The following conclusions and recommendations are derived from the blending evaluations performed in this study.

Conclusion 1: Development of a base glass quantity for blending comparisons included investigation of the effect of waste solid washing efficiency and melter sulfate retention on HLW glass quantity. Based on the simplified estimates, wash efficiencies and melter sulfate retention factors approximating the latest WTP flowsheet values resulted in an estimated HLW glass quantity approximately $10 \%$ less than predicted by HTWOS for the System Plan Unconstrained Case. 
Recommendation 1: While not specifically associated with blending, it is recommended that the HTWOS incorporate a more detailed model of separating soluble from insoluble waste components in the Pretreatment Facility and update the path of sulfur in melters.

Conclusion 2: Identifying specific blends of waste batches that are within a moving $1 \frac{1}{2}$ - to 2-year time window from the System Plan Unconstrained Case waste transfer sequence is estimated to reduce total HLW glass quantities by approximately $20 \%$ relative to the base glass quantity used for comparison in this study. This is in addition to the reductions associated with wash efficiency and sulfate retention factor updates incorporated by the simplified model.

Recommendation 2: Estimates based on specific blends from the Unconstrained Case waste batch sequence indicate the potential HLW glass quantity reductions associated with a modest blending scheme that could be implemented during actual operations. This approach is dependent on the waste retrieval sequence implemented, which varies the waste batches available for blending within a time window.

It is expected that incorporation of the time window blending approach may be difficult to automate in HTWOS. Separate side calculations could be used as inputs to define specific tank blends for a particular waste transfer sequence once it is established (similar to the calculations performed in this study). Therefore, while testing within the HTWOS modeling calculations could be considered, it is recommended that implementation of an automatic routine to select tank farm blending scenarios within the HTWOS model be deferred until the retrieval sequence is projected to remain relatively constant.

Conclusion 3: The preliminary evaluation indicates that blending in the double-shell feed tanks used for transfers to WTP can yield significant HLW glass reductions. This approach could be described as intentionally increasing the effect of incidental blending. The simplified estimates indicate that HLW glass quantity is reduced by approximately $10 \%$ relative to the base glass quantity by using a transfer scheme where the tank farm tank used for waste transfers is refilled each time one half of its contents have been transferred to WTP.

Recommendation 3: Estimates in this study indicate that a waste transfer sequence that enhances incidental blending within tank farms can result in a significant reduction in HLW glass quantities. This approach is projected to be somewhat independent of the ultimate waste retrieval sequence and appears amenable to automation in HTWOS. However, the simplified analysis does not address potential logistic issues that may arise by implementing the blending scheme. It is recommended that approach of enhancing incidental blending during waste transfers through the double-shell tanks (DST) be tested using HTWOS to determine if logistics are feasible and confirm the blending benefits predicted by the simplified calculations.

While not fully evaluated, initial blending results suggest that a combination of tank farm blending, blending in the WTP feed transfer tanks, and optimization of the retrieval/staging/transfer sequence can yield total HLW glass quantities that approach the total blend case without need for major changes to the overall retrieval strategy and sequence. 


\subsection{APPROACH}

The following summarizes conceptual methods used for this study.

- $\quad$ Existing HLW glass formulation calculator models were used (development of new glass models/calculators is not included in the study scope). Simplified spreadsheet models have been developed to estimate HLW melter feed compositions from feed vector or other waste composition data. Output from these models is used as input to the existing HLW glass formulation calculator models.

- $\quad$ System Plan feed and glass batch data were reviewed to identify potential opportunities for blending. Limiting components for specific batches were identified and potential opportunities for mitigating problem components explored. For example, certain feed batches have problem components that significantly restrict waste loading, while batches that are currently planned for processing in roughly the same time frame have reduced quantities of these problem components. These may represent productive blending opportunities that can be accomplished with modest changes to waste retrieval and WTP feed staging plans.

- $\quad$ System Plan results show relatively low waste loadings for a number of batches based on sodium and sulfate content. WTP process performance assumptions were examined to evaluate the potential to mitigate glass waste loading constraints by improved washing of the sludge to remove sodium, sulfate, and other soluble components. The effect of melter sulfate retention on HLW glass quantity was also examined.

- Where waste batch blending is identified as an attractive method of reducing glass quantities, the waste batches were traced to their original source tank.

The potential impact of alternative transfer rules within the DST system were investigated using the HLW glass formulation calculator combined with estimates of waste batch composition changes projected by the transfer rule changes. Where feasible, transfer rules are developed as part of the study.

The following limitations apply to this study:

- $\quad$ This study is based on existing WTP feed vector information on projected waste batch inventories, wash factors, and leach factors.

- The study is based on use of existing HLW glass formulation/calculation models. Glass quantity calculations presented herein use the limits as stated; that is, no allowances are added for measurement uncertainty, uncertainty in the glass models, or other operational inefficiencies. 
- $\quad$ Technical work for the current study was developed based on the draft Revision 4 of the System Plan issued in April 2009. The Baseline Case that appears in the final issued version of the System Plan, Revision 4 was added later and, therefore, was not directly considered in the blending cases reported herein. It is expected that the conclusions and recommendations remain generally valid for the Baseline Case, although exact numerical values are likely to be slightly different for the Baseline Case.

\subsection{RESULTS}

This section provides a summary of results, while Section 7.0 provides an expanded description of the analysis for each alternative.

\subsection{CALCULATION TOOLS AND MACRO BATCH DEFINITION}

Spreadsheet workbooks listed in Table 4-1 were used for calculations supporting the blending study. Workbooks shown with SVF numbers SVF-MARxx were developed specifically to support this study and other mission analysis work and were assigned interim tracking numbers pending assignment of WRPS SVF numbers. SVF 1427 and 1623 were previously developed by Washington River Protection Solutions (WRPS) and were used to perform HLW glass formulation calculations for the blending study. Additional information on the simplified spreadsheet modeling approach is provided in RPP-RPT-42577, River Protection Project Mission Analysis Material Balance Description.

The calculation sequence generally starts with a "feed vector," which defines the overall sequence, scheduled transfer dates, and composition of waste feed batches planned to be transferred from tank farms to the WTP for a given scenario. The feed vector defines solid phase composition, liquid phase composition, mass, volume, and wash factors/leach factors for specific components. Results presented in this report are based on the System Plan Unconstrained Case feed vector, HTWOS output file "batches-to-wtp-fully-water-washed, case SP4 UC, run date 3/31/2009." This case defines 450 waste feed batches to be transferred.

SVF-1768 - Feed Vector to Macro Batch Calculator is used to combine feed vector batches into processing batches for current studies. For the base case, the 450 feed vector batches are combined to produce 116 macro batches as discussed in Section 6.1. The output of this spreadsheet provides input data for SVF-1767 Mission Analysis Process Stream Calculator. For each macro batch SVF-1767 calculates several WTP process streams based on a simplified steady state mass balance model, and input performance factors related to WTP process performance assumptions. Net waste feed oxides incorporated into the HLW glass are calculated and the results are arranged in an array that is directly compatible with the input data format required for the existing HLW glass calculator programs (SVF-1427 and SVF-1623). For each macro batch, the Process Stream Calculator also calculates the low-activity waste (LAW) glass mass, waste loading, and liquid process waste compositions for the LAW process. 
Workbook SVF-1824 was developed to support the feed transfer tank blending evaluation. This workbook takes the macro batch output from SVF-1768 and calculated a set of blended macro batches based on a feed tank blending scenario. Output of SVF-1824 is pasted into SVF-1767 Mission Analysis Process Stream Calculator for calculation of WTP process streams.

Data on net melter feed oxides to HLW glass are provided as input to the HLW glass calculator spreadsheets (SVF-1427 and SVF-1623). These perform optimization routines intended to minimize HLW glass quantity for each macro batch. SVF-1623 is a modified version of SVF-1427. Calculations were performed for approximately 1000 macro batches using both models and the results cross checked. In all cases the resulting glass quantities were either equal or smaller using SVF-1623, while all glass constraints were met. The conclusion from this comparison is that SVF-1623 is more effective in optimizing the HLW glass formulation. SVF-1427 also frequently fails to converge and must be run multiple times to get convergence, while SVF-1623 rarely fails to converge. Therefore, all HLW glass results included in this report were generated using SVF-1623.

Results for each group of macro batches from the glass calculator spreadsheet are compiled in SVF-1817 Mission Analysis Glass Batch Results Summary. This spreadsheet also performs analyses of the glass data and formats key results into a one-page summary. The one-page summaries for glass runs used for this report are provided in Appendix A. Appendix B provides a summary of feed vector batches and primary source tanks that are included in each macro batch for the various blending cases. 
Table 4-1. Spreadsheets Used for Blending Study.

\begin{tabular}{|c|c|c|}
\hline SVF Number & Workbook Title & Summary Description \\
\hline $\begin{array}{l}\text { SVF-1756 } \\
\text { Previously } \\
\text { SVF-MAR02 }\end{array}$ & $\begin{array}{l}\text { SVF-1756 Performance Factor } \\
\text { Calculation - Planning Case }\end{array}$ & $\begin{array}{l}\text { This workbook calculates selected process performance } \\
\text { factors based on the System Plan planning case summary } \\
\text { mass balance in SVF-1663 Rev. } 1 \text {. }\end{array}$ \\
\hline $\begin{array}{l}\text { SVF-1768 } \\
\text { Previously } \\
\text { SVF-MAR03 }\end{array}$ & $\begin{array}{l}\text { YYMMDD-0 SVF-1768 - } \\
\text { Macro Batch Calculator - UC - }\end{array}$ & $\begin{array}{l}\text { This workbook combines feed vector batches for the } \\
\text { Unconstrained Case into macro batches. The number of } \\
\text { macro batches and the feed vector batches included in each } \\
\text { macro batch varies with the specific study or case under } \\
\text { consideration. }\end{array}$ \\
\hline $\begin{array}{l}\text { SVF-1767 } \\
\text { Previously } \\
\text { SVF-MAR04 }\end{array}$ & $\begin{array}{l}\text { YYMMDD-N-SVF-1767 } \\
\text { Mission Analysis Process } \\
\text { Stream Calculator }\end{array}$ & $\begin{array}{l}\text { Workbook calculates selected WTP process streams for each } \\
\text { macro batch. WTP performance factors and SBS recycle } \\
\text { configuration may be varied to evaluate effect on output } \\
\text { process stream characteristics. Process streams calculated } \\
\text { include HLW melter feed net of offgas losses, LAW glass, } \\
\text { SBS recycle stream, and liquid process effluent streams. }\end{array}$ \\
\hline $\begin{array}{l}\text { SVF-1817 } \\
\text { Previously } \\
\text { SVF-MAR05 }\end{array}$ & $\begin{array}{l}\text { YYMMDD-N-SVF-1817 } \\
\text { Mission Analysis Glass Batch } \\
\text { Results Summary }\end{array}$ & $\begin{array}{l}\text { This workbook compiles results of HLW glass calculator runs } \\
\text { and performs data analysis calculations using glass calculator } \\
\text { results. }\end{array}$ \\
\hline $\begin{array}{l}\text { SVF-1824 } \\
\text { previously } \\
\text { SVF-MAR15 } \\
\end{array}$ & $\begin{array}{l}\text { YYMMDD-N-SVF-1824 } \\
\text { Mission Analysis Feed Tank } \\
\text { Blending Blended-Batch } \\
\text { Calculator }\end{array}$ & $\begin{array}{l}\text { This workbook calculates blended macro batches assuming a } \\
\text { feed tank blending scenario. }\end{array}$ \\
\hline $\begin{array}{l}\text { SVF-1427 } \\
\text { Rev } 0\end{array}$ & $\begin{array}{l}\text { SP3_HLW_Glass_Limit_Sensiti } \\
\text { vity.xls }\end{array}$ & $\begin{array}{l}\text { Calculates optimized HLW glass composition for each macro } \\
\text { batch based on melter feed waste oxide composition and } \\
\text { defined glass composition limits. }\end{array}$ \\
\hline $\begin{array}{l}\text { SVF-1623 } \\
\text { Rev } 0\end{array}$ & $\begin{array}{l}\text { HLW_Glass_Formulation_Verif } \\
\text { y_v_0.xlsm }\end{array}$ & $\begin{array}{l}\text { Calculates optimized HLW glass composition for each macro } \\
\text { batch based on melter feed waste oxide composition and } \\
\text { defined glass composition limits. }\end{array}$ \\
\hline $\begin{array}{l}\text { HLW } \\
\text { LAW }\end{array}$ & $\begin{array}{l}\text { vel waste. } \\
\text { tivity waste. }\end{array}$ & $\begin{array}{ll}\text { SBS } & =\text { submerged bed scrubber. } \\
\text { WTP } & =\text { Waste Treatment and Immobilization Plant. }\end{array}$ \\
\hline
\end{tabular}

\subsection{DEVELOPMENT OF A BASE CASE FOR BLENDING COMPARISONS}

Prior to development of blending comparisons, key WTP processing parameters were examined to assess their impact on HLW glass quantities. HLW glass quantities were found to be fairly sensitive to pretreatment solids washing efficiency and HLW melter sulfate retention assumptions. These were examined in more detail and compared with HTWOS results and current WTP flowsheet bases. Based on the result of this evaluation a base case for comparisons is established with the following key characteristics:

- $\quad 116$ macro batches of waste transferred to WTP, based on consolidation from 450 feed vector batches for the System Plan Unconstrained Case. Most of the difference between the 116 macro batches and the feed vector is a result of the 160,000-gallon limit on volume of HLW batches transferred. This limitation results in about six feed vector batches required to transfer a single tank/batch of HLW. The groups of feed vector 
batches with the same composition are combined for the 116 macro batch base case substantially reduce the number of batches compared to the feed vector. The set of 116 macro batches was designed to avoid meaningful waste blending. Appendix B identifies specific feed vector batches and primary waste source tanks for each of the 116 macro batches.

- Overall purge efficiency for soluble components averages about $99 \%$ for the base case.

- $\quad 67 \%$ sulfate retention for the HLW melter.

A second case was defined that attempts to take credit only for incidental blending of HLW and LAW waste that occurs in WTP due to parallel processing of the high solids HLW and low solids LAW batches. This case resulted in 56 macro batches. Appendix B identifies specific feed vector batches and primary waste source tanks for each of the 56 macro batches. Development of the base case is summarized in the following sections, and is discussed in more detail in Section 7.1.

\subsubsection{Evaluation of Solids Washing Efficiency}

Initial steps in the WTP process include caustic leaching to dissolve selected components and ultrafiltration that splits the waste into two streams: (1) a solids free feed stream for ion exchange and (2) a concentrated solids slurry stream. The solids slurry is washed by repeated dilution with water and reconcentration by purging liquid via the ultra filters. For some batches oxidative leaching to remove chromium is also performed and the slurry is washed again and reconcentrated by purging liquid though the ultra filters. The concentrated washed slurry and concentrated neutralized eluate from ion exchange are combined and transferred from pretreatment to HLW vitrification.

SVF-1767 Mission Analysis Process Stream Calculator models removal of soluble sulfur, aluminum, phosphorus, and chromium as two steps: (1) initial purge of liquid to concentrate the slurry to $20 \mathrm{wt} \%$ solids concentration, and (2) water washing and reconcentration of the leached solids. Overall purge efficiency for soluble components (combine initial solids concentration and washing) typically averages about $99 \%$ with $95 \%$ solids washing efficiency. Because of the sodium added during leaching, sodium washing is modeled simply as a parameter ( $\mathrm{P}_{\mathrm{Na} \text { (aq), 19b,15LSol }}$ ) that is proportional to soluble sodium concentration in the final washed leached solids slurry. The base case value of $\mathrm{P}_{\mathrm{Na}(\mathrm{aq}), 19 \mathrm{~b}, 15 \mathrm{LSol}}$ is 0.023 , which is equivalent to a dissolved sodium concentration of $0.25 \mathrm{~mole} / \mathrm{L}$ in the final washed solids slurry with $20 \mathrm{wt} \%$ leached solids (see also Section 7.1.1).

\subsubsection{Comparison of Calculated High-Level Waste Feed with Hanford Tank Waste} Operations Simulator Results. Calculated HLW feed components (Stream 19, Figure 1-1) and comparable HTWOS values for the System Plan Planning Case (SVF-1663 Rev. 1) are listed in Table 4-2. Figure 4-1 shows the results for sulfate graphically. Graphs for other components are included in Section 7.1.1.2. Conclusion from this comparison is that the overall purge efficiency for soluble components is about $98 \%$ for the System Plan Initial Planning Case. 


\section{RPP-RPT-42968 Revision 0}

Table 4-2. Results of Solids Washing Calculations.

\begin{tabular}{|c|c|c|c|c|c|c|}
\hline & SVF-MA & Calculatio & for HLW I & d (Stream & & SVF1663 \\
\hline Wash Efficiency & $100.00 \%$ & $98.00 \%$ & $95.00 \%$ & $90.00 \%$ & $80.00 \%$ & Not given \\
\hline $\begin{array}{l}\text { Total Purge } \\
\text { Efficiency }\end{array}$ & $100.0 \%$ & $99.7 \%$ & $99.3 \%$ & $98.5 \%$ & $97.0 \%$ & Not given \\
\hline $\begin{array}{l}\text { Sulfur as } \mathrm{SO}_{4} \text {, } \\
\mathrm{kg}\end{array}$ & $9.92 \mathrm{E}+04$ & $1.10 \mathrm{E}+05$ & $1.27 \mathrm{E}+05$ & $1.54 \mathrm{E}+05$ & $2.09 \mathrm{E}+05$ & $1.70 \mathrm{E}+05$ \\
\hline Total Al, kg & $1.90 \mathrm{E}+06$ & $1.92 \mathrm{E}+06$ & $1.95 \mathrm{E}+06$ & $1.99 \mathrm{E}+06$ & $2.09 \mathrm{E}+06$ & $1.98 \mathrm{E}+06$ \\
\hline $\mathrm{Al}(\mathrm{aq}), \mathrm{kg}$ & $0.00 \mathrm{E}+00$ & $1.92 \mathrm{E}+04$ & $4.81 \mathrm{E}+04$ & $9.61 \mathrm{E}+04$ & $1.92 \mathrm{E}+05$ & $1.50 \mathrm{E}+05$ \\
\hline $\begin{array}{l}\text { Phosphorus as } \\
\mathrm{PO}_{4}, \mathrm{~kg}\end{array}$ & $3.80 \mathrm{E}+05$ & $3.93 \mathrm{E}+05$ & 4.13E+05 & $4.46 \mathrm{E}+05$ & $5.12 \mathrm{E}+05$ & $4.72 \mathrm{E}+05$ \\
\hline $\mathrm{Na}, \mathrm{kg}$ & $1.64 \mathrm{E}+06$ & $1.83 \mathrm{E}+06$ & $2.11 \mathrm{E}+06$ & $2.56 \mathrm{E}+06$ & $3.44 \mathrm{E}+06$ & $3.24 \mathrm{E}+06$ \\
\hline $\mathrm{P}_{\mathrm{Na}(\mathrm{aq}), 19 \mathrm{~b}, 15 \mathrm{LSOl}}$ & 0 & 0.0092 & 0.023 & 0.045 & 0.088 & Not given \\
\hline $\begin{array}{l}\mathrm{Na} \text { (final) } \\
\mathrm{Mole} / \mathrm{L}\end{array}$ & 0 & 0.05 & 0.25 & 0.50 & 1.0 & Not given \\
\hline
\end{tabular}

$\mathrm{Al} \quad=\quad$ aluminum.

$\mathrm{HLW}=$ high-level waste.

$\mathrm{Na}=$ sodium.

Figure 4-1. Sulfate in Stream 19 Versus Overall Washing Efficiency.

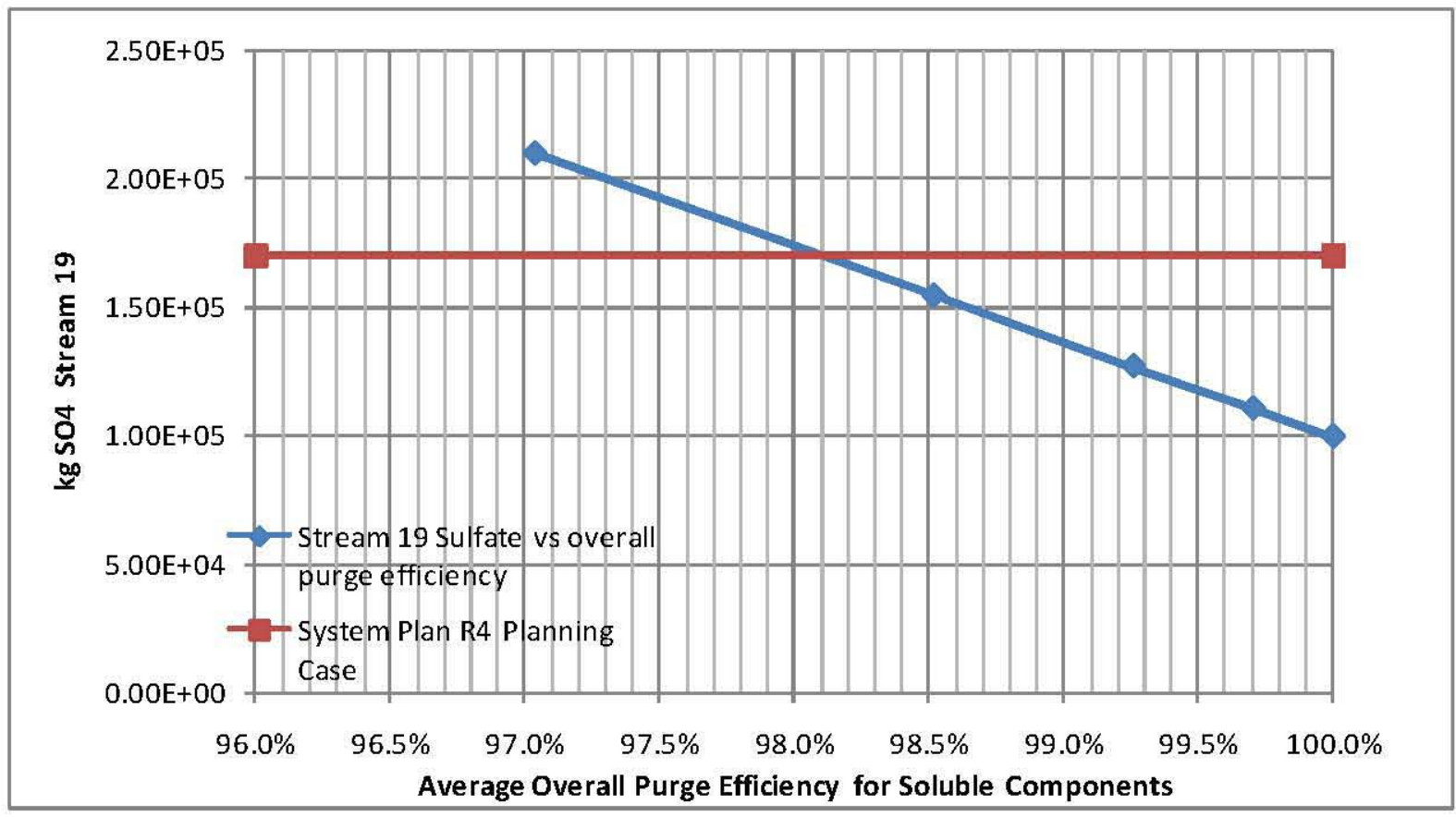


4.2.1.2 Effect of Wash Efficiency on High-Level Waste Glass Quantity. Glass quantity was calculated for each of the 116 base case macro batches as a function of purge efficiency for soluble components. Results for total glass quantity are shown in Table 4-3 and Figure 4-2. Increasing overall purge efficiency from 96 to $99 \%$ reduces estimated HLW glass by about $13 \%$ while increasing from 99 to $100 \%$ reduces HLW glass by an additional $4.5 \%$. Results for each of the 116 macro batches show that some batches are strongly influenced by purge efficiency; while for other there is little or no effect on glass quantity as washing efficiency is increased (see Section 7.1.1.2). This suggests that optimization of plant operations could involve batch by batch adjustment of purge efficiency.

Table 4-3. Effect of Solids Washing on Total High-Level Waste Glass Quantity.

\begin{tabular}{|l|c|c|c|c|}
\hline & \multicolumn{4}{|c|}{ 116 Macro Batch-(No Blending) } \\
\hline Average Overall Purge Efficiency for Solubles & $100 \%$ & $\mathbf{9 9 \%}$ & $98 \%$ & $96 \%$ \\
\hline Glass quantity (MT)* & 37,500 & $\mathbf{3 9 , 2 0 0}$ & 41,100 & 45,100 \\
\hline
\end{tabular}

*Based on melter sulfate retention of $67 \%$.

MT = metric tons.

Figure 4-2. Effect of Soluble Component Purge Efficiency on High-Level Waste Glass Quantity.

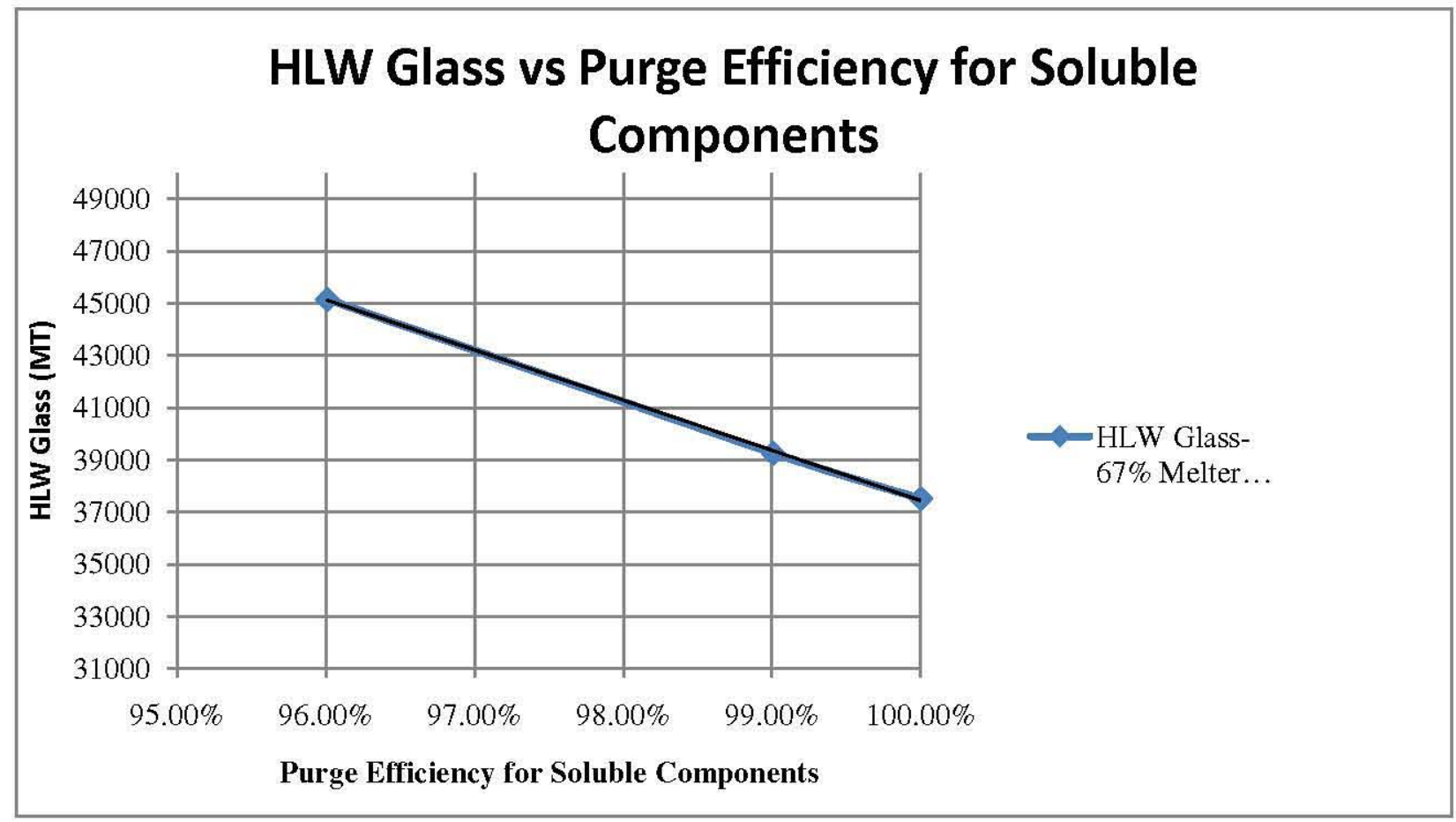




\subsubsection{Melter Sulfate Retention}

During heating and melting of melter feed, a portion of the sulfate is driven off as semi-volatile and gaseous sulfur compounds and reports to the melter offgas. Most of the sulfur compounds are removed from the offgas and report to the submerged bed scrubber condensate stream. Because sulfate content of HLW glass may limit waste loading, fractional sulfate retention in the glass is an important parameter for estimating required HLW glass quantity. Table 4-4 and Figure 4-3 summarize the results of calculated HLW glass quantity versus melter sulfate retention for the 116 macro batch base case. The case with $98 \%$ average overall purge efficiency for soluble components and $100 \%$ HLW melter sulfate retention corresponds approximately to the System Plan Unconstrained Case HTWOS calculation. The most recent WTP flowsheet (24590-WTP-RPT-PT-02-005, Flowsheet bases, Assumptions and Requirements) indicates an expected average melter sulfate retention of $67 \%$, which is used for the base case calculations herein.

Table 4-4. Effect of Melter Sulfate Retention on High-Level Waste Glass Quantity.

\begin{tabular}{|l|c|c|c|c|c|c|c|}
\hline & \multicolumn{7}{|c|}{116 Macro Batch No Blending } \\
\hline $\begin{array}{l}\text { Average Overall } \\
\text { Purge Efficiency }\end{array}$ & $96 \%$ & $96 \%$ & $98 \%$ & $98 \%$ & $99 \%$ & $\mathbf{9 9 \%}$ & $99 \%$ \\
\hline $\begin{array}{l}\text { Melter Sulfate } \\
\text { Retention }\end{array}$ & $100 \%$ & $67 \%$ & $100 \%$ & $67 \%$ & $100 \%$ & $\mathbf{6 7 \%}$ & $40 \%$ \\
\hline $\begin{array}{l}\text { Glass Quantity } \\
\text { (Metric Tons) }\end{array}$ & 50,800 & 45,100 & 45,100 & 41,100 & 42,600 & $\mathbf{3 9 , 2 0 0}$ & 37,400 \\
\hline
\end{tabular}

Figure 4-3. Effect of Melter Sulfate Retention and Purge Efficiency on High-Level Waste Glass.

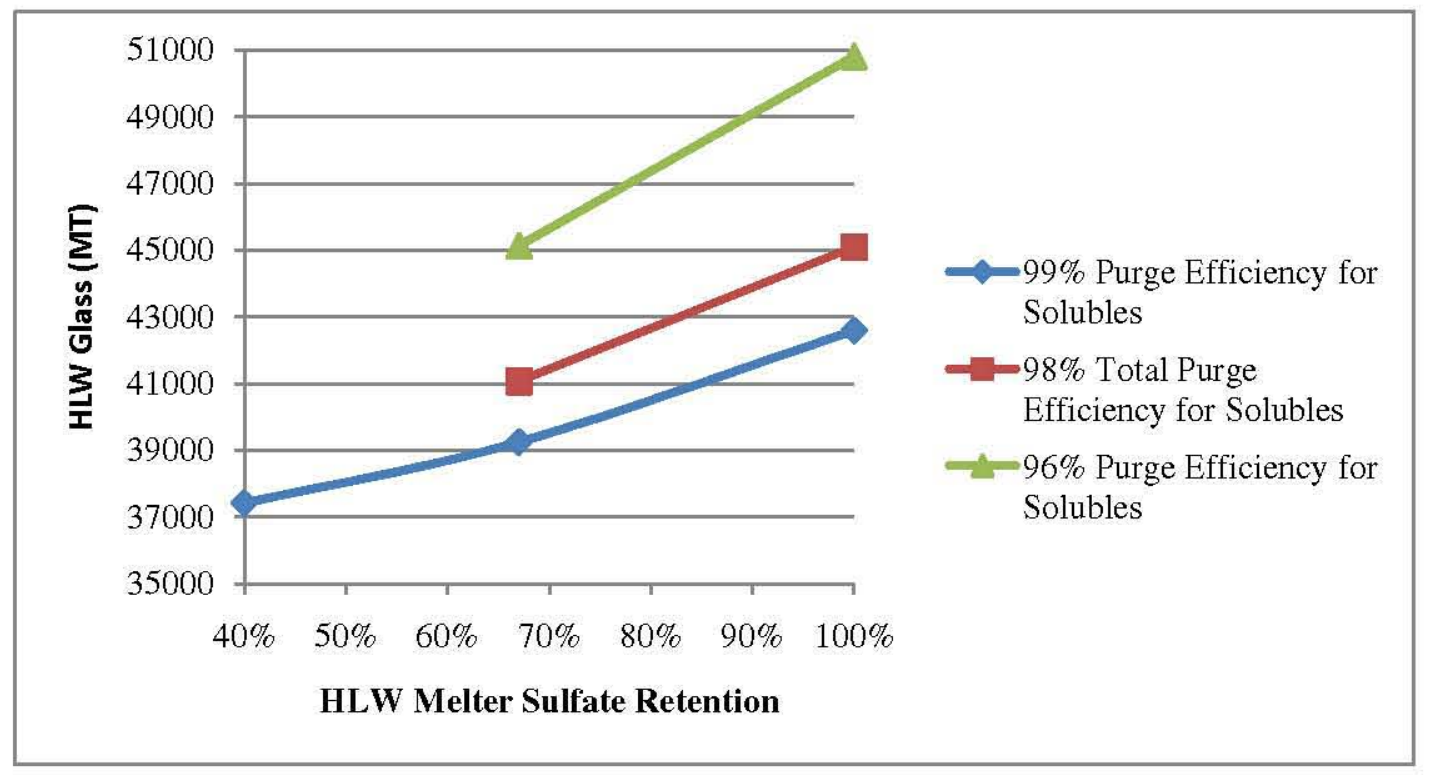


RPP-RPT-42968 Revision 0

\subsection{INITIAL BLENDING RESULTS}

Two conceptual blending approaches were evaluated: (1) blending in the tank farms during preparation of waste batches for transfer to WTP; and (2) blending in the tank used to transfer waste to WTP. Results are summarized in Sections 4.3.1 and 4.3.2, respectively. Sections 7.2 and 7.3 provide additional details.

\subsubsection{Tank Farm Batch Blending}

Results of tank farm blending evaluations are summarized in Table 4-5 and Figure 4-4. Blending evaluations were performed for four cases in addition to the 116 macro batch case:

- $\quad$ Single Macro Batch-Total Blend: All 450 feed vector batches were combined into a single total blend. With base case process performance factors, the estimated HLW glass quantity is reduce to about $29,000 \mathrm{MT}$, a $26 \%$ reduction compared to the 116 macro batch base case.

- 56 Macro Batch with WTP Incidental Blending: The case combines HLW and LAW batches planned for roughly the same time frame to approximately simulate incidental blending that results from parallel processing of HLW and LAW batches in WTP. This change results in about $7 \%$ reduction in estimated HLW glass compared to the 116 macro batch no blending case.

- 23 Macro Match Blend: Limiting components for the 116 macro batch case were reviewed and potentially attractive tank farm blending groups were selected based on planned batch delivery dates listed in the Unconstrained Case feed vector. For each blending group, the time between the earliest and latest planned delivery date was limited to approximately two years. No blending was performed on the first four batches or first two years of operations based on the assumption that blending will be accomplished, in part, during refilling of tanks that are initially emptied. This blending case resulted in an approximate $20 \%$ HLW glass reduction compared to the 116 macro batch base case and about $7 \%$ more glass than the single macro batch total blend.

- 21 Macro Batch Blend: Similar to the 23 macro batch case except the waste delivery window for blend groups was reduced to about 18 months. Estimated HLW glass quantity is essentially the same as the 23 macro batch case.

The 23 and 21 macro batch cases results are for an initial first-cut analysis. Some additional improvement may be possible by carefully examining the results for each of the blended batches, testing potential alternative combinations, and making adjustments to better optimize blending results. Also note that because of the way the waste batches are grouped, most of the benefit of WTP incidental blending discussed for the 56 macro batch case is also captured by the 23 and 21 macro batch cases. 
Table 4-5. Summary of Initial Tank Farm Blending Results.

\begin{tabular}{|c|c|c|c|c|c|c|c|c|}
\hline \multirow[b]{2}{*}{$\begin{array}{l}\text { Average Overall } \\
\text { Purge Efficiency }\end{array}$} & \multicolumn{3}{|c|}{$\begin{array}{l}116 \text { Macro Batch-No } \\
\text { Blending }\end{array}$} & \multirow{2}{*}{$\begin{array}{c}\text { 56 Macro Batch- } \\
\text { WTP Incidental } \\
\text { Blending }\end{array}$} & \multicolumn{2}{|c|}{$\begin{array}{l}23 \text { Macro } \\
\text { Batch Blend }\end{array}$} & \multirow{2}{*}{$\begin{array}{c}\begin{array}{c}21 \\
\text { Macro } \\
\text { Batch } \\
\text { Blend }\end{array} \\
99 \%\end{array}$} & \multirow{2}{*}{ 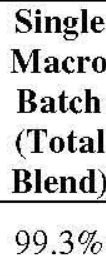 } \\
\hline & $100 \%$ & $99 \%$ & $96 \%$ & & $99 \%$ & $96 \%$ & & \\
\hline $\begin{array}{l}\text { HLW Glass } \\
(\mathrm{MT})^{*}\end{array}$ & 37,500 & 39,200 & 45,100 & 36,400 & 31,100 & 35,800 & 30,900 & 29,000 \\
\hline
\end{tabular}

*Based on $67 \%$ melter sulfate retention.

HLW = high-level waste.

MT = metric tons.

Figure 4-4. Effect of Blending and Purge Efficiency on High-Level Waste Glass Quantity.

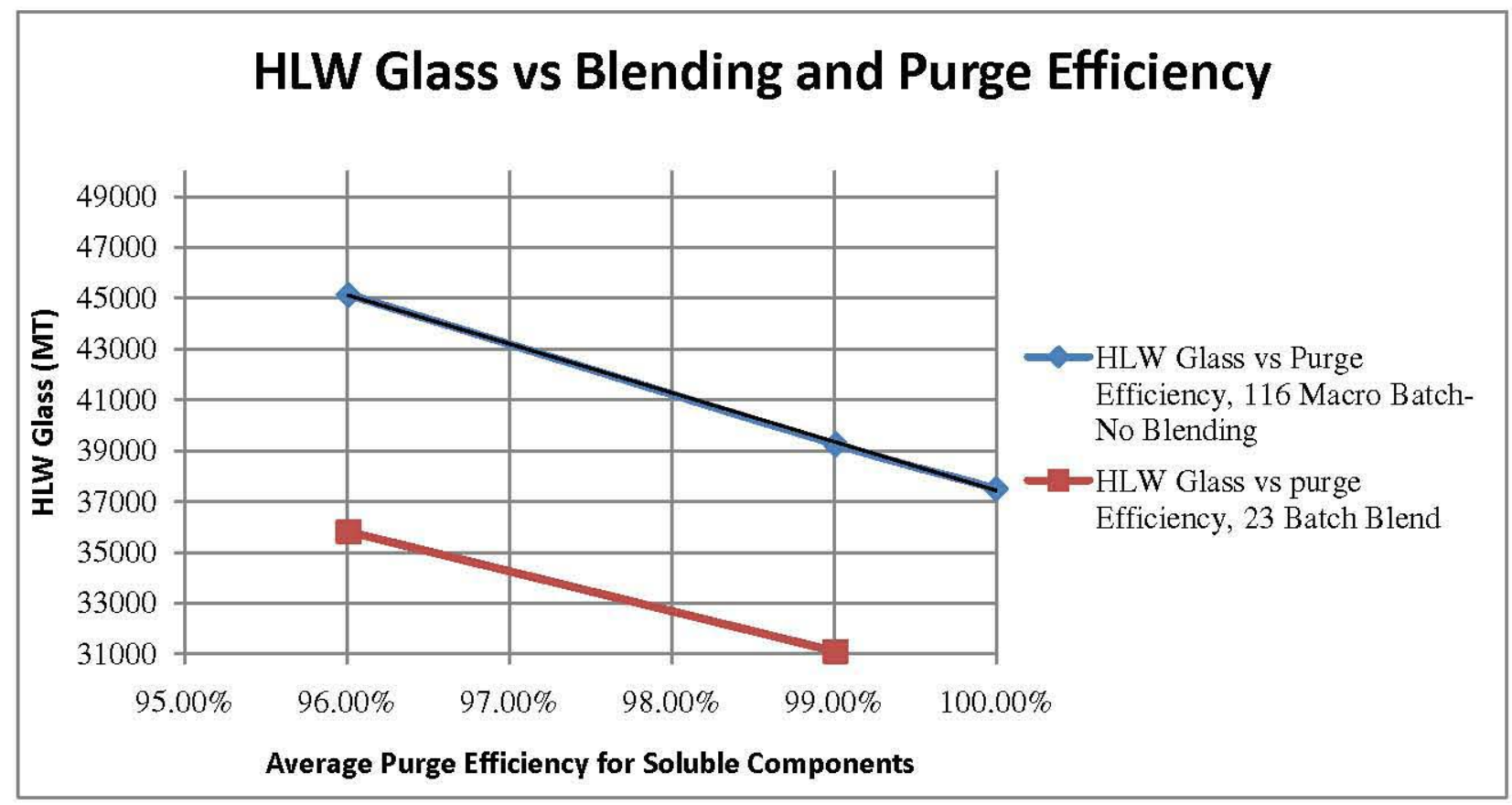

\subsubsection{Blending of Partial Batches in Waste Feed Transfer Tanks}

To assess the impact of blending in the WTP feed transfer tanks a simplified blending model was developed based on assuming that tank farm tanks used for transfers to WTP ("feed tanks") are only half emptied before being refilled. Therefore, the incoming waste batch is always blended with half of the prior batch.

The 56 macro batch set was used as the set of source tanks. The batches were blended using a simple feed tank blending scenario to yield 112 blended macro batches (see Section 7.3). The feed vector processing sequence was used without attempting to further improve or optimize the processing sequence. Results are shown in Table 4-6 and compared with the 56 macro batch 
base case, the 116 macro batch base case, the 23 macro batch tank farm blending case discussed in Section 4.3.1, and a total blend of all tank waste. The WTP feed transfer tank blending case shows approximately $11 \%$ glass reduction compared to the 56 batch case, or $17 \%$ reduction compared to the no blend 116 macro batch case. The feed tank blend case is about $4 \%$ higher than the 23 macro batch tank farm blending case and almost $12 \%$ higher than the total blend. Feed tank blending performance could be further improved by using slightly more complex concepts such as using two source tanks in parallel or in series, by optimization of the waste feed sequence, and/or by combining feed tank blending with tank farm blending.

Table 4-6. Feed Tank Blending Results.

\begin{tabular}{|l|c|c|c|c|c|}
\hline Macro Batch Case & 56 Macro Batch & $\begin{array}{l}112 \text { Macro } \\
\text { Batch Blend }\end{array}$ & $\begin{array}{l}\mathbf{1 1 6} \text { Macro } \\
\text { Batch }\end{array}$ & $\begin{array}{l}\text { 23 Macro } \\
\text { Batch Blend }\end{array}$ & $\begin{array}{l}\text { Single Macro } \\
\text { Batch }\end{array}$ \\
\hline Blending scenario & $\begin{array}{l}\text { WTP Incidental } \\
\text { Blending } \\
\text { (Combine HLW } \\
\text { and LAW) }\end{array}$ & $\begin{array}{l}\text { WTP Feed } \\
\text { Transfer Tank, } \\
1 / 2 \text { Batch } \\
\text { Blending }\end{array}$ & $\begin{array}{l}\text { No } \\
\text { Blending }\end{array}$ & $\begin{array}{l}\text { Tank Farm } \\
\text { Blending }\end{array}$ & $\begin{array}{l}\text { Total Blend of } \\
\text { All Wastes }\end{array}$ \\
\hline $\begin{array}{l}\text { HLW Melter Sulfate } \\
\text { Retention }\end{array}$ & $67 \%$ & $67 \%$ & $\mathbf{6 7 \%}$ & $67 \%$ & $67 \%$ \\
\hline $\begin{array}{l}\text { Average Purge Efficiency } \\
\text { for Soluble Components }\end{array}$ & $99 \%$ & $99 \%$ & $\mathbf{9 9 \%}$ & $99 \%$ & $99 \%$ \\
\hline HLW Glass Quantity (MT) & 36,400 & 32,400 & $\mathbf{3 9 , 2 0 0}$ & 31,100 & 29,000 \\
\hline LAW Glass Quantity (MT) & 543,000 & 532,000 & $\mathbf{5 6 1 , 0 0 0}$ & 529,000 & 517,000 \\
\hline
\end{tabular}

HLW = high-level waste.

MT = metric tons.

LAW = low-activity waste. $\quad$ WTP $\quad$ = Waste Treatment and Immobilization Plant.

\subsubsection{Low-Activity Waste Glass Impacts from Blending}

Primary focus of the current study is HLW glass. However, process modeling calculations also provided information on the effect of blending on LAW glass. These results are provided for information in Table 4-6. The results show that a small but meaningful reduction in LAW glass is expected from blending.

\subsection{FUNCTIONS REQUIREMENTS AND OBJECTIVES}

Figure 5-1 is a simplified process flow diagram for the RPP system based on the System Plan Initial Planning and Unconstrained Cases. The Baseline Case is similar, except that an Aluminum Removal Facility is added to process waste upstream of the WTP. The RPP system is comprised of four major subsystems (storage, treatment, offsite disposal, and onsite disposal). The following provides a brief description of the facilities (planned or operational) within each subsystem for the Initial Planning and Unconstrained cases, which is summarized from the System Plan. 


\section{$5.1 \quad$ FUNCTIONS}

For purposes of the current study, primary functions of the RPP system include waste storage, treatment, offsite disposal, and onsite disposal. The following provides a brief description of the functions and related facilities (planned or operational) that perform each function, summarized from the System Plan.

\subsubsection{Storage}

Storage encompasses numerous facilities used for tank waste management until the waste is delivered to treatment. These facilities include 149 single-shell tanks (SST), 28 DSTs, 71 inactive miscellaneous underground storage tanks, and 242-A Evaporator. In general, waste is retrieved from SSTs and accumulated in DSTs. DST supernates are periodically processed through the 242-A Evaporator to reduce the waste volume held in DST inventory.

The entire DST storage capacity cannot be allotted to waste storage from SST retrievals. The combined DST storage capacity is $32.3 \mathrm{Mgal}$, of which approximately $27 \mathrm{Mgal}$ is consumed by existing DST inventory. Furthermore, some DST capacity must be reserved to address operating constraints.

Inherent within the storage function is the incidental and intentional blending that occurs as waste is moved from tank to tank as it is staged for delivery to WTP for treatment. 
Figure 5-1. River Protection Project System Unconstrained Case Simplified Process Flow Diagram.

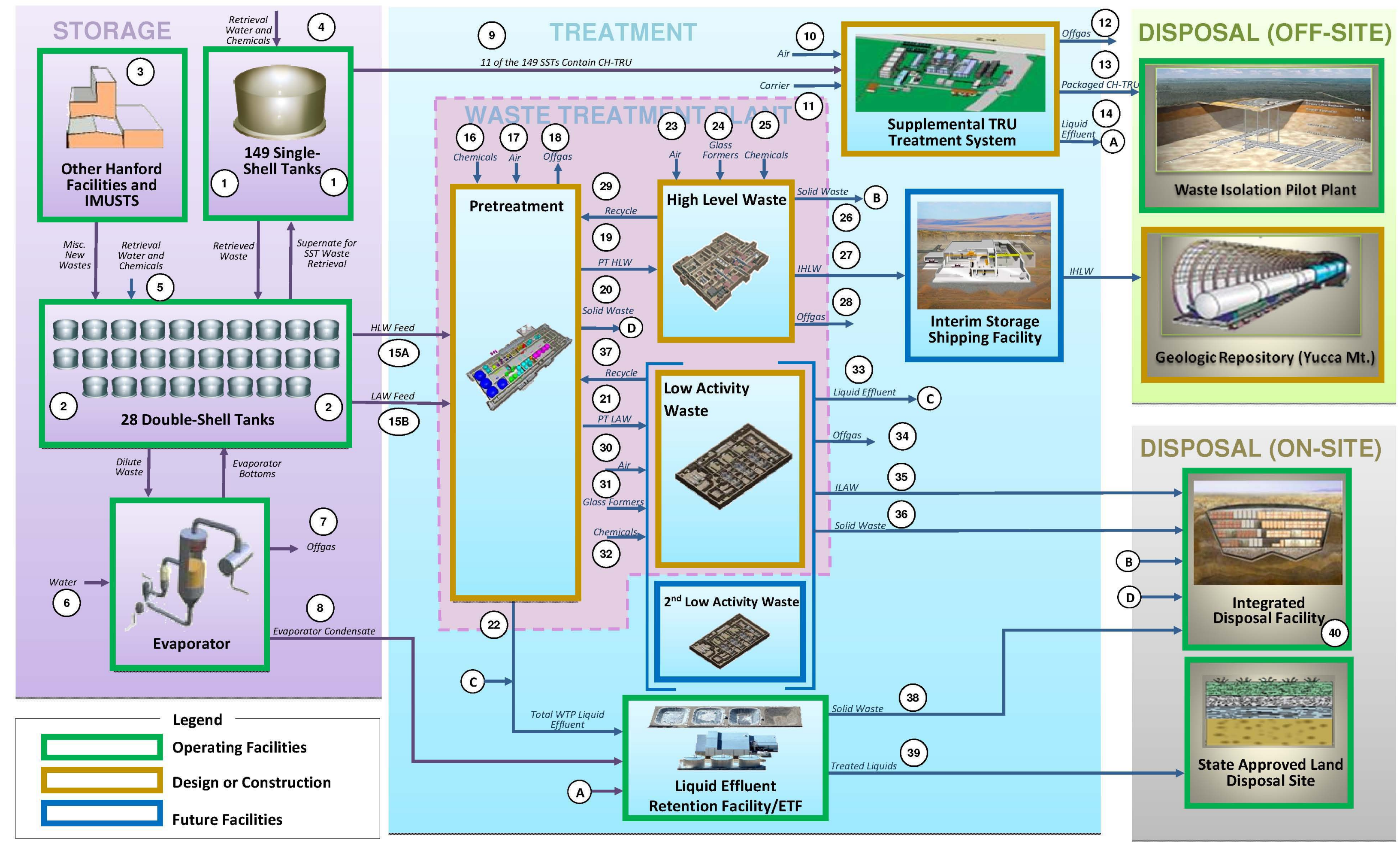

Source: ORP-11242, 2009, River Protection Project System Plan, Rev. 4, Office of River Protection, U.S. Department of Energy, Richland, Washington. 


\subsubsection{Treatment}

Treatment encompasses the WTP, Second LAW Facility, Supplemental Transuranic (TRU) Treatment System, Hanford Shipping Facility, and Liquid Effluent Retention Facility/Effluent Treatment Facility. For the Baseline Case, treatment also includes the Aluminum Removal Facility. Only the Liquid Effluent Retention Facility and Effluent Treatment Facility are existing facilities. The others are either in the planning or construction phase of implementation.

The Pretreatment Facility will receive DST waste and process it into HLW and LAW fractions. This facility also receives a recycle stream from each vitrification facility. The Pretreatment Facility process includes concentration, caustic and oxidative leaching, ultrafiltration, and cesium ion exchange. The resulting HLW and LAW are subsequently transferred to their respective vitrification facility. Liquid effluents from the Pretreatment Facility are transferred to the Liquid Effluent Retention Facility/Effluent Treatment Facility for processing.

The HLW Vitrification Facility will immobilize HLW in glass, which is poured into stainless steel canisters. On average each IHLW canister will hold 3.04 MTG. The IHLW canisters will be transferred to the Hanford Shipping Facility for interim storage until their transport to the National Geologic Repository for disposal.

The LAW Vitrification Facility will immobilize LAW in glass, which is poured into stainless steel packages. On average each immobilized LAW (ILAW) package will hold 5.92 MTG. The ILAW packages will be transferred to the onsite Integrated Disposal Facility for disposal. Hot commissioning of HLW and LAW vitrification facilities is scheduled to start in May 2018. The Second LAW Facility is envisioned to use a process flowsheet similar to the WTP LAW Vitrification. However, required throughput capacity will vary depending on assumptions embodied in its processing mission. Some supplemental pretreatment capacity may also be needed to support the Second LAW Facility.

Eleven SSTs are projected to contain contact-handled TRU (CH-TRU) waste. This waste is planned to be processed with a supplemental treatment system and packaged in 55-gallon drums for offsite disposal at the Waste Isolation Pilot Plant.

\subsubsection{Disposal}

The disposal function includes interim storage of immobilized waste and transportation to the disposal site. Hanford's IHLW canisters will be disposed of at an offsite geologic repository. However, the repository has not been sited and its availability is uncertain. The Hanford Shipping Facility will interim store IHLW canisters and prepare the canisters for offsite transport once shipments to the repository commence. The facility will initially provide storage capacity for 2,000 IHLW canisters, and will be expandable as needed.

The Liquid Effluent Retention Facility/Effluent Treatment Facility was designed to interim store and treat 242-A Evaporator process condensate and other dilute aqueous waste streams from various sources (including the WTP). The aqueous waste is decontaminated to yield a liquid 
fraction suitable for disposal at the state-approved land disposal site and a solid fraction acceptable for disposal at the Integrated Disposal Facility.

The Integrated Disposal Facility will accept ILAW packages and failed melters from the WTP, mixed low-level waste and low-level waste from various Hanford Site generators, and potentially mixed low-level waste and low-level waste from offsite generators.

\subsection{REQUIREMENTS AND OBJECTIVES}

There are a large number of requirements related to tank waste processing and disposal. However, requirements and objectives specifically related to the current study are primarily focused on the following:

- Minimize overall life cycle cost, including: cost of constructing new facilities; operations; decontamination and decommissioning; and storage, transportation, and disposal of immobilized waste product.

- $\quad$ Minimize schedule risk. Specifically minimize risk of not meeting agreed dates for completion of the waste immobilization mission.

- $\quad$ Minimize safety and environmental impacts and risks.

- $\quad$ For this study it is assumed that no new major capital projects can be started before 2014 .

- 24590-WTP-ICD-MG-01-019, ICD-19-Interface Control Document for Waste Feed, requires the Tank Farm Contractor to "provide the WTP Contractor with samples of each batch at least 180 days before the projected transfer of such waste to the WTP." For some options or sensitivity cases the current study may assume that waste from two or more tanks that have been sampled can be blended after sampling without triggering a requirement for repeat sampling and 180-day hold on the blended waste. For example, if tanks A and B had both been sampled and waste from tank B were added to tank A, a new sample and hold event may not be triggered. Composition of the blended tank would be estimated based on the waste samples from the source tanks. Resampling requirements can significantly affect tank farm logistics for blending options and should be clarified if these options are pursued further.

- It is assumed that borosilicate glass sealed in stainless steel canisters is the required IHLW product, and that established glass property constraints must be met. Results presented in this report assume the same glass property constraints used by the HTWOS model for the System Plan.

- $\quad$ Tank farm operational and safety requirements must be followed. This includes requirements for minimum reserve tank volume and constraints on properties of waste transferred. For the current study it is assumed that there are no constraints on mixing of tank waste. This must be verified before specific scenarios can be implemented. 
Because of the expected high cost of HLW plant operation and for storage, transportation and disposal of IHLW, minimizing the quantity of IHLW is considered to be a major driver towards minimizing overall cost. Similarly, reducing quantity of IHLW is expected to reduce schedule risk. Some options could require additional tank farm operation costs due to increased number of transfers that may partially offset cost savings from reduced IHLW. This trade-off should be considered prior to making a final decision on implementation. Options that involve major new facilities are not currently included in this study. If such options surface, the costs and other impacts of constructing and operating the new facilities will need to be considered.

Options currently identified are expected to have only a small marginal effect on safety and environmental risks. Reduced IHLW quantity will reduce risks related to handling, shipping and disposal operations and may reduce the number and size of onsite storage facilities needed. These may be offset by increased tank farm operations risks if additional tank farm waste transfers are needed.

\subsection{ALTERNATIVE DESCRIPTIONS}

\subsection{BASE CASE FOR BLENDING COMPARISONS}

For the purpose of the current study the starting point for comparisons is the System Plan Unconstrained Case. This includes primarily the feed vector, glass quantity estimates, schedules, and processing facility performance characteristics.

The glass quantity calculations performed for this study use simplified spreadsheet models with somewhat different calculation methods and assumptions as compared to the HTWOS model used for the System Plan Unconstrained Case. Comparing blending results from the spreadsheet models directly with the System Plan results creates the possibility of artificial differences resulting from different calculation methods. Therefore, an unblended base case was developed for blending comparisons. The base case waste feed batches are based on consolidating the 450 Unconstrained Case feed vector batches into 116 macro batches. Adjacent feed vector batches with identical composition are consolidated into macro batches and feed vector batches with very small (essentially negligible) waste content are also consolidated into macro batches. The 116 batch case does not incorporate meaningful blending as compared to the 450 feed vector batches. The major difference between the base case and Unconstrained Case feed batches results from the 160,000 gallon per batch limitation on HLW transfers to WTP. This limitation results in about six feed vector batch transfers in order to transfer the contents of a nominal $1 \mathrm{Mgal}$ tank farm tank containing HLW. The LAW transfers do not have this limitation. The entire contents of an LAW tank can be transferred to WTP in a single transfer.

There are also some differences between process performance assumptions and mass balance calculation methods used to model the WTP processes. Primary differences between the blending base case and the System Plan Unconstrained Case are: (1) In the base case spreadsheet calculations, the solids washing efficiency after leaching is set at $95 \%$ resulting in an average overall purge efficiency for soluble components of about $99 \%$. For comparison, 
calculation methods used by HTWOS result in about $98 \%$ purge efficiency for soluble components. (2) In the base case calculations, credit is taken for reduced sulfate retention (67\%) in the HLW melter. (3) In the base case calculations sodium from neutralized cesium ion exchange eluate is included in the HLW stream.

Key aspects of the Unconstrained Case related to the current study are shown in Table 6-1. In comparison, the total IHLW glass calculated for the base case is 39,200 MT with no blending.

Table 6-1. System Plan Unconstrained Case Description.

\begin{tabular}{|l|l|}
\hline Start of Hot operations & $5 / 31 / 2018$ \\
\hline Completion of HLW Immobilization & $8 / 14 / 2047$ \\
\hline Estimated Total IHLW product (MT) & $44,326^{\mathrm{a}}$ \\
& $45,703^{\mathrm{b}}$ \\
\hline Estimated Total ILAW Product (MT) & $611,000^{\mathrm{b}}$ \\
\hline Feed vector batch transfer to WTP & 450 \\
\hline
\end{tabular}

${ }^{a}$ HTWOS Case: WTP_HLW_Glass_SP4 UC 1-3.0-8.4r0-2009-03-31-at-15-16-26.xls, SVF-1031 Rev. 3.

b Table E-1 of ORP-11242, 2009, River Protection Project System Plan, Rev. 4, Office of River Protection, U.S. Department of Energy, Richland, Washington.

HLW high-level waste.

IHLW = immobilized high-level waste.

MT = metric tons.

ILAW = immobilized low-activity waste.

WTP $=$ Waste Treatment and Immobilization Plant.

\subsection{WASTE TREATMENT AND IMMOBILIZATION PLANT INCIDENTAL BLENDING}

The 116 macro batch grouping includes low solids/LAW batches and high solids/HLW batches. Calculations for 116 macro batch case estimate the glass for each macro batch separately. However, during normal WTP operations HLW and LAW batches will be processed in parallel. Solids removed from the LAW and neutralized ion exchange eluate will be blended with HLW solids being processed at the same time. Therefore, a revised grouping was developed that is intended to roughly simulate the incidental blending in WTP that results from parallel processing of HLW and LAW.

- A total of 56 HLW batches were identified from the original 116 base case.

- $\quad$ Low solids/LAW batches were identified that are scheduled to be delivered in approximately the same time frame as each HLW batch.

- Low solids/LAW batches were selected and combined with the 56 HLW batches resulting in a new set of 56 macro batches. Appendix B Table B-3 identifies the specific batches from the feed vector and 116 macro batch case that were combined to produce each batch for the 56 macro batch case. 
RPP-RPT-42968 Revision 0

\subsection{BLENDING OF WASTE BATCHES IN TANK FARMS}

In this alternative, waste batches staged for transfer to WTP will first be blended in tank farms. There are several ways this might be accomplished operationally. The following provides an example:

- $\quad$ After the first HLW feed tank is emptied, the partial contents of multiple tanks that have been prepared for transfer are transferred into the emptied tank to accomplish a target blend. The freed up space in the source tanks can then be refilled in a planned manner to accomplish additional blending. If desired, it may be feasible to consolidate waste in the source tanks leaving one tank nearly empty allowing fresh waste to be transferred in (See Section 7.2.2 for more detailed examples).

- If all source tanks have been sampled and completed the 180-day hold period, it significantly simplifies tank farm logistics if credit can be taken for source tank sampling, allowing transfer of the receipt/blend tank to WTP without requiring another sample and hold cycle. If this is allowed, the contents of the receipt/blend tank will be calculated based on the fraction of each source tank transferred into it. This blending approach can be considered even if resampling and an additional 180day hold is required; however, the overall timing and logistics could be more difficult and additional costs may be incurred for sampling and analysis.

The blending cases evaluated are based on blending of wastes currently planned to be delivered in roughly the same time frame (e.g., within $1 \frac{1}{2}$ to 2 years based on schedule dates listed for the feed vector batches). This avoids the need for large changes to the overall tank waste retrieval and transfer plans and schedules. There may be some opportunities to further improve blending results by processing waste from selected tanks outside this time window. These could be evaluated further on a case-by-case basis.

\subsection{BLENDING OF PARTIAL BATCHES IN WASTE FEED TANKS}

In this alternative, the tank farm tanks used for transfers to WTP ("feed tanks") are only partially emptied before being refilled so that the incoming waste batch is always blended with part of the prior batch. The following provides a simplified example of how this might work and is shown in a schematic format on Figure 6-1:

- One half the waste volume of the feed tank is first transferred to WTP. Then one half the volume of a second source tank is transferred to the feed tank and blended with the residual waste in the feed tank. One half the volume in the feed tank is then transferred to WTP. The balance of the waste in the source tank is then transferred to the feed tank and blended with its contents. The source tank is now empty and ready to receive waste. 
One half the waste in the feed tank is then transferred to WTP and it is then refilled with one half the contents of a second source tank.

For blending in the WTP feed transfer $\operatorname{tank}(\mathrm{s})$ it would be desirable that if, when the initial feed tank and each of the source tanks has been sampled and completed, the 180-day hold period then the receipt/blend tank would not require another sample and hold cycle. Contents of this tank would be calculated based on the fraction of each source tank transferred into it. This should improve WTP knowledge of the expected properties of incoming batches, since after the first batch $50 \%$ of each batch would consist of waste from the immediately preceding batch. If re-sampling and hold is required, blending further back in the feed staging process may be more desirable. 
Figure 6-1. Feed Transfer Tank Blending Scheme. Initial Condition
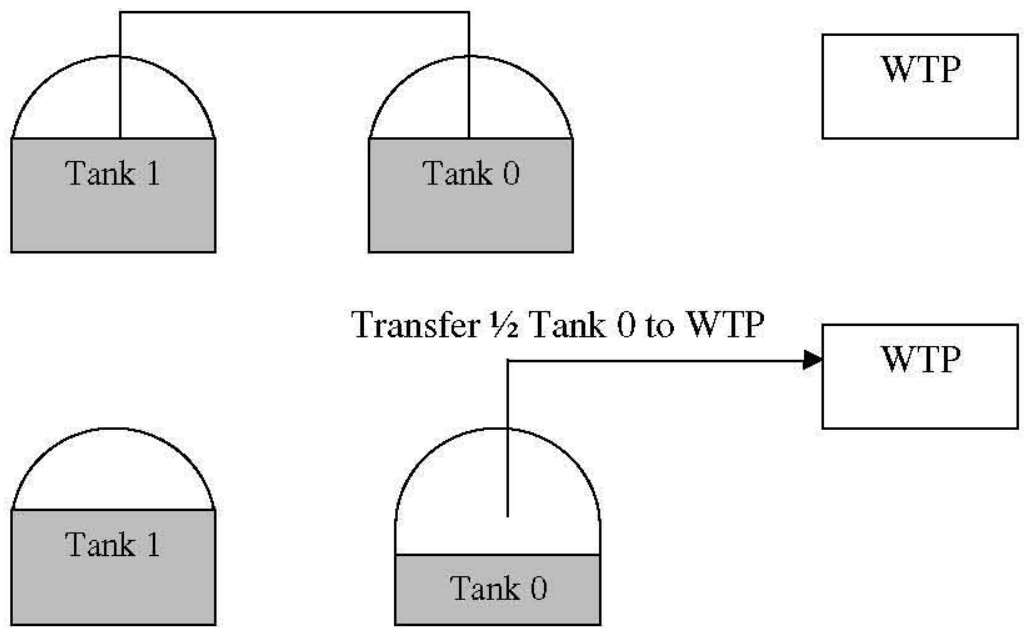

Transfer $1 / 2$ Tank 1 to Tank 0
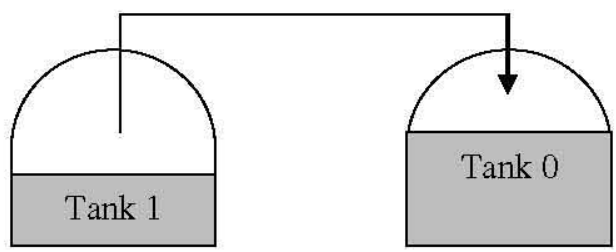

WTP

Transfer $1 / 2$ Tank 0 to WTP
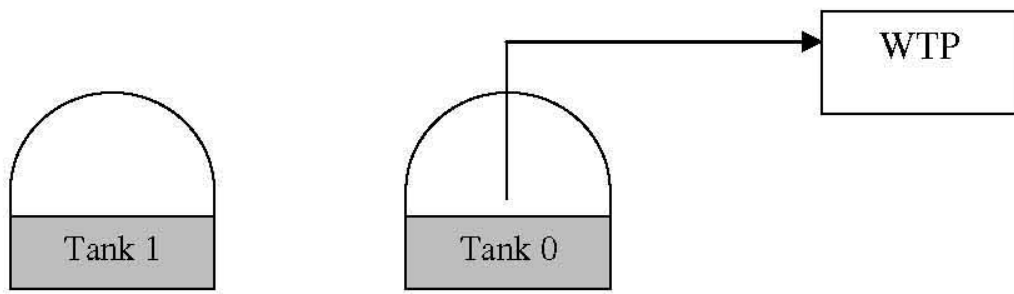

Refill Tank 0 from Tank 1

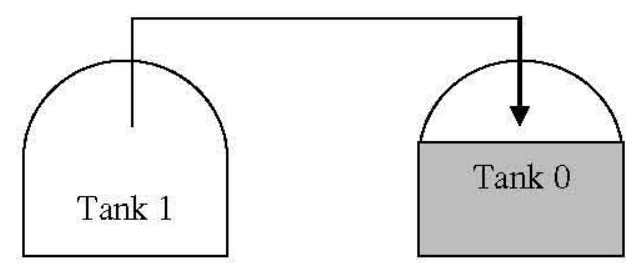

WTP 
There are other more complex ways to apply this concept to further improve blending. Examples:

- Use a three-tank set in series, feed tank, queue tank, and source tank. Transfer one-half the feed tank to WTP, then refill it from the queue tank then refill the queue tank from the source tank.

- Use a three-tank set in parallel, feed tank and two source tanks. Transfer one-half the feed tank volume then refill it from the first source tank. Transfer one-half the feed tank volume then refill it from the second source tank. Transfer one-half the feed tank then refill it from the first source tank, which is now empty and ready to receive more waste.

- $\quad$ Transfer less than one-half the feed tank each time and then refill from a source tank.

- $\quad$ Use a similar approach further back in the feed staging sequence.

\subsection{ALTERNATIVE COMPARISONS}

\subsection{UNBLENDED AND INCIDENTAL BLENDING CASES}

Sections 7.1.1 through 7.1.4 discuss results for two cases that do not take credit for intentional blending prior to delivery to WTP:

- The 116 macro batch case that assumes each batch is processed separately through WTP.

- $\quad$ A 56 macro batch case that assumes HLW and LAW batches are processed in parallel in WTP, resulting in glass quantity reduction due to incidental blending of the LAW and HLW wastes in the WTP.

Prior to development of blending comparisons, key WTP processing parameters were examined to assess their impact on HLW glass quantities. HLW glass quantities were found to be fairly sensitive to pretreatment solids washing efficiency and HLW melter sulfate retention assumptions. These are examined in more detail in the following sections and compared with HTWOS results and current WTP flowsheet bases. Based on the result of this evaluation, a base case for blending comparisons is defined as follows.

- 116 macro batches of waste transferred to WTP. As discussed in Section 6.1, this set of macro batches was designed to avoid meaningful waste blending. Appendix $B$ identifies specific feed vector batches and primary waste source tanks for each of the 116 macro batches. 
- $\quad 95 \%$ leached solids wash efficiency. Overall purge efficiency for soluble components varies by batch and typically averages about $99 \%$ with a $95 \%$ leached solids wash efficiency. Evaluation of solids washing and purge efficiency is discussed in Section 7.1.1.

- $\quad 67 \%$ sulfate retention for the HLW melter. Effect of melter sulfate retention is discussed in Section 7.1.2.

\subsubsection{Evaluation of Solids Washing Efficiency}

Initial steps in the WTP process include caustic leaching to dissolve selected components and ultrafiltration to split the waste into a solids free feed stream for ion exchange and a concentrated solids slurry stream. The solids slurry is then washed by repeated dilution with water and reconcentration by purging liquid through the ultra filters. For some batches oxidative leaching to remove chromium is then performed and the slurry is washed again and reconcentrated by purging liquid though the ultra filters. The washed reconcentrated slurry and concentrated neutralized eluate from ion exchange are transferred from pretreatment to HLW vitrification. SVF-1767 Mission Analysis Process Stream Calculator models removal of soluble sulfur, aluminum, phosphorus, and chromium as two steps: (1) initial purge of liquid through the ultra filters to achieve a $20 \mathrm{wt} \%$ leached solids concentration, and (2) water washing of the leached solids and reconcentration by purging liquid through the ultra filters. The efficiency for purging liquid phase components in the initial solids concentration step is calculated by the spreadsheet, wash efficiency in the second step is set as an input parameter. Overall purge efficiency for soluble components (combine initial solids concentration and washing) varies by batch and typically averages about $99 \%$ with $95 \%$ wash efficiency. Because a variable amount of sodium may be added during leaching, sodium washing is modeled as a parameter $\left(\mathrm{P}_{\mathrm{Na}(\mathrm{aq}), 19 \mathrm{~b}, 15 \mathrm{LSol}}\right)$ that is proportional to the soluble sodium concentration in the final washed and reconcentrated leached solids slurry. The nominal or base case value of $\mathrm{P}_{\mathrm{Na}(\mathrm{aq}), 19 \mathrm{~b}, 15 \mathrm{LSol}}$ is 0.023 , which is equivalent to a dissolved sodium concentration of $0.25 \mathrm{~mole} / \mathrm{L}$ in the washed solids slurry aqueous phase with $20 \mathrm{wt} \%$ leached solids. This equivalence is calculated as follows:

$\mathrm{P}_{\mathrm{Na}(\mathrm{aq}), 19 \mathrm{~b}, 15 \mathrm{LSol}}$ is defined as the ratio of dissolved sodium mass to leached solids mass.

Aqueous phase density for 0.25 molar sodium is estimated at $1.01 \mathrm{~g} / \mathrm{ml}$.

Basis $1 \mathrm{~kg}$ of slurry

Leached Solids Mass $=0.200 \mathrm{~kg}(20 \%)$

Liquid Mass $=0.8 \mathrm{~kg}(80 \%)$

Liquid Volume $=0.8 / 1.01=0.792 \mathrm{~L}$

Sodium in Liquid $=\mathrm{P}_{\mathrm{Na}(\mathrm{aq}), 19 \mathrm{~b}, 15 \mathrm{LSol}} *$ leached solids mass $=0.023 * .2=0.0046 \mathrm{~kg}$

Sodium Concentration $=0.0046 * 1000 \mathrm{~g} /(23(\mathrm{~g} / \mathrm{mole}) * 0.792 \mathrm{~L})=0.25 \mathrm{~mole} / \mathrm{L}$ 
If the leached solids slurry is $5 \mathrm{~mole} / \mathrm{L}$ sodium at $20 \mathrm{wt} \%$ leached solids prior to washing, the $0.25 \mathrm{~mole} / \mathrm{L}$ final concentration assumed for the base case represents approximately $95 \%$ washing efficiency. Note that calculation of sodium in the washed solids slurry does not include sodium in the neutralized cesium ion exchange eluate, which is calculated separately and blended with the concentrated washed solids slurry.

\subsubsection{Comparison of Calculated High-Level Waste Feed with Hanford Tank Waste} Operations Simulator Results. Calculated HLW feed components (Stream 19, Figure 1-1) and comparable values from the System Plan Planning Case (SVF-1663 Rev. 1) are listed in Table 7-1. Figure 7-1a through Figure 7-1d show the results for individual components graphically. Conclusion from this comparison is that the System Plan Planning Case effective overall purge efficiency is about $98 \%$. This is equivalent to a second stage washing efficiency of about $90 \%$ or less.

Table 7-1. Results of Solids Washing Calculations.

\begin{tabular}{|c|c|c|c|c|c|c|}
\hline \multirow[b]{2}{*}{ Wash Efficiency } & \multicolumn{5}{|c|}{ SVF-MAR04 Calculations for HLW Feed (Stream 19)* } & \multirow{2}{*}{$\frac{\text { SVF1663 }}{\text { Not given }}$} \\
\hline & $100.00 \%$ & $98.00 \%$ & $95.00 \%$ & $90.00 \%$ & $80.00 \%$ & \\
\hline $\begin{array}{l}\text { Total Purge } \\
\text { Efficiency }\end{array}$ & $100.0 \%$ & $99.7 \%$ & $99.3 \%$ & $98.5 \%$ & $97.0 \%$ & Not given \\
\hline $\begin{array}{l}\text { Sulfur as } \mathrm{SO}_{4}, \\
\mathrm{~kg}\end{array}$ & $9.92 \mathrm{E}+04$ & $1.10 \mathrm{E}+05$ & $1.27 \mathrm{E}+05$ & $1.54 \mathrm{E}+05$ & $2.09 \mathrm{E}+05$ & $1.70 \mathrm{E}+05$ \\
\hline Total Al, kg & $1.90 \mathrm{E}+06$ & $1.92 \mathrm{E}+06$ & $1.95 \mathrm{E}+06$ & $1.99 \mathrm{E}+06$ & $2.09 \mathrm{E}+06$ & $1.98 \mathrm{E}+06$ \\
\hline $\mathrm{Al}(\mathrm{aq}), \mathrm{kg}$ & $0.00 \mathrm{E}+00$ & $1.92 \mathrm{E}+04$ & $4.81 \mathrm{E}+04$ & $9.61 \mathrm{E}+04$ & $1.92 \mathrm{E}+05$ & $1.50 \mathrm{E}+05$ \\
\hline $\begin{array}{l}\text { Phosphorus as } \\
\mathrm{PO}_{4}, \mathrm{~kg}\end{array}$ & $3.80 \mathrm{E}+05$ & $3.93 \mathrm{E}+05$ & 4.13E +05 & $4.46 \mathrm{E}+05$ & $5.12 \mathrm{E}+05$ & 4.72E+05 \\
\hline $\mathrm{Na}, \mathrm{kg}$ & $1.64 \mathrm{E}+06$ & $1.83 \mathrm{E}+06$ & $2.11 \mathrm{E}+06$ & $2.56 \mathrm{E}+06$ & $3.44 \mathrm{E}+06$ & $3.24 \mathrm{E}+06$ \\
\hline $\mathrm{P}_{\mathrm{Na}(\mathrm{aq}), 19 \mathrm{~b}, 15 \mathrm{LSOl}}$ & 0 & 0.0092 & 0.023 & 0.045 & 0.088 & Not given \\
\hline $\begin{array}{l}\mathrm{Na} \text { (final) } \\
\mathrm{Mole} / \mathrm{L}\end{array}$ & 0 & 0.05 & 0.25 & 0.50 & 1.0 & Not given \\
\hline
\end{tabular}

*090818-5-SVF-MAR04 Macro Batch to Process Stream Calculator Rev. D.xlsm

$\begin{array}{lll}\mathrm{Al} & = & \text { aluminum. } \\ \mathrm{HLW} & = & \text { high-level waste. } \\ \mathrm{Na} & = & \text { sodium. }\end{array}$


RPP-RPT-42968 Revision 0

Figure 7-1. Variation of High-Level Waste Vitrification Feed Component Mass Estimates with Purge Efficiency

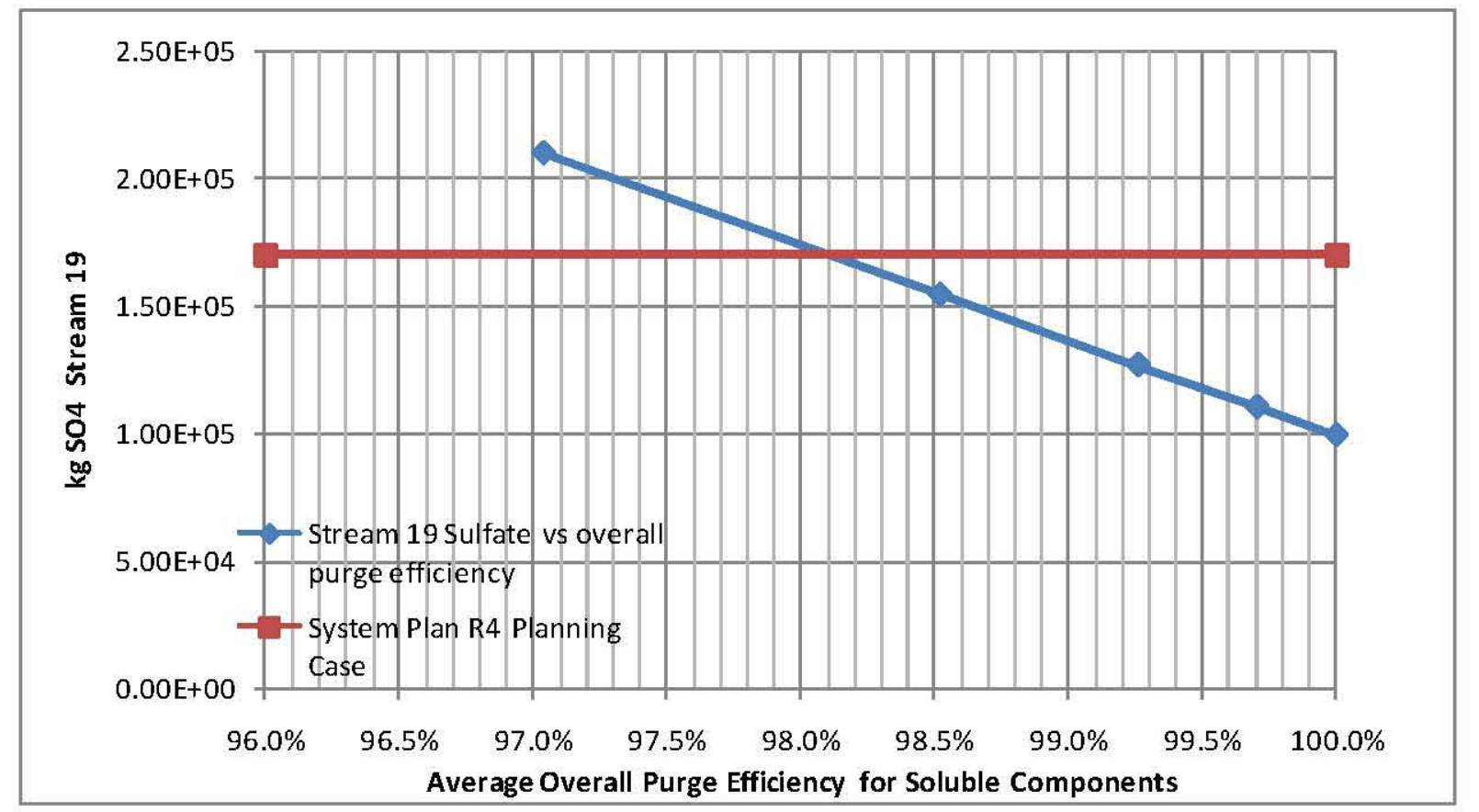

(a) Sulfate in Stream 19 Versus Overall Purge Efficiency

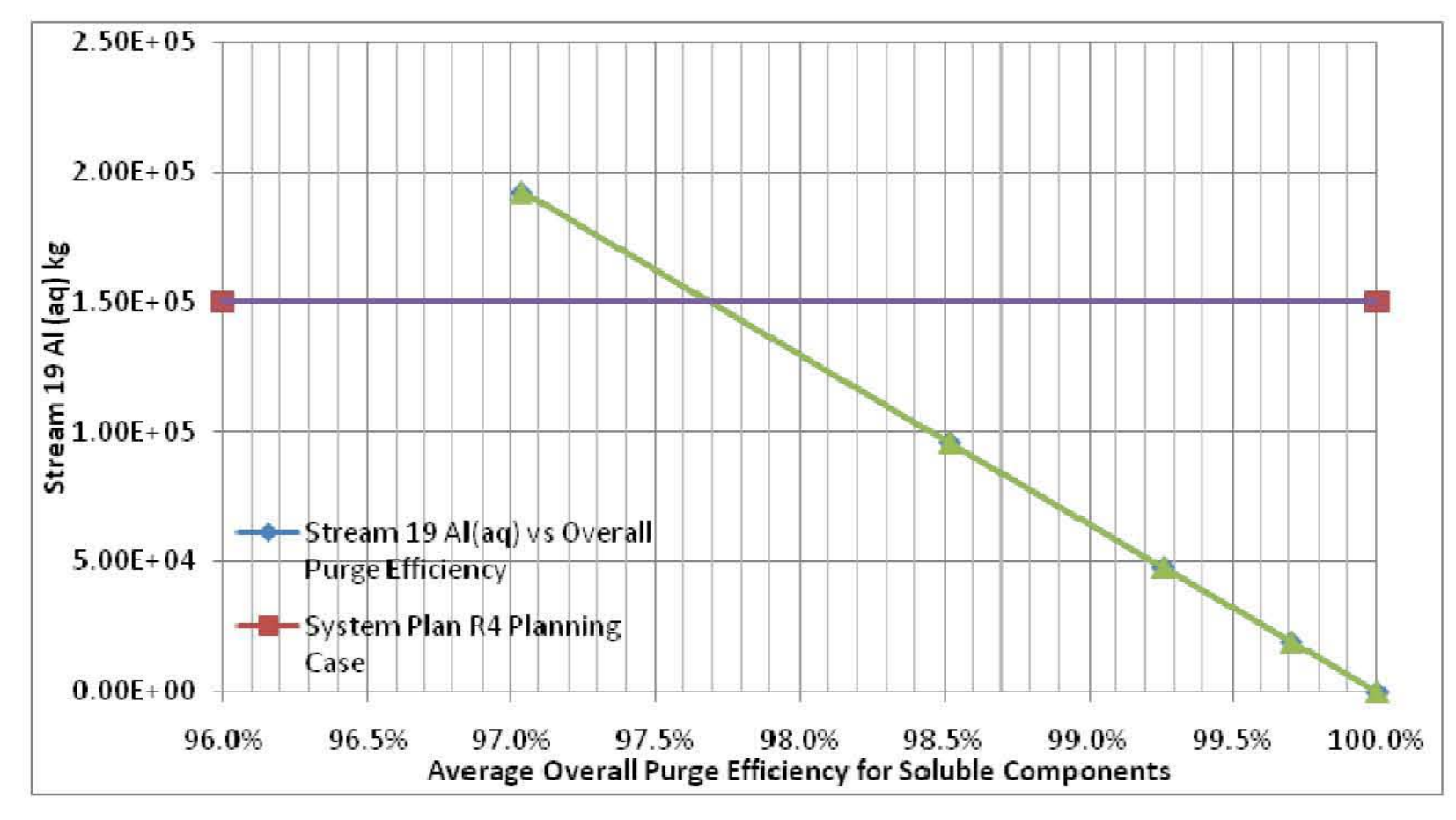

(c) Liquid Phase Aluminum in Stream 19 Versus Overall Purge Efficiency

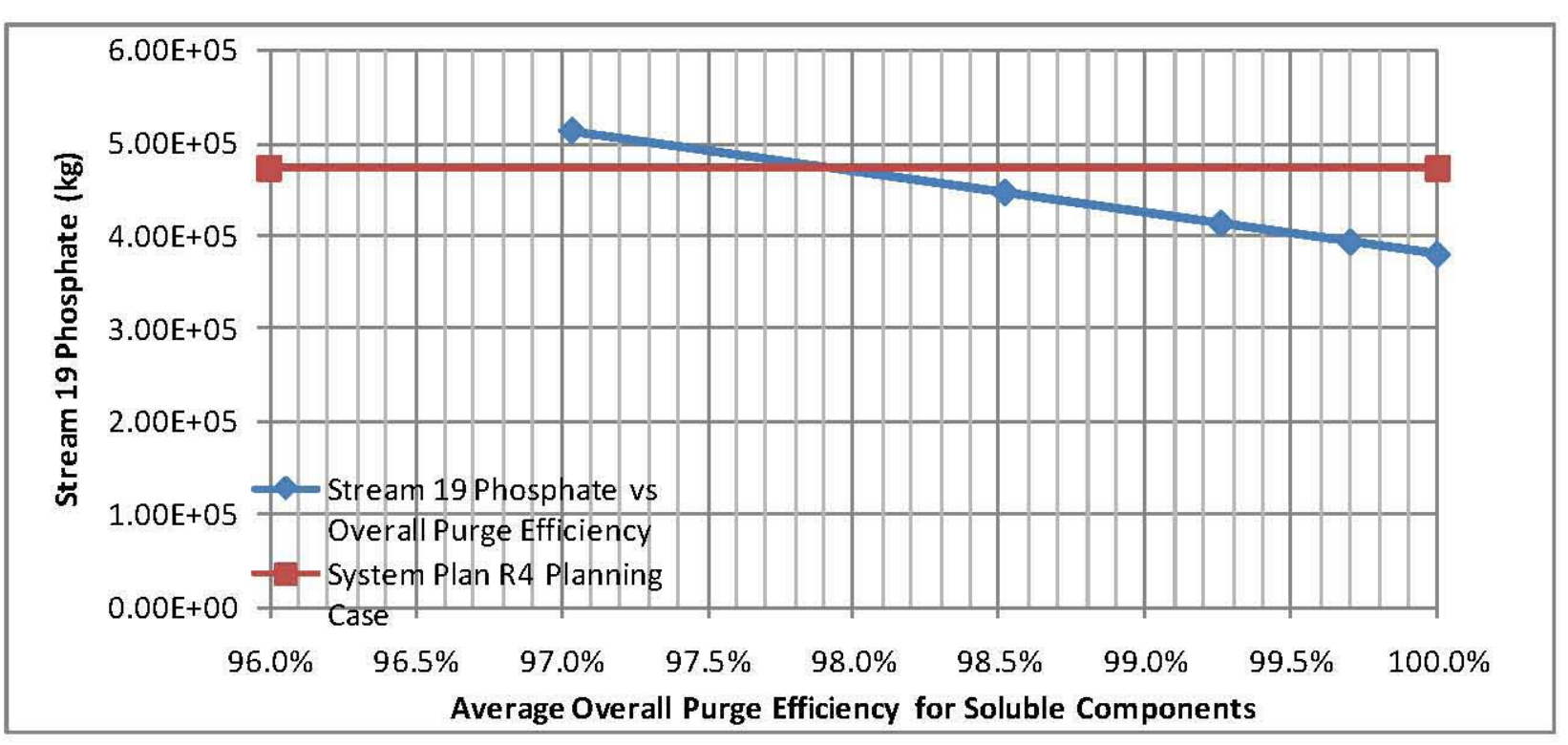

(b) Phosphate in Stream 19 Versus Overall Purge Efficiency

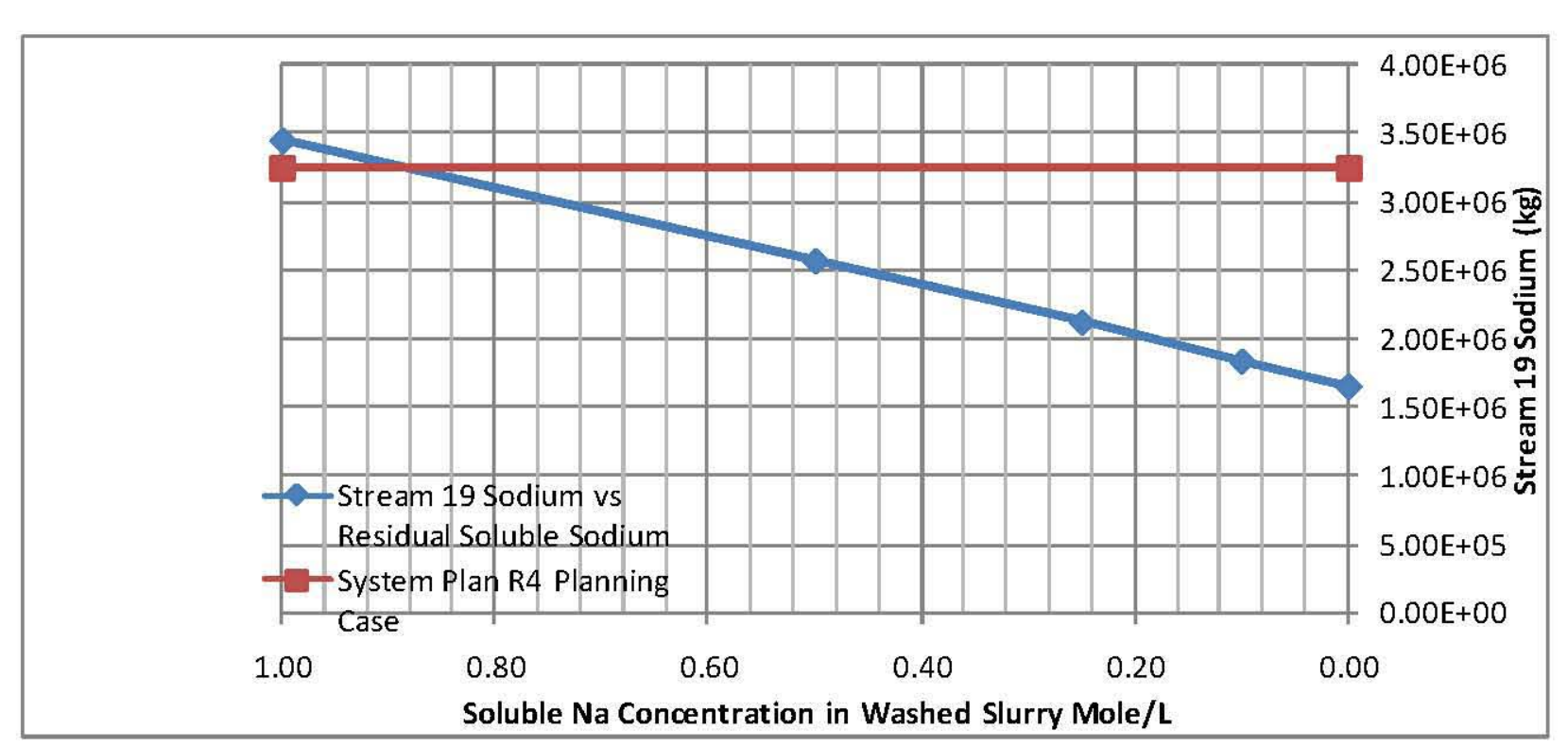

(d) Sodium in Stream 19 Versus Soluble Sodium in Washed Leached Solids Slurry. 
7.1.1.2 Effect of wash efficiency on high-level waste glass quantity. Glass quantity was calculated for each of the 116 base case macro batches as a function of wash efficiency and total purge efficiency for soluble components. Results for total glass quantity are shown in Table 7-2 and

7.1.1.3 Figure 7-2. The results show that increasing from 96 to $99 \%$ overall purge efficiency reduces HLW glass by about $13 \%$ while increasing from 99 to $100 \%$ reduces HLW glass by an additional $4.5 \%$. Based on results presented in Section 7.1.1.1, it appears that the HTWOS model may be somewhat under-washing the solids.

Table 7-3 provides results for each of the 116 macro batches. These results show that some batches are strongly influenced by purge efficiency for soluble components, while for other there is little or no effect on glass quantity as purge efficiency in increased. This suggests that optimization of plant operations may involve batch by batch adjustment of purge efficiency.

Table 7-2. Effect of Solids Washing on Total High-Level Waste Glass Quantity.

\begin{tabular}{|l|c|c|c|c|}
\hline & \multicolumn{4}{|c|}{ 116 Macro Batch-(No Blending) } \\
\hline Wash Efficiency for Leached Solids Slurry & $100 \%$ & $\mathbf{9 5 \%}$ & $90 \%$ & $80 \%$ \\
\hline Average Overall Purge Efficiency for Solubles & $100 \%$ & $\mathbf{9 9 \%}$ & $98 \%$ & $96 \%$ \\
\hline Glass quantity (MT)* & 37,500 & $\mathbf{3 9 , 2 0 0}$ & 41,100 & 45,100 \\
\hline
\end{tabular}

*Based on melter sulfate retention of $67 \%$.

MT metric tons.

Figure 7-2. Effect of Soluble Component Purge Efficiency on High-Level Waste Glass Quantity.

\section{HLW Glass vs Purge Efficiency for Soluble Components}

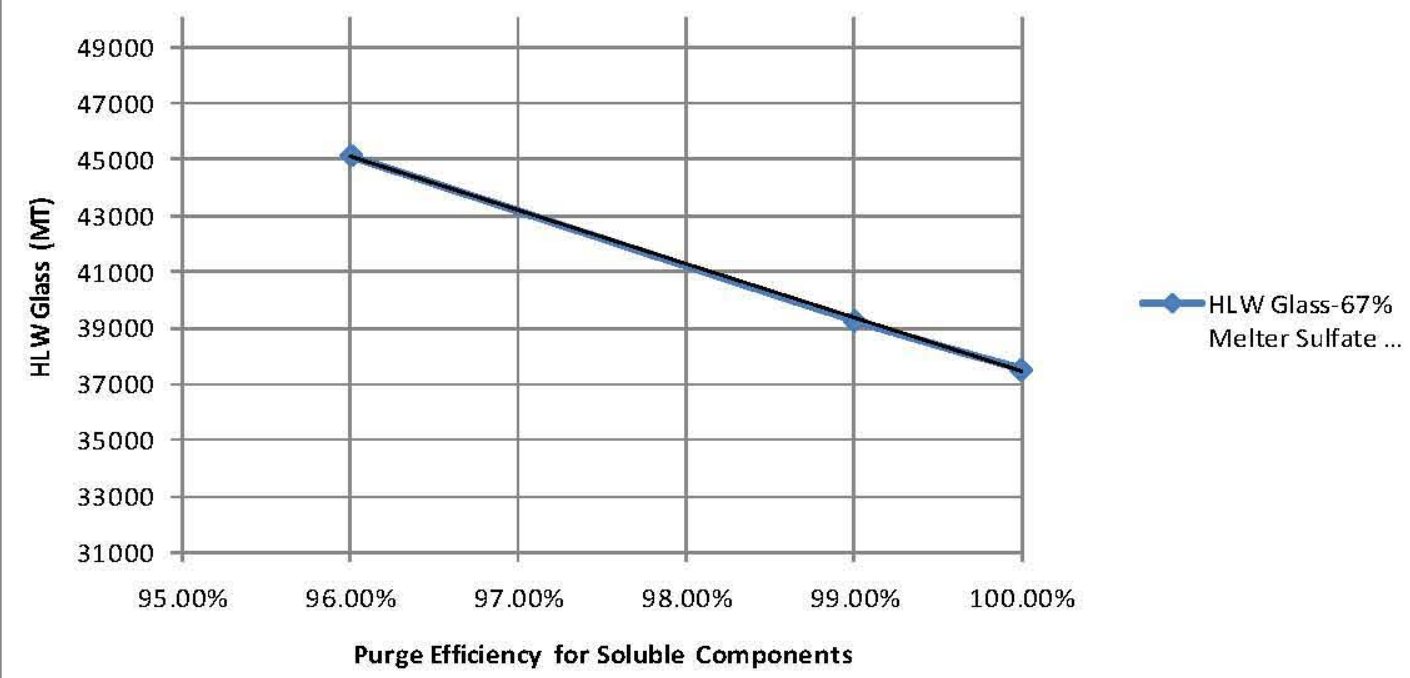


Table 7-3. Effect of Washing Efficiency on Batch by Batch Glass Quantities. (4 pages)

\begin{tabular}{|c|c|c|c|c|c|c|c|}
\hline Spreadsheet: & \multicolumn{7}{|c|}{ SVF-MAR05 HLW Glass Batch Blend Results Summary } \\
\hline Run Number & 090818-3 & $090818-1$ & $090831-2$ & $90818-2$ & 090818-3 & $090831-2$ & $90818-2$ \\
\hline $\begin{array}{l}\text { Wash } \\
\text { Efficiency }\end{array}$ & $100 \%$ & $95 \%$ & $90 \%$ & $80 \%$ & $100 \%$ & $90 \%$ & $80 \%$ \\
\hline $\begin{array}{l}\text { Average } \\
\text { Purge } \\
\text { Efficiency }\end{array}$ & $100 \%$ & $\begin{array}{c}99 \% \\
\text { (Base Case) }\end{array}$ & $98 \%$ & $96 \%$ & $100 \%$ & $98 \%$ & $96 \%$ \\
\hline Batch & \multicolumn{4}{|c|}{ HLW Glass kg } & \multicolumn{3}{|c|}{$\begin{array}{c}\text { Ratio of Glass Mass to Base Case (95\% } \\
\text { Wash Efficiency) }\end{array}$} \\
\hline 1 & 731465 & 731465 & 731,465 & 731465 & 1.000 & 1.000 & 1.000 \\
\hline 2 & 3590 & 3590 & 3,590 & 3590 & 1.000 & 1.000 & 1.000 \\
\hline 3 & 43908 & 46018 & 48,035 & 51975 & 0.954 & 1.044 & 1.129 \\
\hline 4 & 269728 & 269728 & 269,728 & 269728 & 1.000 & 1.000 & 1.000 \\
\hline 5 & 1068541 & 1067848 & $1,067,153$ & 1065757 & 1.001 & 0.999 & 0.998 \\
\hline 6 & 1717209 & 1816964 & $1,922,287$ & 2145267 & 0.945 & 1.058 & 1.181 \\
\hline 7 & 988968 & 1015550 & $1,042,178$ & 1095580 & 0.974 & 1.026 & 1.079 \\
\hline 8 & 1908960 & 1907940 & $1,906,919$ & 1904872 & 1.001 & 0.999 & 0.998 \\
\hline 9 & 801976 & 862635 & 923,345 & 1075823 & 0.930 & 1.070 & 1.247 \\
\hline 10 & 77630 & 81372 & 84,949 & 91937 & 0.954 & 1.044 & 1.130 \\
\hline 11 & 407755 & 415806 & 424,184 & 441230 & 0.981 & 1.020 & 1.061 \\
\hline 12 & 82804 & 87783 & 92,546 & 101855 & 0.943 & 1.054 & 1.160 \\
\hline 13 & 702107 & 783355 & 861,071 & 1012971 & 0.896 & 1.099 & 1.293 \\
\hline 14 & 409348 & 467371 & 522,872 & 631349 & 0.876 & 1.119 & 1.351 \\
\hline 15 & 44911 & 44911 & 44,911 & 44911 & 1.000 & 1.000 & 1.000 \\
\hline 16 & 298412 & 327442 & 355,434 & 410387 & 0.911 & 1.085 & 1.253 \\
\hline 17 & 44587 & 45360 & 46,098 & 47543 & 0.983 & 1.016 & 1.048 \\
\hline 18 & 32272 & 32272 & 32,272 & 32272 & 1.000 & 1.000 & 1.000 \\
\hline 19 & 684499 & 724940 & 765,431 & 846551 & 0.944 & 1.056 & 1.168 \\
\hline 20 & 656798 & 678945 & 701,797 & 747570 & 0.967 & 1.034 & 1.101 \\
\hline 21 & 39671 & 39671 & 39,671 & 39671 & 1.000 & 1.000 & 1.000 \\
\hline 22 & 45308 & 47238 & 49,084 & 52692 & 0.959 & 1.039 & 1.115 \\
\hline 23 & 95321 & 103694 & 111,703 & 127357 & 0.919 & 1.077 & 1.228 \\
\hline 24 & 53635 & 58291 & 62,743 & 71447 & 0.920 & 1.076 & 1.226 \\
\hline 25 & 99988 & 100149 & 107,093 & 122381 & 0.998 & 1.069 & 1.222 \\
\hline 26 & 1095261 & 1113322 & $1,131,390$ & 1167543 & 0.984 & 1.016 & 1.049 \\
\hline 27 & 43296 & 44824 & 46,287 & 49150 & 0.966 & 1.033 & 1.097 \\
\hline 28 & 468454 & 497458 & 525,201 & 579426 & 0.942 & 1.056 & 1.165 \\
\hline 29 & 737722 & 749248 & 760,777 & 783846 & 0.985 & 1.015 & 1.046 \\
\hline 30 & 36027 & 36787 & 37,514 & 38934 & 0.979 & 1.020 & 1.058 \\
\hline 31 & $1,188,601$ & $1,215,876$ & $1,243,164$ & 1297,778 & 0.978 & 1.022 & 1.067 \\
\hline 32 & 365,668 & 366,246 & 366,824 & 367,982 & 0.998 & 1.002 & 1.005 \\
\hline 33 & 188,297 & 202,919 & 217,571 & 246,966 & 0.928 & 1.072 & 1.217 \\
\hline 34 & 660,133 & 708,073 & 756,421 & 854,366 & 0.932 & 1.068 & 1.207 \\
\hline
\end{tabular}


Table 7-3. Effect of Washing Efficiency on Batch by Batch Glass Quantities. (4 pages)

\begin{tabular}{|c|c|c|c|c|c|c|c|}
\hline Spreadsheet: & \multicolumn{7}{|c|}{ SVF-MAR05 HLW Glass Batch Blend Results Summary } \\
\hline Run Number & 090818-3 & $090818-1$ & $090831-2$ & $90818-2$ & 090818-3 & $090831-2$ & $90818-2$ \\
\hline $\begin{array}{l}\text { Wash } \\
\text { Efficiency }\end{array}$ & $100 \%$ & $95 \%$ & $90 \%$ & $80 \%$ & $100 \%$ & $90 \%$ & $80 \%$ \\
\hline $\begin{array}{l}\text { Average } \\
\text { Purge } \\
\text { Efficiency }\end{array}$ & $100 \%$ & $\begin{array}{c}99 \% \\
\text { (Base Case) }\end{array}$ & $98 \%$ & $96 \%$ & $100 \%$ & $98 \%$ & $96 \%$ \\
\hline Batch & \multicolumn{4}{|c|}{ HLW Glass kg } & \multicolumn{3}{|c|}{$\begin{array}{c}\text { Ratio of Glass Mass to Base Case (95\% } \\
\text { Wash Efficiency) }\end{array}$} \\
\hline 35 & $1,375,927$ & $1,397,070$ & $1,418,221$ & $1,460,552$ & 0.985 & 1.015 & 1.045 \\
\hline 36 & 68,744 & $\mathbf{7 3 , 4 7 8}$ & 78,005 & 86,851 & 0.936 & 1.062 & 1.182 \\
\hline 37 & 961,521 & 973,666 & 985,815 & $1,010,125$ & 0.988 & 1.012 & 1.037 \\
\hline 38 & 97,900 & 104,470 & 111,046 & 124,214 & 0.937 & 1.063 & 1.189 \\
\hline 39 & 161,532 & 164,200 & 166,868 & 178,853 & 0.984 & 1.016 & 1.089 \\
\hline 40 & 299,686 & 302,179 & 304,673 & 309,669 & 0.992 & 1.008 & 1.025 \\
\hline 41 & 349,996 & $\mathbf{3 5 4 , 3 2 3}$ & 358,652 & 367,320 & 0.988 & 1.012 & 1.037 \\
\hline 42 & $1,048,801$ & $1,065,844$ & $1,082,895$ & $1,117,011$ & 0.984 & 1.016 & 1.048 \\
\hline 43 & 35,035 & 35,035 & 35,035 & 35,035 & 1.000 & 1.000 & 1.000 \\
\hline 44 & 159,772 & 164,708 & 178,710 & 224,226 & 0.970 & 1.085 & 1.361 \\
\hline 45 & 200,340 & 205,418 & 213,187 & 252,556 & 0.975 & 1.038 & 1.229 \\
\hline 46 & 35,181 & 36,016 & 36,814 & 38,375 & 0.977 & 1.022 & 1.066 \\
\hline 47 & 77,408 & 81,053 & 84,539 & 91,352 & 0.955 & 1.043 & 1.127 \\
\hline 48 & 16,685 & 16,758 & 16,829 & 16,966 & 0.996 & 1.004 & 1.012 \\
\hline 49 & 453,732 & 465,274 & 476,839 & 552,525 & 0.975 & 1.025 & 1.188 \\
\hline 50 & 269,888 & 275,023 & 280,158 & 290,431 & 0.981 & 1.019 & 1.056 \\
\hline 51 & 166,017 & 170,395 & 205,239 & 284,960 & 0.974 & 1.204 & 1.672 \\
\hline 52 & 199,778 & 208,198 & 216,629 & 233,521 & 0.960 & 1.040 & 1.122 \\
\hline 53 & 60,777 & 61,347 & 61,917 & 63,057 & 0.991 & 1.009 & 1.028 \\
\hline 54 & 644,336 & 657,852 & 671,373 & 698,424 & 0.979 & 1.021 & 1.062 \\
\hline 55 & $1,300,169$ & $1,329,676$ & $1,359,198$ & $1,418,278$ & 0.978 & 1.022 & 1.067 \\
\hline 56 & 259,655 & 261,974 & 264,292 & 268,930 & 0.991 & 1.009 & 1.027 \\
\hline 57 & 264,892 & 268,470 & 272,048 & 279,204 & 0.987 & 1.013 & 1.040 \\
\hline 58 & $1,138,330$ & $1,209,464$ & $1,280,634$ & $1,423,088$ & 0.941 & 1.059 & 1.177 \\
\hline 59 & 42,019 & 43,993 & 45,881 & 49,571 & 0.955 & 1.043 & 1.127 \\
\hline 60 & 148,958 & 150,317 & 151,678 & 174,762 & 0.991 & 1.009 & 1.163 \\
\hline 61 & 626,431 & 639,978 & 653,529 & 680,641 & 0.979 & 1.021 & 1.064 \\
\hline 62 & 91,574 & 93,987 & $\mathbf{9 9 , 8 2 7}$ & 113,039 & 0.974 & 1.062 & 1.203 \\
\hline 63 & 533,794 & 560,306 & 586,859 & 640,096 & 0.953 & 1.047 & 1.142 \\
\hline 64 & 26,422 & 26,916 & 27,388 & 28,310 & 0.982 & 1.018 & 1.052 \\
\hline 65 & 30,061 & 30,823 & 31,552 & 32,976 & 0.975 & 1.024 & 1.070 \\
\hline 66 & 196,234 & 200,120 & 204,009 & 243,908 & 0.981 & 1.019 & 1.219 \\
\hline 67 & 427,015 & 443,386 & 459,774 & 492,601 & 0.963 & 1.037 & 1.111 \\
\hline 68 & 516,503 & 533,661 & 550,841 & 586,541 & 0.968 & 1.032 & 1.099 \\
\hline
\end{tabular}


RPP-RPT-42968 Revision 0

Table 7-3. Effect of Washing Efficiency on Batch by Batch Glass Quantities. (4 pages)

\begin{tabular}{|c|c|c|c|c|c|c|c|}
\hline Spreadsheet: & \multicolumn{7}{|c|}{ SVF-MAR05 HLW Glass Batch Blend Results Summary } \\
\hline Run Number & 090818-3 & $090818-1$ & $090831-2$ & $90818-2$ & 090818-3 & $090831-2$ & $90818-2$ \\
\hline $\begin{array}{l}\text { Wash } \\
\text { Efficiency }\end{array}$ & $100 \%$ & $95 \%$ & $90 \%$ & $80 \%$ & $100 \%$ & $90 \%$ & $80 \%$ \\
\hline $\begin{array}{l}\text { Average } \\
\text { Purge } \\
\text { Efficiency }\end{array}$ & $100 \%$ & $\begin{array}{c}99 \% \\
\text { (Base Case) }\end{array}$ & $98 \%$ & $96 \%$ & $100 \%$ & $98 \%$ & $96 \%$ \\
\hline Batch & \multicolumn{4}{|c|}{ HLW Glass kg } & \multicolumn{3}{|c|}{$\begin{array}{c}\text { Ratio of Glass Mass to Base Case (95\% } \\
\text { Wash Efficiency) }\end{array}$} \\
\hline 69 & 429,340 & 466,409 & 503,576 & 578,200 & 0.921 & 1.080 & 1.240 \\
\hline 70 & 376,870 & 386,763 & 396,675 & 416,553 & 0.974 & 1.026 & 1.077 \\
\hline 71 & 924,973 & 947,459 & 969,952 & $1,014,966$ & 0.976 & 1.024 & 1.071 \\
\hline 72 & 58,957 & 61,852 & 64,859 & 71,301 & 0.953 & 1.049 & 1.153 \\
\hline 73 & 276,871 & 288,771 & 307,658 & 386,502 & 0.959 & 1.065 & 1.338 \\
\hline 74 & 17,445 & $\mathbf{1 7 , 5 1 7}$ & 17,587 & 17,722 & 0.996 & 1.004 & 1.012 \\
\hline 75 & 420,024 & 425,802 & 431,599 & 538,275 & 0.986 & 1.014 & 1.264 \\
\hline 76 & 27,711 & 27,732 & 27,752 & 27,792 & 0.999 & 1.001 & 1.002 \\
\hline 77 & 411,519 & 420,324 & 429,142 & 446,821 & 0.979 & 1.021 & 1.063 \\
\hline 78 & 26,247 & 26,264 & 26,281 & 26,313 & 0.999 & 1.001 & 1.002 \\
\hline 79 & 292,099 & 338,912 & 386,211 & 482,302 & 0.862 & 1.140 & 1.423 \\
\hline 80 & 27,031 & 27,867 & 28,666 & 30,229 & 0.970 & 1.029 & 1.085 \\
\hline 81 & 85,072 & 88,370 & 91,670 & 98,274 & 0.963 & 1.037 & 1.112 \\
\hline 82 & 448,911 & 495,620 & 540,297 & 627,622 & 0.906 & 1.090 & 1.266 \\
\hline 83 & 33,136 & 34,600 & 36,003 & 38,744 & 0.958 & 1.041 & 1.120 \\
\hline 84 & 27,699 & 27,703 & 27,708 & 27,716 & 1.000 & 1.000 & 1.000 \\
\hline 85 & 25,989 & 25,991 & 25,993 & 25,996 & 1.000 & 1.000 & 1.000 \\
\hline 86 & 21,474 & 21,654 & 21,827 & 22,164 & 0.992 & 1.008 & 1.024 \\
\hline 87 & 628,822 & 690,778 & 753,459 & 881,049 & 0.910 & 1.091 & 1.275 \\
\hline 88 & 26,759 & 27,443 & 28,098 & 29,378 & 0.975 & 1.024 & 1.071 \\
\hline 89 & 338,436 & 409,737 & 481,928 & 629,053 & 0.826 & 1.176 & 1.535 \\
\hline 90 & 27,161 & 27,542 & 27,906 & 28,618 & 0.986 & 1.013 & 1.039 \\
\hline 91 & 29,860 & 34,878 & 39,901 & 49,961 & 0.856 & 1.144 & 1.432 \\
\hline 92 & 26,659 & 26,659 & 26,659 & 26,659 & 1.000 & 1.000 & 1.000 \\
\hline 93 & 453,631 & 466552 & 481,936 & 559,444 & 0.972 & 1.033 & 1.199 \\
\hline 94 & 396,025 & 456869 & 518,568 & 644,606 & 0.867 & 1.135 & 1.411 \\
\hline 95 & 4877 & 5565 & 6254 & 7635 & 0.876 & 1.124 & 1.372 \\
\hline 96 & 1428 & 1532 & 1632 & 1827 & 0.932 & 1.065 & 1.192 \\
\hline 97 & 6710 & 6803 & 6893 & 7068 & 0.986 & 1.013 & 1.039 \\
\hline 98 & 311 & 317 & 322 & 333 & 0.981 & 1.018 & 1.053 \\
\hline 99 & 881 & 904 & 925 & 968 & 0.975 & 1.024 & 1.071 \\
\hline 100 & 268 & 282 & 288 & 308 & 0.950 & 1.022 & 1.091 \\
\hline 101 & 484,813 & 626,009 & 768,336 & 1056,438 & 0.774 & 1.227 & 1.688 \\
\hline 102 & 642,148 & 720,669 & 799,255 & 956,622 & 0.891 & 1.109 & 1.327 \\
\hline
\end{tabular}




\section{RPP-RPT-42968 Revision 0}

Table 7-3. Effect of Washing Efficiency on Batch by Batch Glass Quantities. (4 pages)

\begin{tabular}{|c|c|c|c|c|c|c|c|}
\hline Spreadsheet: & \multicolumn{7}{|c|}{ SVF-MAR05 HLW Glass Batch Blend Results Summary } \\
\hline Run Number & $090818-3$ & $090818-1$ & $090831-2$ & $90818-2$ & $090818-3$ & $090831-2$ & $90818-2$ \\
\hline $\begin{array}{l}\text { Wash } \\
\text { Efficiency }\end{array}$ & $100 \%$ & $95 \%$ & $90 \%$ & $80 \%$ & $100 \%$ & $90 \%$ & $80 \%$ \\
\hline $\begin{array}{l}\text { Average } \\
\text { Purge } \\
\text { Efficiency }\end{array}$ & $100 \%$ & $\begin{array}{c}99 \% \\
\text { (Base Case) }\end{array}$ & $98 \%$ & $96 \%$ & $100 \%$ & $98 \%$ & $96 \%$ \\
\hline Batch & \multicolumn{4}{|c|}{ HLW Glass kg } & \multicolumn{3}{|c|}{$\begin{array}{c}\text { Ratio of Glass Mass to Base Case (95\% } \\
\text { Wash Efficiency) }\end{array}$} \\
\hline 103 & 135,847 & 168,888 & 202,208 & 269,700 & 0.804 & 1.197 & 1.597 \\
\hline 104 & 542,867 & 558,740 & 574,636 & 626,545 & 0.972 & 1.028 & 1.121 \\
\hline 105 & 167,814 & 176,454 & 185,389 & 204,207 & 0.951 & 1.051 & 1.157 \\
\hline 106 & 169,612 & 170,622 & 171,634 & 173,660 & 0.994 & 1.006 & 1.018 \\
\hline 107 & 3,541 & $\mathbf{3 , 6 3 5}$ & 4,378 & 6078 & 0.974 & 1.204 & 1.672 \\
\hline 108 & 8,963 & 9,086 & 9,210 & 11,486 & 0.986 & 1.014 & 1.264 \\
\hline 109 & 216,236 & 253,263 & 299,984 & 393,486 & 0.854 & 1.184 & 1.554 \\
\hline 110 & 22,145 & 22,583 & 23,022 & 27,524 & 0.981 & 1.019 & 1.219 \\
\hline 111 & 279,207 & 341,261 & 403,711 & 529,813 & 0.818 & 1.183 & 1.553 \\
\hline 112 & 42,521 & 44,965 & 51,653 & 65,149 & 0.946 & 1.149 & 1.449 \\
\hline 113 & 36 & 37 & 39 & 45 & 0.972 & 1.033 & 1.199 \\
\hline 114 & 439,821 & 469,346 & 498,925 & 558,248 & 0.937 & 1.063 & 1.189 \\
\hline 115 & 17,956 & 17,956 & 17,956 & 17,956 & 1.000 & 1.000 & 1.000 \\
\hline 116 & 73,600 & 73,600 & 73,600 & 74,919 & 1.000 & 1.000 & 1.018 \\
\hline $\begin{array}{l}\text { Total glass } \\
\text { (kg) }\end{array}$ & $37,498,282$ & $39,243,052$ & $41,064,826$ & $45,136,420$ & 0 & 1.046 & 1.146 \\
\hline
\end{tabular}

HLW = high-level waste. 


\subsubsection{Melter Sulfate Retention}

During heating and melting of melter feed a portion of the sulfate is driven off and reports to the melter offgas as semi-volatile and gaseous sulfur compounds. Most of the sulfur compounds are removed from the offgas by the submerged bed scrubber, electrostatic precipitator, and demister, and report to the submerged bed scrubber condensate stream. Because sulfate content of HLW glass may limit waste loading, fractional sulfate retention in the glass in an important parameter for estimating required HLW glass quantity. Table 7-4 and Figure 7-3 summarize the results of calculated HLW glass quantity versus melter sulfate retention for the 116 macro batch base case. The case with $98 \%$ average overall purge efficiency for soluble components and $100 \%$ HLW melter sulfate retention corresponds approximately to the System Plan Unconstrained Case HTWOS calculation. The most recent WTP flowsheet (24590-WTP-RPT-PT-02-005) indicates the expected average melter sulfate retention is $67 \%$.

Table 7-4. Effect of Melter Sulfate Retention on High-Level Waste Glass Quantity.

\begin{tabular}{|l|c|c|c|c|c|c|c|}
\hline & \multicolumn{7}{|c|}{116 batch no blend } \\
\hline $\begin{array}{l}\text { Leached Solids } \\
\text { Wash Efficiency }\end{array}$ & $80 \%$ & $80 \%$ & $90 \%$ & $90 \%$ & $95 \%$ & $\mathbf{9 5 \%}$ & $95 \%$ \\
\hline $\begin{array}{l}\text { Average Overall } \\
\text { Purge Efficiency }\end{array}$ & $96 \%$ & $96 \%$ & $98 \%$ & $98 \%$ & $99 \%$ & $\mathbf{9 9 \%}$ & $99 \%$ \\
\hline $\begin{array}{l}\text { HLW Sulfate } \\
\text { Retention }\end{array}$ & $100 \%$ & $67 \%$ & $100 \%$ & $67 \%$ & $100 \%$ & $\mathbf{6 7 \%}$ & $40 \%$ \\
\hline $\begin{array}{l}\text { HLW Glass } \\
\text { quantity }\end{array}$ & 50,800 & 45,100 & 45,100 & 41,100 & 42,600 & $\mathbf{3 9 , 2 0 0}$ & 37,400 \\
\hline
\end{tabular}

HLW = high-level waste.

Figure 7-3. Effect of Melter Sulfate Retention and Purge Efficiency on High-Level Waste Glass Quantity.

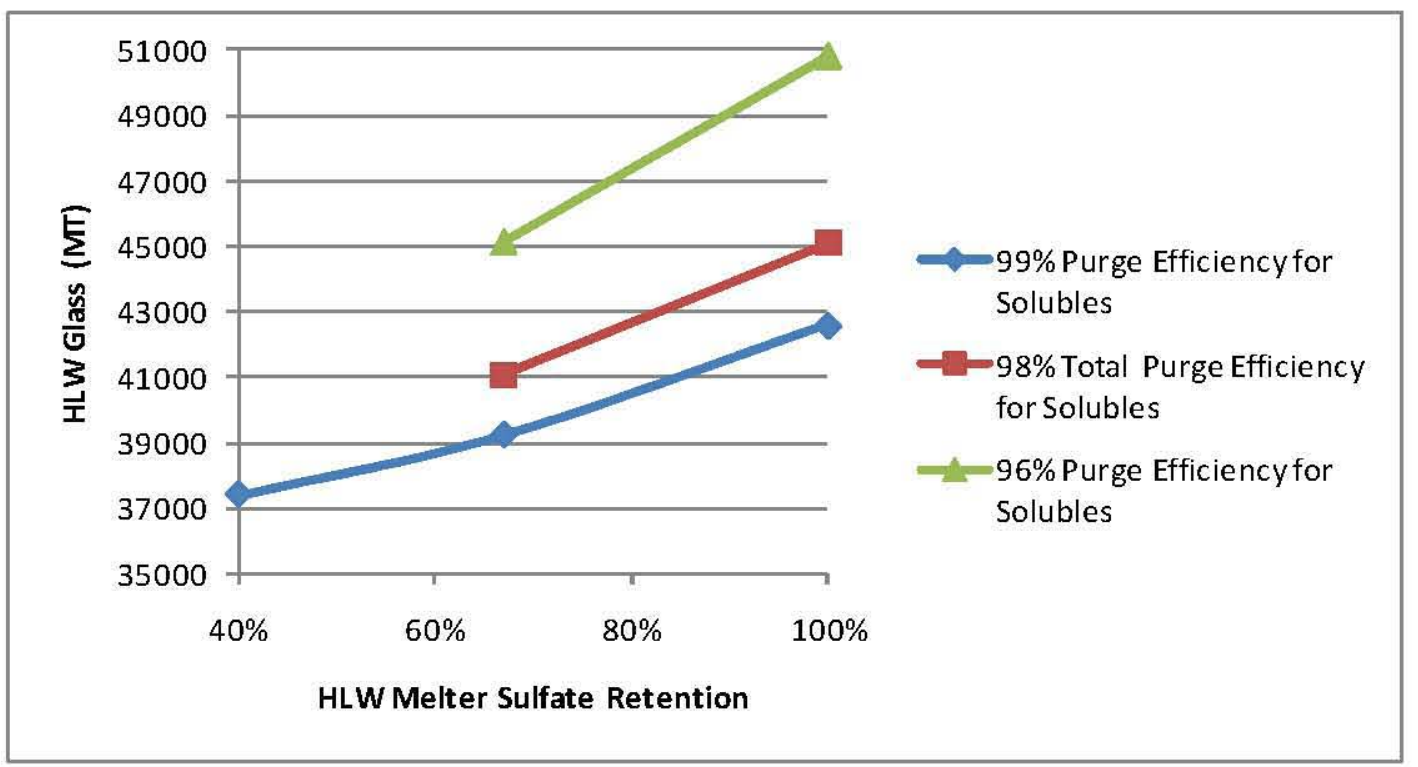




\subsubsection{Base Case Results}

For the current study, an unblended base case for comparisons is established with the following key characteristics:

- $\quad 116$ macro batches of waste transferred to WTP based on consolidation from 450 feed vector batches for the System Plan Draft Revision 4 Unconstrained Case.

- $\quad 95 \%$ leached solids slurry wash efficiency. Overall purge efficiency for soluble components varies by batch and typically averages about $99 \%$ with $95 \%$ wash efficiency.

- $\quad 67 \%$ sulfate retention for the HLW melter.

Estimated total IHLW glass for the base case is $39,200 \mathrm{MT}$.

\subsubsection{Waste Treatment and Immobilization Plant Incidental Blending}

The 56 macro batch case was developed to simulate incidental blending due to parallel processing of HLW and LAW in the WTP (see Section 6.2). HLW glass quantity results for the 56 macro batch case are shown in Table 7-5 and compared with the original 116 macro batch base case. Combining the LAW and HLW batches results in about $7 \%$ decrease in estimated HLW glass. This is partly because of blending of solids in the LAW with solids in the HLW, and partly because of blending sodium from cesium ion eluate with the HLW solids.

Table 7-5. Comparison of 56 and 116 Macro Batch Case High-Level Waste Glass Quantities.

\begin{tabular}{|l|l|l|}
\hline Macro Batch Case & 56 Macro Batch $^{\mathrm{a}}$ & $116 \mathrm{Macro} \mathrm{Batch}^{\mathrm{b}}$ \\
\hline HLW Melter Sulfate Retention & $67 \%$ & $67 \%$ \\
\hline Solids Washing Efficiency & $95 \%$ & $95 \%$ \\
\hline HLW Glass Quantity (MT) & 36,400 & 39,200 \\
\hline
\end{tabular}

a091207-1-SVF-1817 Mission Analysis Glass Batch Blend Results Summary Rev. A.xlsm

b091204-1-SVF-MAR05 HLW Glass Batch Blend Results Summary Rev. D.xlsm

HLW = high-level waste.

MT = metric tons.

\subsection{BLENDING OF WASTE BATCHES IN TANK FARMS}

Blending of waste batches in tank farms involves targeted mixing of waste batches in tank farms to prepare blended batches for transfer to WTP. This approach was found to allow a significant reduction in HLW quantity as discussed in Section 7.2.1. Preliminary assessment of impacts to tank farms is discussed in Section 0. 
RPP-RPT-42968 Revision 0

7.2.1 Effect of Blending Waste Batches on High-Level Waste Quantity

Results of initial blending evaluations are summarized in Table 7-6, 
Figure 7-4, and Figure 7-5. Three tank farm blending cases were developed for comparison with 116 and 56 macro batch cases:

- $\quad$ Single Macro Batch-Total Blend: For this case, all 450 feed vector batches were combined into a single total blend. With base case process performance factors the estimated HLW glass quantity is reduce to about $29,000 \mathrm{MT}$, a $26 \%$ reduction compared to the 116 macro batch base case.

- 23 Macro Match Blend: Limiting components for the 116 macro batch case were reviewed and potentially attractive blending groups were selected based on the planned batch delivery dates shown in the Unconstrained Case feed vector. For each blending group the time between the earliest and latest planned delivery date was limited to approximately two years. No blending was performed on the first four batches or first two years of operations. This blending case resulted in an approximate $20 \%$ HLW glass reduction compared to the 116 macro batch base case and about $7 \%$ more than the single macro batch total blend.

- 21 Macro Batch Blend: Similar to the 23 macro batch case except the waste delivery window was reduced to about 18 months. Estimated HLW glass quantity is essentially the same as the 23 macro batch case.

The 23 and 21 macro batch cases were developed by identifying components or properties that limit waste loading for each of the 116 macro batches. Then, by inspection, potentially attractive blending combinations within the time window were identified and macro batches were grouped for blending. Only a first pass was made; that is, there was no attempt to examine results and identify or test other combinations to optimize the overall blending result. Additional reductions in HLW glass quantity may be possible by further analysis, testing of alternative combinations, and making adjustments to better optimize blending results. Note that because of the way the waste batches were grouped, most of the benefit of WTP incidental blending is also captured by the 23 and 21 macro batch cases.

Table 7-6. Summary of Initial Tank Farm Blending Results.

\begin{tabular}{|l|c|c|c|c|c|c|c|c|}
\hline & \multicolumn{3}{|c|}{$\begin{array}{c}116 \text { Macro Batch-No } \\
\text { Blending }\end{array}$} & $\begin{array}{c}\text { 56 Macro Batch- } \\
\text { WTP Incidental } \\
\text { Blend }\end{array}$ & \multicolumn{2}{|c|}{$\begin{array}{c}23 \text { Macro } \\
\text { Batch Blend }\end{array}$} & $\begin{array}{c}21 \text { Macro } \\
\text { Batch } \\
\text { Blend }\end{array}$ & $\begin{array}{c}\text { Single Macro } \\
\text { Batch (Total } \\
\text { Blend) }\end{array}$ \\
\hline Wash Efficiency & $100 \%$ & $\mathbf{9 5 \%}$ & $80 \%$ & $95 \%$ & $95 \%$ & $80 \%$ & $95 \%$ & $95 \%$ \\
\hline $\begin{array}{l}\text { Average Overall } \\
\text { Purge Efficiency }\end{array}$ & $100 \%$ & $\mathbf{9 9 \%}$ & $96 \%$ & $99 \%$ & $99 \%$ & $96 \%$ & $99 \%$ & $99.3 \%$ \\
\hline HLW Glass (MT) & 37,500 & $\mathbf{3 9 , 2 0 0}$ & 45,100 & 36,400 & 31,100 & 35,800 & 30,900 & 29,000 \\
\hline
\end{tabular}

HLW = high-level waste. $\quad$ WTP = Waste Treatment and Immobilization Plant.

MT = metric tons. 
Figure 7-4. Effect of Blending and Purge Efficiency on High-Level Waste Glass.

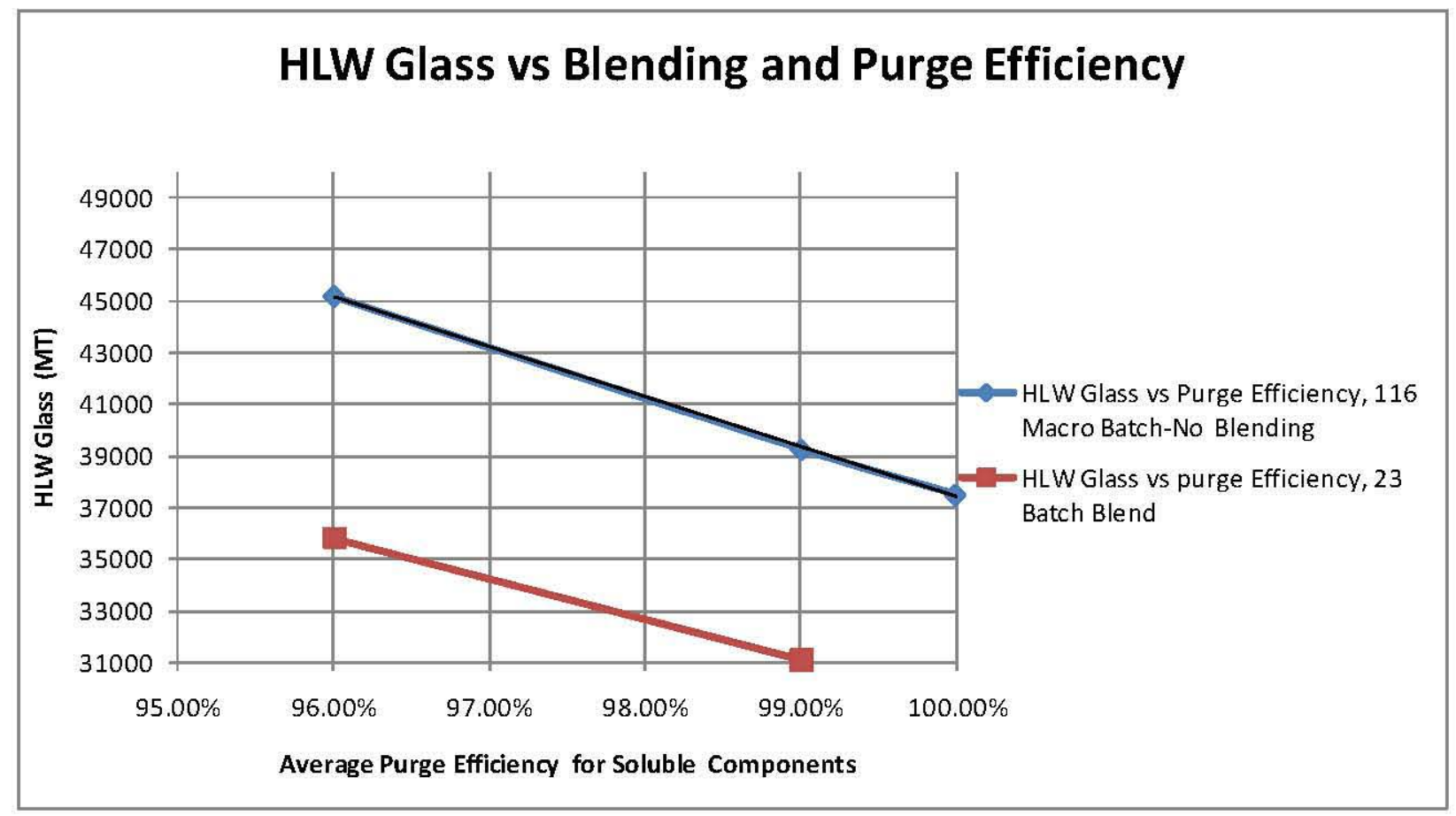

Figure 7-5. Effect of Blending and Sulfate Retention on High-Level Waste Glass Quantity.

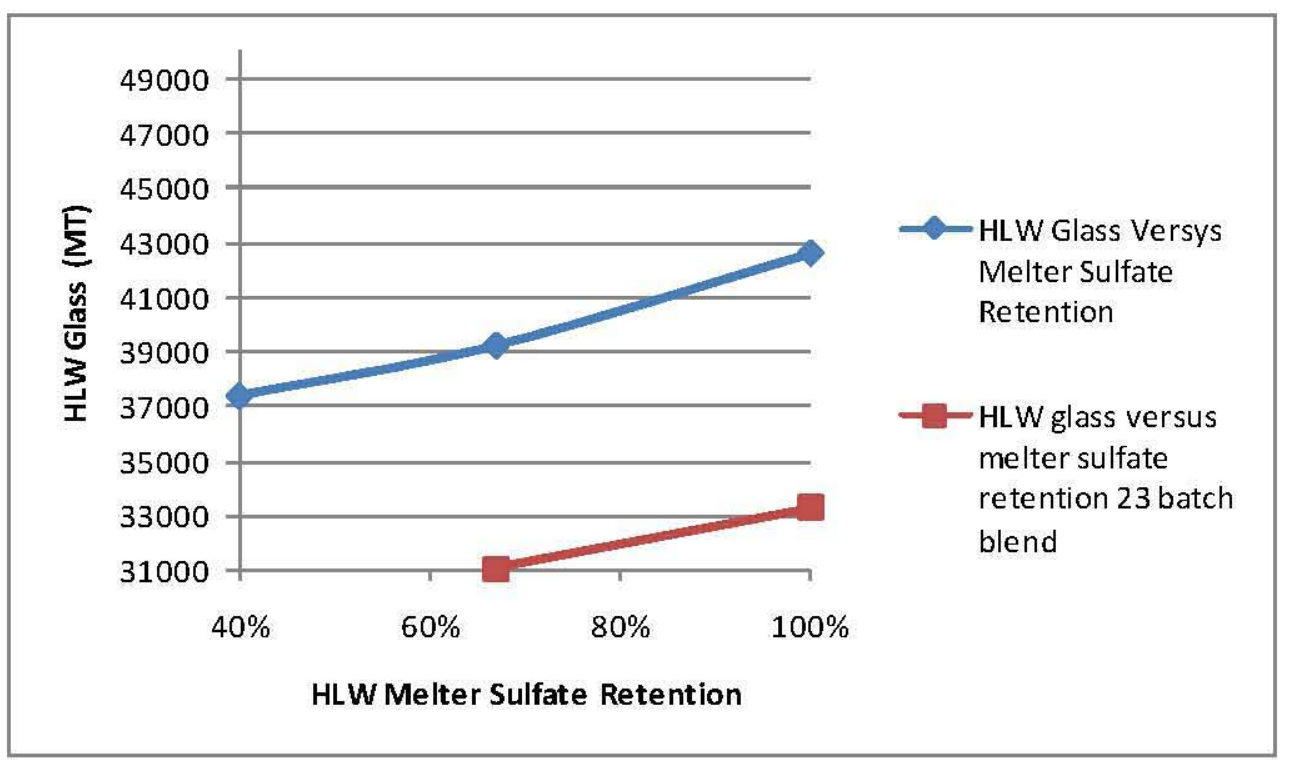


RPP-RPT-42968 Revision 0

\subsubsection{Potential Impacts to Tank Farm Operations}

There are likely to be a number of impacts to tank farms from implementing a strategy to blend groups of tank waste batches. Potential impacts identified include the following:

- $\quad$ An increase in required tank farm waste transfers can generally be expected from any tank farm blending strategy.

- Increased sampling may be required. The amount of additional sampling may vary significantly with the blending scenario and with tank waste sampling requirements, which have not yet been fully defined.

- $\quad$ Some impact to timing or need dates for retrieval and transfer system upgrades can be expected in order to facilitate blending.

\section{Additional Tank Farm Waste Transfers}

In order to assess the magnitude of additional tank farm waste transfers, a simplified example is developed below based on the 23 macro batch blending case discussed in Section 7.2.1. This scenario assumes blending to prepare each blended batch involves a number of waste batches initially staged in tank farm source tanks. The source tanks are numbered Tank 1,2,3, etc. There is an additional tank numbered Tank 0 that serves as a WTP waste feed transfer tank. It is assumed that Tank 1 is also set up to serve as a WTP waste feed transfer tank. It is assumed that Tank 0 is initially empty after transferring its contents to WTP. Two and three source tank batch blend scenarios are as follows.

\section{Two Source Tank Scenario}

Tank 0 is initially empty after transferring its contents to WTP. Tank 1 and 2 each transfer half of their contents to Tank 0 . Contents of Tank 0 are mixed to prepare the first portion of the blended batch and readied for transfer to WTP. The Tank 0 contents are then transferred to WTP. Because of the 160,000 gallon limit on HLW transfers to WTP, about six transfers are required to transfer the batch to WTP assuming a nominal $1 \mathrm{Mgal}$ batch size.

After transferring half of its contents to Tank 0, Tank 2 transfers its remaining contents to Tank 1. Contents of Tank 1 are then mixed and transferred to WTP, again requiring about six transfers because of the 160,000 gallon transfer limit. It is assumed that two transfers are required to empty Tank 2 , one transfer for the first half to Tank 0 , and one transfer for the second half to Tank 1 . After transfer to Tank 1 , Tank 2 is empty and ready to receive waste.

If the assumed no-blending alternative involves transfer of Tank 1 and then Tank 2 directly to WTP, total transfers are 12 (six per tank batch). The above scenario results in 15 total transfers-12 to WTP and three between tank farm tanks. This is three additional transfers compared to the no blend case. If Tank 2 cannot directly transfer to WTP and its contents must be first transferred to Tank 0 or Tank 1 , then the no blend scenario requires one additional 
transfer between tank farm tanks. In this case the blending scenario results in two additional transfers. For the current analysis the first assumption is used (results in maximum calculated additional transfers).

\section{Three Source Tank Scenario}

Tank 0 is initially empty after transferring its contents to WTP. Tanks 1,2 , and 3 each transfer one-third of their contents to Tank 0 . Contents of Tank 0 are then mixed and transferred to WTP.

Tank 3 then transfers half its remaining contents to Tank 1 and half to Tank 2. Tank 3 is now empty and ready to receive waste. Tank 1 and 2 contents are then handled in the same way as the two tank scenario above.

If the assumed no-blending scenario involves transfer of Tank 0 , then Tank 1, then Tank 2, then Tank 3 directly to WTP, the above scenario results in eight additional tank farm transfers. If Tank 2 or 3 cannot directly transfer to WTP and must be first transferred to Tank 0 or 1 , the scenario results in fewer additional transfers. For this analysis the first case assumption is used (results in maximum calculated additional transfers).

\section{Extension to Larger Numbers of Source Tanks}

Extension of the above analysis to additional numbers of source tanks gives the results show in Table 7-7. In all cases the number of additional transfers shown is based on the assumption that any of the source tanks can transfer directly to WTP, which results in the minimum number of transfers for the no-blend case and the maximum number of additional transfers for the blending case.

Table 7-7. Impact of Tank Farm Blending on Required Waste Transfers.

\begin{tabular}{|c|c|}
\hline Number of Source Tanks & Additional Transfers \\
\hline 1 & 0 \\
\hline 2 & 3 \\
\hline 3 & 8 \\
\hline 4 & 15 \\
\hline 5 & 24 \\
\hline 6 & 35 \\
\hline
\end{tabular}

Table 7-8 illustrates application of the above scenarios to the 23 macro batch blending case. For the 23 macro batch case discussed in Section 7.2.1, there are 16 macro batches that involve blending of HLW batches. For each of these batches, the number of additional transfers required is shown based on the number of HLW batches included in the blended batch and the results shown in Table 7-7. Additional transfers are not expected to be required for blending the HLW fraction of LAW batches ( $<3.8 \mathrm{wt} \%$ solids) with the HLW solids, because these are expected to be blended in WTP without the need for additional tank farm transfers. As shown in Table 7-8, applying the simplified analysis above to the 23 macro batch blending case results in 208 additional tank farm transfers for the life of the project. This is considered to be a conservative number, because in the later stages of the program it should be feasible to accomplish much of the blending as the source tank batches are prepared and staged (e.g., from 200 West Area tanks and SST retrievals). Based on a conservative allowance of $\$ 192,000$ average per transfer 
(email from Shuford, D., to aemconsult1@aol.com, "Cost Basis for transfers," [Shuford, D., 2009-09-08]) and 208 additional transfers the estimated cost for additional transfers is $\$ 40$ million.

Table 7-8. Additional Tank Farm Transfers for

23 Macro Batch Blending Case.

\begin{tabular}{|c|c|c|}
\hline $\begin{array}{c}\text { Blended Macro Batch } \\
\text { Number }\end{array}$ & $\begin{array}{c}\text { Number of HLW Batches in } \\
\text { Blended Macro Batch }\end{array}$ & Increased Transfers \\
\hline 1 & 1 & 0 \\
\hline 2 & 0 & 0 \\
\hline 3 & 0 & 0 \\
\hline 4 & 1 & 0 \\
\hline 5 & 3 & 5 \\
\hline 6 & 2 & 3 \\
\hline 7 & 4 & 15 \\
\hline 8 & 2 & 3 \\
\hline 9 & 1 & 0 \\
\hline 10 & 6 & 35 \\
\hline 11 & 4 & 15 \\
\hline 12 & 5 & 24 \\
\hline 13 & 1 & 0 \\
\hline 14 & 3 & 5 \\
\hline 15 & 1 & 0 \\
\hline 16 & 3 & 5 \\
\hline 17 & 4 & 15 \\
\hline 18 & 5 & 24 \\
\hline 19 & 2 & 3 \\
\hline 20 & 2 & 3 \\
\hline 21 & 2 & 3 \\
\hline 22 & 4 & 15 \\
\hline 23 & 6 & 35 \\
\hline Total & 62 & 208 \\
\hline
\end{tabular}

HLW = high-level waste.

\subsection{BLENDING OF PARTIAL BATCHES IN WASTE FEED TANKS}

This section summarizes initial results for the concept of blending partial batches in tank farm feed tanks used to transfer batches of waste to WTP. To illustrate the potential benefits from this approach, the effect on HLW glass are presented in Section 0 for one simplified feed tank blending case. Section 7.3.2 discusses potential tank farm impacts from feed tank blending. 
RPP-RPT-42968 Revision 0

\subsubsection{Blending Half Batches in the Feed Transfer Tanks}

Initial work showed that the 116 macro batch grouping and sequence was not well suited to the feed tank blending evaluation. This grouping includes low solids/LAW batches and high solids/HLW batches. Arrangement in the original sequence frequently results in a half of a high solids HLW batch being blended with half of a low solids LAW batch, which differs from the intended blending approach. Therefore the 56 macro batch grouping that roughly simulates incidental blending in WTP was used as the starting point for feed tank blending. To assess the impact of blending in a WTP feed tank, a simplified blending model was developed by assuming tank farm tanks used for transfers to WTP ("feed tanks") are only partially emptied before being refilled. Therefore, the incoming waste batch is always blended with part of the prior batch. The following describes the assumed scenario:

- $\quad$ One half of the first feed batch is transferred to WTP, and then one half the second waste batch is transferred to the feed tank and blended with the residual waste from the first batch. One half the blended feed batch is then transferred to WTP. The balance of the second batch is then blended with remaining contents of the feed tank. The source tank is now empty and ready to receive waste. One half the blended feed batch is then transferred to WTP and it is then refilled with one half the next source batch, and so on.

The 56 macro batch set was used as the starting point. These batches were blended as described above to yield 112 blended macro batches. The feed vector processing sequence was used without attempting to further improve or optimize the processing sequence. Results are shown in Table 7-9 and compared with the 56 macro batch case, the 116 macro batch base case, the 23 macro batch tank farm blending case discussed in Section 7.2, and a total blend of all tank waste. The feed tank blending case shows approximately $11 \%$ glass reduction compared to the 56 batch case or $17 \%$ reduction compared to the no blend 116 macro batch base case. The feed tank blend case is about $4 \%$ higher than the 23 macro batch tank farm blending case and almost $12 \%$ higher than the total blend.

While blending to reduce HLW quantity is the main focus of the current study, the modeling results also produced data on LAW glass impacts. LAW glass data is provided for information in Table 7-9 and shows that blending is expected to yield small but significant reductions in LAW glass quantity.

Feed tank blending performance could be further improved by using slightly more complex concepts such as:

- Use two or more source tanks in parallel. For example transfer one half batch from feed tank, then refill from source tank 1 and blend, transfer one half batch from feed tank, then refill from source tank 2 . Then either switch back to source tank 1 or transfer the contents of one source tank into the other source tank.

- Use two or more source tanks in series. For example transfer half batch from feed tank, then refill with half batch from source tank 1, then refill source tank 1 from source tank 2 . 
- $\quad$ Optimization of the waste feed sequence. For example alternate source tanks with opposite limiting components.

- $\quad$ Combine feed tank blending with tank farm blending.

While the above concepts have not been formally analyzed, they are likely to result in significant additional improvement over the simpler feed tank blending scenario results presented in Table 7-9.

\begin{tabular}{|l|c|c|c|c|c|}
\hline \multicolumn{7}{|c|}{ Table 7-9. Summary of Blending Results. } \\
\hline Run Identification* & $091207-1$ & $091208-1$ & $\mathbf{0 9 1 2 0 4 - 1}$ & $090818-6$ & $090819-1$ \\
\hline Macro Batch Case & $\begin{array}{c}56 \text { Macro } \\
\text { Batch }\end{array}$ & $\begin{array}{c}112 \text { Macro } \\
\text { Batch Blends }\end{array}$ & $\begin{array}{c}\mathbf{1 1 6} \text { Macro } \\
\text { Batch }\end{array}$ & $\begin{array}{c}23 \text { Macro } \\
\text { Batch Blend }\end{array}$ & $\begin{array}{c}\text { Single Macro } \\
\text { Batch }\end{array}$ \\
\hline $\begin{array}{c}\text { Combine } \\
\text { HLW and } \\
\text { LAW } \\
\text { batches }\end{array}$ & $\begin{array}{c}\text { Feed tank, 1/2 } \\
\text { batch blending }\end{array}$ & None & $\begin{array}{c}\text { Tank Farm } \\
\text { Blending }\end{array}$ & Total Blend \\
\hline $\begin{array}{l}\text { HLW Melter Sulfate } \\
\text { Retention }\end{array}$ & $67 \%$ & $67 \%$ & $\mathbf{6 7 \%}$ & $67 \%$ & $67 \%$ \\
\hline fverage Purge Efficiency & $99 \%$ & $99 \%$ & $\mathbf{9 9 \%}$ & $99 \%$ & $99 \%$ \\
\hline HLW Glass Quantity (MT) & 36,400 & 32,400 & $\mathbf{3 9 , 2 0 0}$ & 31,100 & 29,000 \\
\hline LAW Glass Quantity (MT) & 543,000 & 532,000 & $\mathbf{5 6 1 , 0 0 0}$ & 529,000 & 517,000 \\
\hline
\end{tabular}

*Run Number for SVF-1817 Mission Analysis Glass Batch Blend Results Summary Rev. A.xlsm or MAR05 HLW Glass Batch Blend Results Summary Rev. C.xlsm. See Appendix A for Glass Run Summary Sheets.

HLW = high-level waste. $\mathrm{MT}=$ metric tons.

LAW = low-activity waste.

\subsubsection{Potential Impacts to Tank Farm Operations}

There are likely to be a number of impacts to tank farms from implementing a strategy to blend waste in the WTP feed transfer tanks. Potential impacts identified include the following:

- $\quad$ An increase in required tank farm waste transfers can generally be expected from any tank farm blending strategy.

- Increased sampling may be required. The amount of additional sampling will vary with the blending scenario and with tank waste sampling requirements, which have not yet been fully defined.

- $\quad$ There may be some impact to timing/need dates for retrieval and transfer system upgrades to facilitate blending. 
RPP-RPT-42968 Revision 0

\section{Additional Tank Farm Waste Transfers}

Estimating the number of additional transfers for feed tank blending depends in part on assumptions concerning transfers from the source tanks directly to WTP. If one assumes that a the same feed tank is generally used for HLW transfers to WTP, then about seven transfers are required to transfer a nominal $1 \mathrm{Mgal}$ batch from each source tank to WTP (one transfer from the source tank to the feed tank and six transfers from the feed tank to WTP). However, if it is assumed that each source tank transfers directly to WTP, then only six transfers are required per source tank. For the feed tank blending scenario eight transfers are required per source tank: six transfers from the feed tank to WTP plus two transfers from the source tank to the feed tank, assuming half of the source tank contents are transferred each time. The additional transfers per source tank batch are then either 1 or 2 . Using the larger number (2) and assuming $56 \mathrm{HLW}$ source tank batches, 112 additional transfers are required.

Feed tank blending could also be considered for LAW batches. If it were applied to all 116 HLW and LAW source tank batches, and a conservative value of two extra transfers per batch is assumed, 232 additional transfers are required.

Based on a cost allowance of $\$ 192,000$ average per transfer (Shuford, D., 2009-09-08,) the estimated maximum cost for additional transfers is $\$ 22$ million for 112 transfers to $\$ 45$ million for 232 transfers (likely near the low end of this range).

\section{Sampling and Retrieval System Impacts}

The impact to tank waste sampling depends on the interpretation of sampling requirements and the overall blending scenario. There is no apparent effect on the amount of tank farm sampling and analysis required if it is assumed that when the initial feed tank batch and each source tank batch are sampled and qualified the subsequent feed tank blend does not have to be resampled. On the other hand if the feed tank must be resampled and qualified each time it is blended then it appears that the required amount of sampling and analysis could roughly double for the batches that are blended. If each of the 112 sludge batch blends must be sampled rather than the 56 sludge source batches, 56 additional sampling events would be required. If the blending and sampling logic is also applied to the low solids LAW batches up to 116 additional sampling events could be required.

Sampling of the source tanks prior to blending appears to be clearly the preferred approach if resampling the feed tank after blending can be avoided. Besides reducing the number of sampling events, it should improve overall staging and transfer logistics.

Tank farm blending may result in a modest acceleration of the need dates for retrieval systems and source tank sampling. For example, with no blending the second tank would not need to make a transfer until the first tank was empty. With the example feed tank blending approach, the second tank would need to transfer to the feed tank when it is only half empty. Therefore, the need date for transfers from second tank is moved up by the amount of time required to process half the contents of the first tank. 


\subsection{QUALITATIVE ASSESSMENT OF BLENDING ALTERNATIVES}

The blending concepts presented herein were subjected to a qualitative assessment against each of the seven criterion briefly described below.

- $\quad$ Safety - Safety factors include, but are not limited to, criticality safety, radiological safety, and industrial safety.

- $\quad$ Regulatory - The assessment considers any issues that might create unusual difficulties associated with permitting, regulatory agency acceptance, or stakeholder acceptance.

- Technical Maturity - An assessment of the concepts/technology robustness.

- Operability and Maintainability - Potential operability and maintainability issues including, but not limited to, complexity of process control and operations, and generation of secondary wastes.

- Programmatic Risk - An assessment of the programmatic risk including compatibility with the RPP System (e.g., the effect on immobilized waste volume) and the potential acceptance of the technology by Management (WRPS, U.S. Department of Energy Office of River Protection, etc.) and stakeholders.

- $\quad$ Schedule - Positive or negative impact to the RPP mission schedule.

- $\quad$ Cost - Positive or negative impact to the RPP mission lifecycle cost. 
Table 7-10 presents a qualitative assessment for tank blending alternatives presented in this study. Cost and schedule impacts are summarized in the table. Additional cost and schedule details are provided in subsequent sections.

Table 7-10. Qualitative Assessments of Tank Blending Alternatives.

\begin{tabular}{|l|l|}
\hline \multicolumn{1}{|c|}{ Criterion } & \multicolumn{1}{c|}{ Assessment Conclusions } \\
\hline Safety & $\begin{array}{l}\text { Worker safety risk may be increased due to increased number of tank farm } \\
\text { transfers, but decreased by shortened mission duration and reduced number of } \\
\text { glass filled canisters to handle and ship. }\end{array}$ \\
\hline Regulatory & Blending does not require any additional permitting. \\
\hline Technical Maturity & Transfers are a relatively robust technology (TRL > 6). \\
\hline $\begin{array}{l}\text { Operability and } \\
\text { Maintainability }\end{array}$ & $\begin{array}{l}\text { Additional waste transfers may minimally increase the maintenance required on } \\
\text { the waste transfer system. } \\
\text { Blending provides a more uniform feed to WTP, which is expected to improve } \\
\text { operations. }\end{array}$ \\
\hline Programmatic Risk & $\begin{array}{l}\text { Reducing the quantity of HLW reduces overall schedule risk. } \\
\text { No issues were identified that increase programmatic risks. }\end{array}$ \\
\hline Schedule & Blending is expected to decrease mission duration. \\
\hline Cost & $\begin{array}{l}\text { Blending increases tank farms operating costs, while reducing costs for WTP } \\
\text { operations and immobilized HLW transportation and disposal. Overall mission } \\
\text { costs are expected to be significantly reduced by blending. }\end{array}$ \\
$\begin{array}{l}\text { HLW } \\
\text { TRL high-level waste. } \\
=\text { Technology Readiness Level. }\end{array}$
\end{tabular}

\subsubsection{Schedule Impact}

Blending will reduce the amount of HLW produced thereby shortening the lifecycle of the HLW treatment facility. It is estimated that 2 to 3 years of WTP operations can be eliminated by the blending options, assuming that other portion of the project keep up with HLW processing.

\subsubsection{Cost Impact}

Costs to implement blending are expected to be modest and primarily involve an increased number of tank farm transfers. Based on a cost allowance of $\$ 192,000$ average per transfer (Shuford, D., 2009-09-08) the estimated cost range for additional transfers is from $\$ 22$ million for 112 transfers to $\$ 45$ million for 232 transfers (likely near the low end of this range). Cost savings are expected to result from reduced IHLW canisters to be stored, transported and disposed; and reduced operating duration for the WTP. Table 7-11 shows the calculation of potential cost savings for tank farm blending and feed tank blending as compared to WTP incidental blending. Blending is also expected to result in some reduction in immobilize LAW and improvement in plant operations due to a more uniform feed. These potential benefits are not counted in the projected cost savings calculations shown in Table 7-11. 
Blending is expected to improve WTP operations by providing more consistent and predictable waste feed material that avoids extremes of composition. The increased average waste loading resulting from blending will allow for faster waste processing. Impacts to tank space vary with scenario and time. With the blending scenarios presented, tank space impacts in the early years are expected to be small. Based on expected faster waste processing rates, tank space may be increased in the later years.

Table 7-12 shows the impact of tank blending study on RPP mission requirements.

Table 7-11. Cost Savings for Blending Scenarios.

\begin{tabular}{|c|c|c|c|}
\hline Blending Case & $\begin{array}{c}112 \text { Macro } \\
\text { Batch Blends }\end{array}$ & $\begin{array}{c}56 \text { Macro Batch } \\
\text { (Base) }\end{array}$ & $\begin{array}{l}23 \text { Macro Batch } \\
\text { Blend }\end{array}$ \\
\hline Blending scenario & $\begin{array}{c}\text { Feed tank, } 1 / 2 \\
\text { batch blending }\end{array}$ & $\begin{array}{l}\text { WTP Incidental } \\
\text { Blending }\end{array}$ & Tank Farm Blending \\
\hline Added Tank Farm Costs (millions) ${ }^{\mathbf{a}}$ & $\$ 45$ & $\$ 0$ & $\$ 40$ \\
\hline HLW Glass Quantity (MT) & 32,400 & 36,400 & 31,100 \\
\hline 56 Macro Batch HLW Glass Quantity (MT) & 36,400 & 36,400 & 36,400 \\
\hline HLW Glass Reduction (MT) & 4,000 & 0 & 5,300 \\
\hline HLW Production Days Reduction (days) ${ }^{b}$ & 762 & 0 & 1,009 \\
\hline HLW Production Years Reduction (years) & 2.09 & 0.0 & 2.77 \\
\hline HLW Production Savings (millions) ${ }^{c}$ & $\$ 900$ & $\$ 0$ & $\$ 1,190$ \\
\hline HLW Canister Reduction ${ }^{d}$ & 1,315 & 0 & 1,743 \\
\hline HLW Canister Savings (millions) ${ }^{e}$ & $\$ 1,580$ & $\$ 0$ & $\$ 2,090$ \\
\hline $\begin{array}{l}\text { Total HLW Blending Savings } \\
\text { (millions, rounded) }\end{array}$ & $\$ 2,435$ & $\$ 0$ & $\$ 3,240$ \\
\hline
\end{tabular}

${ }^{a}$ Maximum number of transfers times $\$ 192,000 /$ transfer.

${ }^{b}$ Based on glass production rate of 5.25 MT/day from ORP-11242, 2009, River Protection Project System Plan, Rev. 4, Office of River Protection, U.S. Department of Energy, Richland, Washington.

${ }^{c}$ Equal to the number of years times $\$ 430$ million/year.

${ }^{\mathrm{d}}$ Based on HLW canister glass capacity of 3.04 MT from ORP-11242.

${ }^{\mathrm{e}}$ Based on $\$ 1.2$ million cost per HLW canister for offsite transportation and disposal.
HLW = high-level waste.
MT = metric tons. 
RPP-RPT-42968 Revision 0

Table 7-12. Qualitative Assessment of Tank Blending against River Protection Project Mission Requirements.

\begin{tabular}{|c|c|}
\hline MAR Criterion* & Assessment Conclusions \\
\hline RPP Mission Success Criteria & Allows early WTP mission completion. \\
\hline No new capital project work before 2014 & No capital equipment. \\
\hline WTP Pretreatment Facility & No impact \\
\hline WTP LA W Vitrification Facility & No significant impact. \\
\hline WTP HLW Vitrification Facility & $\begin{array}{l}\text { Decreases mission duration for HLW vitrification } \\
\text { facility. }\end{array}$ \\
\hline Supplemental Pretreatment Facility & $\begin{array}{l}\text { Increases capacity required for supplemental } \\
\text { pretreatment to support reduced HLW vitrification } \\
\text { duration. }\end{array}$ \\
\hline Second LAW Facility & $\begin{array}{l}\text { Increases capacity required for second LAW } \\
\text { Facility to support reduced HLW vitrification } \\
\text { duration. Partly offset by small reduction in total } \\
\text { LAW glass required. }\end{array}$ \\
\hline $\begin{array}{l}\text { Supplemental CH-TRU Treatment and Packaging } \\
\text { Facility }\end{array}$ & No impact \\
\hline Waste Disposal Quantities & Reduces the amount of IHLW and ILAW. \\
\hline DST Space & Varies with scenario. Impact not large. \\
\hline Secondary Waste Quantities & $\begin{array}{l}\text { No impact to quantity, but increases the capacity } \\
\text { required to support reduced tank waste processing } \\
\text { mission duration }\end{array}$ \\
\hline Closure & No impact \\
\hline
\end{tabular}

* Section 2.0 in RPP-RPT-41742, 2009, River Protection Project Mission Analysis Report, Rev. 0, Washington River Protection Solutions, Richland, Washington.

$\begin{array}{llll}\text { CH-TRU } & =\text { contact-handled transuranic (waste). } & \text { LAW } & =\text { low-activity waste. } \\ \text { DST } & =\text { double-shell tank. } & \text { MAR } & =\text { mission analysis report. } \\ \text { HLW } & =\text { high-level waste. } & \text { RPP } & =\text { River Protection Project. } \\ \text { IHLW } & =\text { immobilized high-level waste. } & \text { WTP } & =\text { Waste Treatment and Immobilization Plant. } \\ \text { ILAW } & =\text { immobilized low-activity waste. } & & \end{array}$


RPP-RPT-42968 Revision 0

\subsection{APPLICATION TO HANFORD TANK WASTE OPERATION SIMULATOR MODELING}

Blending options should be considered in developing future system plan updates to support improved feed staging plans and related program and project activities. Transfer rules, batch selection algorithms, or other methods could be developed to allow HTWOS to define waste batch staging scenarios that minimize required glass volumes. Or alternatively, the blending strategy could be supplied as an input to HTWOS. Based on experience during development of the current study the following ideas are offered as a starting point.

- The glass models are an effective tool for identifying potentially attractive batches to be blended. Typically, attractive blending candidates have glass compositions with different primary limiting components or properties. Ideally, the secondary limiting components of each batch should also be different than the primary and secondary limiting components of the other batch. Primary limiting components or properties are defined as the components or properties that actually limit waste loading for a given waste batch. Secondary limiting components or properties are those that are near but below their limits with the optimized glass formulation.

- $\quad$ A method is needed to convert raw waste compositions into estimated melter feed/glass compositions to provide waste feed input data for the glass models. The Process Stream Calculator worksheet has proven to be useful for this purpose in the current study and does not require complex iterative calculations. A similar approach could be considered to assist in selecting candidate feed blending batches for HTWOS. Alternatively the existing HTWOS or WTP G2 models could be used.

- Implementation of a feed transfer tank blending strategy into HTWOS may be relatively straight forward if it is based on simply accepting the waste staging sequence that is presented rather than attempting to also optimize the retrieval and staging sequence based on blending. The concept of leaving substantial heels in tanks prior to refilling could also be applied further back in the staging supply chain to accomplish additional incidental blending.

- Development of a computer routine to allow HTWOS to automatically select an optimized staging, blending, and transfer sequence could prove to be fairly complex. An alternative is to perform waste blending optimization studies and provide the results as input to HTWOS in order to support System Plan updates. This could involve identification of attractive candidate blend sets based on glass models and limiting components; trial runs with HTWOS to help refine the candidate blend sets; and input from tank farms, project, and program personnel as to waste staging and sequence alternatives that are likely to be practical. 
- $\quad$ The preferred approach may involve implementation of some automatic calculation features into HTWOS coupled with targeted blending studies to support major System Plan updates.

\subsection{REFERENCES}

24590-WTP-ICD-MG-01-019, ICD-19-Interface Control Document for Waste Feed, Rev. 4, Bechtel National, Inc., Richland, Washington.

24590-WTP-RPT-PT-02-005, Flowsheet Bases, Assumptions and Requirements, Rev. 4, Bechtel National, Inc., Richland, Washington.

ORP-11242, 2009, River Protection Project System Plan, Rev. 4, Office of River Protection, U.S. Department of Energy, Richland, Washington.

RPP-RPT-26040, 2006, Pairwise Blending of High-Level Waste, Rev. 0, CH2MHill Hanford Group, Inc., Richland, Washington

RPP-RPT-41742, 2009, River Protection Project Mission Analysis Report, Rev. 0, Washington River Protection Solutions, LLC, Richland, Washington.

RPP-RPT-42577, 2009, River Protection Project Mission Analysis Material Balance Description, Rev. 0, Washington River Protection Solutions, LLC, Richland, Washington.

Shuford, D., 2009-09-08, "Cost Basis for transfers," (e-mail to aemconsult1@aol.com), Washington River Protection Solutions, LLC, Richland, Washington.

SVF-1427,SP3_HLW_Glass_Limit_Sensitivity.xls, Rev. 0, February 21, 2008, CH2MHill Hanford Group, Inc., Richland, Washington

SVF-1623,HLW_Glass_Formulation_Verify_y_O.xlsm, Rev. 0, January 7, 2009, Washington River Protection Solutions, LLC, Richland, Washington.

SVF-1663, Balance_Graphic_SP4_PC_2009_03_30_at_20_02_39.xls, SP4 Planning Case-3.08.4r0-2009-03-30-at-20-02-39, Rev 1, April 2, 2009, Washington River Protection Solutions, LLC, Richland, Washington. 
RPP-RPT-42968 Revision 0

APPENDIX A - HIGH-LEVEL WASTE GLASS RUN SUMMARIES 
RPP-RPT-42968 Revision 0

\section{High Level Waste Glass Run Summaries}

\begin{tabular}{|c|c|c|c|}
\hline \multicolumn{4}{|l|}{ Index of Glass Runs } \\
\hline Glass Results File & Comments & $\begin{array}{l}\text { Stream } \\
\text { Calculator } \\
\text { File }\end{array}$ & Description \\
\hline $090818-1$ & $\begin{array}{l}\text { LAW glass } 5.61 \mathrm{E}+08 \mathrm{~kg} \\
\text { HLW Glass (MT) } 3.92 \mathrm{E}+04\end{array}$ & $090817-1$ & Base case 116 macro batch \\
\hline $090818-2$ & HLW Glass (MT) 4.51E+04 & $090817-2$ & Low wash efficiency 116 macro batch \\
\hline $090818-3$ & HLW Glass (MT) 3.75E +04 & $090817-3$ & High Wash Efficiency 116 macro batch \\
\hline $090818-4$ & HLW Glass (MT) $4.26 \mathrm{E}+04$ & $090817-4$ & $\begin{array}{l}100 \% \text { melter sulfate retention } 116 \text { macro } \\
\text { batch }\end{array}$ \\
\hline $090818-6$ & $\begin{array}{l}\text { LAW Glass 5.29E+08 kg } \\
\text { HLW Glass (MT) } 3.11 \mathrm{E}+04\end{array}$ & $090818-1$ & Base case 23 macro batch \\
\hline $090818-7$ & HLW Glass (MT) $3.58 \mathrm{E}+04$ & $090818-2$ & Low $(80 \%)$ wash efficiency 23 macro batch \\
\hline $090818-8$ & HLW Glass (MT) $3.33 \mathrm{E}+04$ & $090818-3$ & $\begin{array}{l}100 \% \text { melter sulfate retention, otherwise base } \\
\text { case, } 23 \text { macro batch }\end{array}$ \\
\hline $090818-9$ & $\begin{array}{l}\text { HLW Glass (MT) } \\
4.15 \mathrm{E}+04\end{array}$ & $090818-4$ & $\begin{array}{l}100 \% \text { sulfate retention and low ( } 80 \%) \text { wash } \\
\text { eff. } 23 \text { macro batch }\end{array}$ \\
\hline $090819-1$ & $\begin{array}{l}\text { LAW Glass 5.17E+08 kg } \\
\text { HLW Glass (MT) } 2.90 \mathrm{E}+04\end{array}$ & $090818-5$ & $\begin{array}{l}\text { Base case single macro batch } \\
\text { Also includes washing study on feed stream } \\
\text { calculator sheet LAG }\end{array}$ \\
\hline $090819-2$ & HLW Glass (MT) 2.91E+04 & $090818-6$ & $\begin{array}{l}100 \% \text { melter sulfate retention single macro } \\
\text { batch }\end{array}$ \\
\hline $090819-3$ & HLW Glass (MT) 3.74E+04 & $090819-1$ & $\begin{array}{l}\text { Low }(40 \%) \text { melter sulfate retention, } \\
\text { otherwise Base case } 116 \text { macro batch }\end{array}$ \\
\hline 090819-4 & HLW Glass (MT) $5.08 \mathrm{E}+04$ & 090819-2 & $\begin{array}{l}100 \% \text { sulfate retention and low wash eff. } 116 \\
\text { macro batch }\end{array}$ \\
\hline $090820-1$ & $\begin{array}{l}\text { LAW Glass } 5.29 \mathrm{E}+08 \mathrm{~kg} \\
\text { HLW Glass (MT)3.09E+04 }\end{array}$ & $090820-1$ & Base Case 21 Macro batch \\
\hline $090831-1$ & $\begin{array}{l}\text { HLW Glass (MT) } \\
4.51 \mathrm{E}+04\end{array}$ & $090831-1$ & $\begin{array}{l}90 \% \text { Wash Efficiency, } 100 \% \text { sulfate } \\
\text { retention, } 116 \text { macro batch }\end{array}$ \\
\hline $090831-2$ & $\begin{array}{l}\text { HLW Glass (MT) } \\
4.11 \mathrm{E}+04\end{array}$ & $090831-2$ & $\begin{array}{l}90 \% \text { Wash Efficiency, } 67 \% \text { melter sulfate } \\
\text { retention } 116 \text { macro batch }\end{array}$ \\
\hline $091204-1$ & $\begin{array}{l}\text { HLW Glass (MT)3.924E+04 } \\
\text { LAW Glass (MT) 5.613E+05 }\end{array}$ & 091204-1 & $\begin{array}{l}\text { Base case } 116 \text { macro batch (repeat run of } \\
\text { glass run 090818-1 with finalized versions of } \\
\text { spreadsheets) }\end{array}$ \\
\hline 091207-1- & $\begin{array}{l}\text { HLW Glass (MT) 3.64E+04 } \\
\text { LAW Glass (MT) 5.434E+05 }\end{array}$ & 091204-1 & $\begin{array}{l}56 \text { Macro Batch-WTP Incidental Blending. } \\
95 \% \text { Wash Efficiency, } 67 \% \text { melter sulfate } \\
\text { retention }\end{array}$ \\
\hline $091208-1$ & $\begin{array}{l}\text { HLW Glass (MT) 3.24E+04 } \\
\text { LAW Glass (MT) 5.32E+05 }\end{array}$ & $091208-1$ & $\begin{array}{l}56 \text { Macro Batch-WTP Incidental Blending. } \\
\text { Blended to } 112 \text { batches by transferring half } \\
\text { the batch then refilling feed transfer tank. }\end{array}$ \\
\hline
\end{tabular}


RPP-RPT-42968 Revision 0

\begin{tabular}{|c|c|c|c|c|c|}
\hline \multirow[b]{2}{*}{ BASE CASE } & \multicolumn{4}{|c|}{ HLW GLASS PRODUCTION ESTIMATE SUMMARY RESULTS } & \\
\hline & & & & & \\
\hline \multicolumn{6}{|c|}{ Case Description: } \\
\hline \multicolumn{6}{|c|}{ 090818-1-SVF-MAR05 HLW Glass Batch Blend Results Summary Rev. C.xlsm } \\
\hline & & & & & \\
\hline & & & & & \\
\hline & & & & & \\
\hline \multicolumn{6}{|l|}{ Waste feed: } \\
\hline \multicolumn{6}{|c|}{ 090813-1 SVF-MAR03 - Feed Vector to Macro Batch Calculator - Rev G.xIsm } \\
\hline \multicolumn{6}{|c|}{ SP4 Unconstrained Case Feed Vector Batches - 116 macro batches } \\
\hline \multicolumn{6}{|c|}{ 090817-1-SVF-MAR04 Macro Batch to Process Stream Calculator Rev. D.xIsm } \\
\hline \multicolumn{6}{|c|}{\begin{tabular}{|l|l|l|} 
WTP Process & \\
\end{tabular}} \\
\hline \multicolumn{6}{|c|}{ Base Case Run 116 macro batch } \\
\hline \multicolumn{6}{|c|}{ Base Case Run 116 macro batch } \\
\hline & & & & & \\
\hline Selected & & Symbol & Value & Symbol & Value \\
\hline \multirow[t]{3}{*}{$\overline{\text { Parameters }}$} & & $\mathrm{PNa}, \mathrm{LAT}, 15$ & 1.500 & PS, 29a, 19 & 0.3300 \\
\hline & & Pwash,S & 0.050 & IXNa & 235 \\
\hline & & $\mathrm{PNa}(\mathrm{aq}), 19 \mathrm{~b}, 15 \mathrm{LSol}$ & 0.023 & Pwash,Al & 0.050 \\
\hline Glass Model: & & \multicolumn{3}{|c|}{ YYMMDD_N HLW Glass SVF-1623 Rev. 0-A } & \\
\hline Glass Limits & & \multicolumn{4}{|c|}{ Reference case limits from RPP-MA SP3_HLW_Glass_Limit - Rev A } \\
\hline \multicolumn{6}{|c|}{ Summary resı 090818-1-SVF-MAR05 HLW Glass Batch Blend Results Summary Rev. C.xIsm } \\
\hline & \multicolumn{2}{|c|}{ Base Case Run 116 macro batch } & & & \\
\hline & \multicolumn{3}{|c|}{ YYMMDD_N HLW Glass SVF-1623 Rev. 0-A } & & \\
\hline Limiting & Number of & Waste oxide & Glass Mas & Ave Waste & Percent of \\
\hline Component & Feed Batches & MT & MT & Loading & Glass mass \\
\hline $\mathrm{SO} 3$ & 18 & $1.56 \mathrm{E}+03$ & $5.80 \mathrm{E}+03$ & $26.82 \%$ & $14.77 \%$ \\
\hline $\mathrm{P} 2 \mathrm{O} 5$ & 5 & $2.95 E+02$ & $1.03 E+03$ & $28.61 \%$ & $2.63 \%$ \\
\hline $\mathrm{Cr} 2 \mathrm{O} 3$ & 1 & $1.17 \mathrm{E}+02$ & $2.53 E+02$ & $46.01 \%$ & $0.65 \%$ \\
\hline $\mathrm{Al} 2 \mathrm{O} 3$ & 14 & $3.18 \mathrm{E}+03$ & $1.25 \mathrm{E}+04$ & $25.50 \%$ & $31.82 \%$ \\
\hline $\mathrm{Fe} 2 \mathrm{O} 3$ & 4 & $3.57 E+02$ & $1.09 \mathrm{E}+03$ & $32.69 \%$ & $2.78 \%$ \\
\hline $\mathrm{Na} 2 \mathrm{O}$ & 34 & $1.26 \mathrm{E}+03$ & $3.31 E+03$ & $38.17 \%$ & $8.42 \%$ \\
\hline $\mathrm{Zr}$ & 2 & $3.50 E+02$ & 2,976 & $11.75 \%$ & $7.58 \%$ \\
\hline & & & & & \\
\hline & & & & & \\
\hline & & & & & \\
\hline Other & 38 & $5.40 E+03$ & $1.23 E+04$ & $43.91 \%$ & $31.34 \%$ \\
\hline Total & 116 & $1.25 E+04$ & $3.92 E+04$ & $31.90 \%$ & $100 \%$ \\
\hline
\end{tabular}


RPP-RPT-42968 Revision 0

\begin{tabular}{|c|c|c|c|c|c|}
\hline & \multicolumn{4}{|c|}{ HLW GLASS PRODUCTION ESTIMATE SUMMARY RESULTS } & \\
\hline \multicolumn{2}{|c|}{ Low Washing Efficiency } & & & & \\
\hline \multicolumn{2}{|c|}{ Case Description: } & & & & \\
\hline \multicolumn{5}{|c|}{ 090818-2-SVF-MAR05 HLW Glass Batch Blend Results Summary Rev. C.xlsm } & \\
\hline \multirow[t]{2}{*}{ Waste feed: } & & & & & \\
\hline & & & & & \\
\hline \multicolumn{5}{|c|}{ 090813-1SVF-MAR03 - Feed Vector to Macro Batch Calculator - Rev G.xIsm } & \\
\hline \multicolumn{4}{|c|}{ SP4 Unconstrained Case Feed Vector Batches - 116 macro batches } & & \\
\hline \multicolumn{5}{|c|}{ 090817-2-SVF-MAR04 Macro Batch to Process Stream Calculator Rev. D.xIsm } & \\
\hline WTP Process & & & & & \\
\hline \multicolumn{6}{|c|}{ Low $(80 \%)$ wash efficiency, otherwise Base Case Run } \\
\hline \multicolumn{6}{|c|}{ Evaluate low wash efficiency with 116 macro batch } \\
\hline & & & & & \\
\hline Selected & & Symbol & Value & Symbol & Value \\
\hline \multirow[t]{3}{*}{ Parameters } & & PNa, LAT, 15 & 1.500 & PS, 29a, 19 & 0.3300 \\
\hline & & Pwash,S & 0.200 & $\mathrm{IXNa}$ & 235 \\
\hline & & $\mathrm{PNa}(\mathrm{aq}), 19 \mathrm{~b}, 15 \mathrm{LSol}$ & 0.088 & Pwash,Al & 0.200 \\
\hline & & & & & \\
\hline Glass Model: & & \multicolumn{3}{|c|}{ YYMMDD_N HLW Glass SVF-1623 Rev. 0-A } & \\
\hline Glass Limits & & \multicolumn{4}{|c|}{ Reference case limits from RPP-MA SP3_HLW_Glass_Limit - Rer } \\
\hline \multirow{3}{*}{ Summary results: } & \multicolumn{5}{|c|}{ 090818-2-SVF-MAR05 HLW Glass Batch Blend Results Summary Rev. C.xIsm } \\
\hline & \multicolumn{4}{|c|}{ Low $(80 \%)$ wash efficiency, otherwise Base Case Run } & \\
\hline & \multicolumn{3}{|c|}{ YYMMDD_N HLW Glass SVF-1623 Rev. 0-A } & & \\
\hline Limiting & Number of & Waste oxide & Glass Mass & Ave Waste & Percent of \\
\hline Component & Feed Batches & MT & MT & Loading & Glass mass \\
\hline SO3 & 29 & $2.84 \mathrm{E}+03$ & $1.02 \mathrm{E}+04$ & $27.97 \%$ & $22.52 \%$ \\
\hline P2O5 & 5 & $5.76 \mathrm{E}+02$ & $1.53 E+03$ & $37.68 \%$ & $3.39 \%$ \\
\hline $\mathrm{Cr} 2 \mathrm{O} 3$ & 1 & $1.48 \mathrm{E}+02$ & $3.93 E+02$ & $37.70 \%$ & $0.87 \%$ \\
\hline $\mathrm{Al} 2 \mathrm{O} 3$ & 12 & $3.68 \mathrm{E}+03$ & 1. $30 E+04$ & $28.24 \%$ & $28.87 \%$ \\
\hline $\mathrm{Fe} 2 \mathrm{O} 3$ & 3 & $3.78 \mathrm{E}+02$ & $1.02 \mathrm{E}+03$ & $37.12 \%$ & $2.26 \%$ \\
\hline $\mathrm{Na} 2 \mathrm{O}$ & 41 & 2. $20 \mathrm{E}+03$ & $5.48 \mathrm{E}+03$ & $40.22 \%$ & $12.14 \%$ \\
\hline $\mathrm{Zr}$ & 2 & 349.585319 & 2970.628857 & $11.77 \%$ & $6.58 \%$ \\
\hline & & & & & \\
\hline & & & & & \\
\hline & & & & & \\
\hline Other & 23 & 4.77E+03 & $1.06 E+04$ & $45.22 \%$ & $23.38 \%$ \\
\hline Total & 116 & $1.49 \mathrm{E}+04$ & $4.51 E+04$ & $33.12 \%$ & $100 \%$ \\
\hline
\end{tabular}


RPP-RPT-42968 Revision 0

\begin{tabular}{|c|c|c|c|c|c|}
\hline & \multicolumn{4}{|c|}{ HLW GLASS PRODUCTION ESTIMATE SUMMARY RESULTS } & \\
\hline \multicolumn{6}{|c|}{$100 \%$ Washing Efficiency } \\
\hline \multicolumn{6}{|c|}{ Case Description: } \\
\hline \multicolumn{6}{|c|}{ 090818-3-SVF-MAR05 HLW Glass Batch Blend Results Summary Rev. C.xIsm } \\
\hline & & & & & \\
\hline & & & & & \\
\hline & & & & & \\
\hline \multicolumn{6}{|l|}{ Waste feed: } \\
\hline & & & & & \\
\hline \multicolumn{6}{|c|}{ 090813-1SVF-MAR03 - Feed Vector to Macro Batch Calculator - Rev G.xIsm } \\
\hline \multicolumn{5}{|c|}{\begin{tabular}{|l|l|} 
SP4 Unconstrained Case Feed Vector Batches - 116 macro batches &
\end{tabular}} & \\
\hline \multicolumn{6}{|c|}{ 090817-3-SVF-MAR04 Macro Batch to Process Stream Calculator Rev. D.xIsm } \\
\hline \multicolumn{6}{|c|}{\begin{tabular}{l|l|l|l} 
WTP Process & \\
\end{tabular}} \\
\hline \multicolumn{6}{|c|}{$100 \%$ wash efficiency, otherwise Base Case Run } \\
\hline \multicolumn{6}{|c|}{ Evaluate very high wash efficiency with 116 macro batch } \\
\hline & & & & & \\
\hline Selected & & Symbol & Value & Symbol & Value \\
\hline \multirow[t]{3}{*}{ Parameters } & & PNa, LAT, 15 & 1.500 & PS, 29a, 19 & 0.3300 \\
\hline & & Pwash,S & 0.000 & $\mathrm{IXNa}$ & 235 \\
\hline & & $\mathrm{PNa}(\mathrm{aq}), 19 \mathrm{~b}, 15 \mathrm{LSol}$ & 0.000 & Pwash,Al & 0.000 \\
\hline Glass Model: & & \multicolumn{3}{|c|}{ YYMMDD_N HLW Glass SVF-1623 Rev. 0-A } & \\
\hline Glass Limits & & \multicolumn{4}{|c|}{ Reference case limits from RPP-MA SP3_HLW_Glass_Limit - Rev A } \\
\hline \multirow{3}{*}{ Summary results: } & \multicolumn{5}{|c|}{ 090818-3-SVF-MAR05 HLW Glass Batch Blend Results Summary Rev. C.xIsm } \\
\hline & \multicolumn{3}{|c|}{$100 \%$ wash efficiency, otherwise Base Case Run } & & \\
\hline & \multicolumn{3}{|c|}{ YYMMDD_N HLW Glass SVF-1623 Rev. 0-A } & & \\
\hline Limiting & Number of & Waste oxide & Glass Mass & Ave Waste & Percent of \\
\hline Component & Feed Batches & MT & MT & Loading & Glass mass \\
\hline $\mathrm{SO} 3$ & 17 & $1.43 E+03$ & $5.10 \mathrm{E}+03$ & $28.05 \%$ & $13.61 \%$ \\
\hline P2O5 & 5 & $2.82 E+02$ & $1.02 E+03$ & $27.73 \%$ & $2.71 \%$ \\
\hline $\mathrm{Cr} 2 \mathrm{O} 3$ & 0 & $0.00 \mathrm{E}+00$ & $0.00 E+00$ & N/A & $0.00 \%$ \\
\hline $\mathrm{Al} 2 \mathrm{O} 3$ & 14 & $2.94 \mathrm{E}+03$ & 1. $21 \mathrm{E}+04$ & $24.21 \%$ & $32.37 \%$ \\
\hline $\mathrm{Fe} 2 \mathrm{O} 3$ & 4 & 3. $38 \mathrm{E}+02$ & $1.09 \mathrm{E}+03$ & $30.92 \%$ & $2.91 \%$ \\
\hline $\mathrm{Na} 2 \mathrm{O}$ & 34 & $1.16 \mathrm{E}+03$ & $2.96 \mathrm{E}+03$ & $39.12 \%$ & $7.89 \%$ \\
\hline $\mathrm{Zr}$ & 2 & 349.585319 & 2977.501046 & $11.74 \%$ & $7.94 \%$ \\
\hline & & & & & \\
\hline & & & & & \\
\hline & & & & & \\
\hline Other & 40 & $5.18 \mathrm{E}+03$ & 1. $22 \mathrm{E}+04$ & $42.40 \%$ & $32.57 \%$ \\
\hline Total & 116 & 1. $17 E+04$ & 3. $75 E+04$ & $31.13 \%$ & $100 \%$ \\
\hline
\end{tabular}


RPP-RPT-42968 Revision 0

HLW GLASS PRODUCTION ESTIMATE SUMMARY RESULTS

$100 \%$ sulfate retention

Case Description:

090818-4-SVF-MAR05 HLW Glass Batch Blend Results Summary Rev. C.xlsm

Waste feed:

090813-1 SVF-MAR03 - Feed Vector to Macro Batch Calculator - Rev G.xIsm

SP4 Unconstrained Case Feed Vector Batches - 116 macro batches

090817-4-SVF-MAR04 Macro Batch to Process Stream Calculator Rev. D.xIsm

WTP Process

$100 \% \mathrm{HLW}$ melter sulfate retention otherwise Base Case Run

Evaluate sensitivity to $100 \%$ sulfate retention 116 macro batch

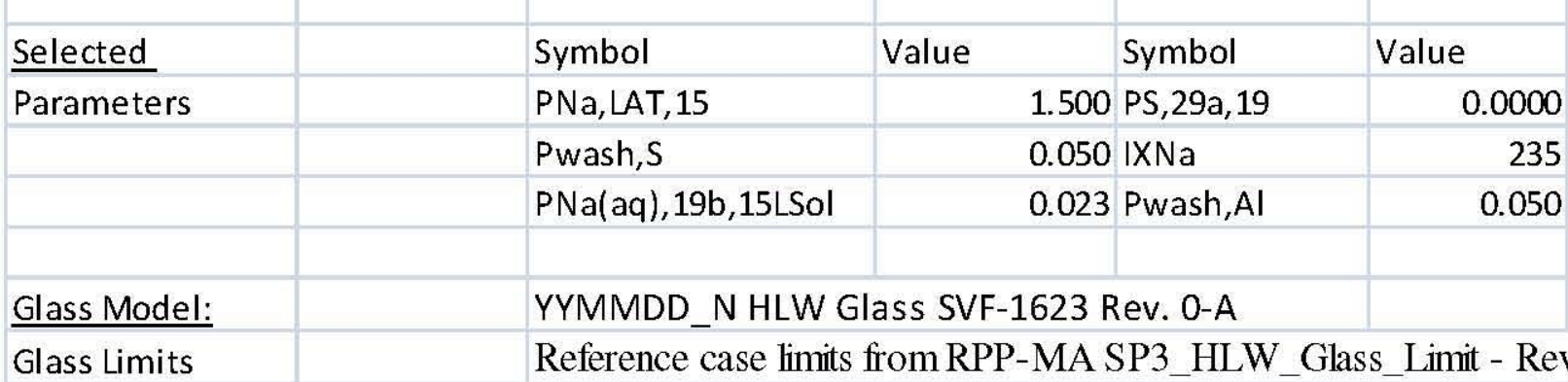

Summary results: 090818-4-SVF-MAR05 HLW Glass Batch Blend Results Summary Rev. C.xIsm $100 \% \mathrm{HLW}$ melter sulfate retention otherwise Base Case Run YYMMDD_N HLW Glass SVF-1623 Rev. 0-A

\begin{tabular}{|c|c|c|c|c|c|}
\hline Limiting & Number of & Waste oxide & Glass Mass & Ave Waste & Percent of \\
\hline Component & Feed Batches & MT & MT & Loading & Glass mass \\
\hline $\mathrm{SO} 3$ & 32 & $2.52 E+03$ & 1.11E+04 & $22.66 \%$ & $26.16 \%$ \\
\hline P2O5 & 4 & $2.43 E+02$ & $8.67 E+02$ & $28.01 \%$ & $2.04 \%$ \\
\hline $\mathrm{Cr} 2 \mathrm{O} 3$ & 1 & 1. $17 \mathrm{E}+02$ & $2.53 E+02$ & $46.04 \%$ & $0.59 \%$ \\
\hline $\mathrm{Al} 2 \mathrm{O} 3$ & 12 & $3.02 E+03$ & 1. $20 E+04$ & $25.10 \%$ & $28.23 \%$ \\
\hline $\mathrm{Fe} 2 \mathrm{O} 3$ & 4 & $3.58 \mathrm{E}+02$ & $1.09 \mathrm{E}+03$ & $32.73 \%$ & $2.57 \%$ \\
\hline $\mathrm{Na} 2 \mathrm{O}$ & 32 & 1.17E+03 & 3.10E+03 & $37.79 \%$ & $7.28 \%$ \\
\hline $\mathrm{Zr}$ & 2 & 349.585319 & 2975.497942 & $11.75 \%$ & $6.99 \%$ \\
\hline & & & & & \\
\hline & & & & & \\
\hline Other & 29 & 4.77E+03 & $1.11 E+04$ & $42.88 \%$ & $26.15 \%$ \\
\hline Total & 116 & $1.26 E+04$ & $4.26 E+04$ & $29.48 \%$ & $100 \%$ \\
\hline
\end{tabular}


RPP-RPT-42968 Revision 0

\begin{tabular}{|c|c|c|c|c|c|}
\hline & \multicolumn{4}{|c|}{ HLW GLASS PRODUCTION ESTIMATE SUMMARY RESULTS } & \\
\hline \multicolumn{6}{|l|}{ Case Description: } \\
\hline \multicolumn{6}{|c|}{ 090818-6-SVF-MAR05 HLW Glass Batch Blend Results Summary Rev. C.xIsm } \\
\hline & & & & & \\
\hline & & & & & \\
\hline & & & & & \\
\hline \multicolumn{6}{|l|}{ Waste feed: } \\
\hline & & & & & \\
\hline \multicolumn{6}{|c|}{ 09-08-13-2 SVF-MAR03 - Feed Vector to Macro Batch Calculator - Rev G.xIsm } \\
\hline \multicolumn{6}{|c|}{ SP4 Unconstrained Case Feed Vector Batches - 23 Batch blending evaluation } \\
\hline \multicolumn{6}{|c|}{ 090818-1-SVF-MAR04 Macro Batch to Process Stream Calculator Rev. D.xIsm } \\
\hline \multicolumn{6}{|c|}{\begin{tabular}{|l|l|l|l|} 
WTP Process & & \\
\end{tabular}} \\
\hline \multicolumn{6}{|c|}{ Base Case run 23 macro batch blend } \\
\hline \multicolumn{6}{|c|}{ evaluate effect of partial blending } \\
\hline Selected & & Symbol & Value & Symbol & Value \\
\hline \multirow[t]{3}{*}{ Parameters } & & PNa, LAT, 15 & 1.500 & PS,29a,19 & 0.3300 \\
\hline & & Pwash,S & 0.050 & IXNa & 235 \\
\hline & & $\mathrm{PNa}(\mathrm{aq}), 19 \mathrm{~b}, 15 \mathrm{LSol}$ & 0.023 & Pwash,Al & 0.050 \\
\hline Glass Model: & & \multicolumn{3}{|c|}{ YYMMDD N HLW Glass SVF-1623 Rev. 0-A } & \\
\hline Glass Limits & & \multicolumn{4}{|c|}{ Reference case limits from RPP-MA SP3_HLW_Glass_Limit - Rev A } \\
\hline \multirow[t]{3}{*}{ Summary results: } & \multicolumn{5}{|c|}{ 090818-6-SVF-MAR05 HLW Glass Batch Blend Results Summary Rev. C.xIsm } \\
\hline & \multicolumn{2}{|c|}{ Base Case run 23 macro batch blend } & & & \\
\hline & \multicolumn{3}{|c|}{ YYMMDD_N HLW Glass SVF-1623 Rev. 0-A } & & \\
\hline Limiting & Number of & Waste oxide & Glass Mass & Ave Waste & Percent of \\
\hline Component & Feed Batches & MT & MT & Loading & Glass mass \\
\hline $\mathrm{SO} 3$ & 3 & $1.45 \mathrm{E}+03$ & $3.63 \mathrm{E}+03$ & $39.86 \%$ & $11.68 \%$ \\
\hline P2O5 & 1 & 1. $10 \mathrm{E}+02$ & 3. $17 E+02$ & $34.78 \%$ & $1.02 \%$ \\
\hline $\mathrm{Cr} 2 \mathrm{O} 3$ & 0 & $0.00 E+00$ & $0.00 E+00$ & N/A & $0.00 \%$ \\
\hline $\mathrm{Al} 2 \mathrm{O} 3$ & 2 & $6.39 E+02$ & $1.99 \mathrm{E}+03$ & $32.19 \%$ & $6.39 \%$ \\
\hline $\mathrm{Fe} 2 \mathrm{O} 3$ & 2 & $3.22 E+02$ & $1.00 \mathrm{E}+03$ & $32.18 \%$ & $3.22 \%$ \\
\hline $\mathrm{Na} 2 \mathrm{O}$ & 1 & $1.33 \mathrm{E}+00$ & $3.59 E+00$ & $37.02 \%$ & $0.01 \%$ \\
\hline $\mathrm{Zr}$ & 1 & $6.57 E+02$ & 1,883 & $34.88 \%$ & $6.06 \%$ \\
\hline & & & & & \\
\hline & & & & & \\
\hline Other & 13 & $9.29 \mathrm{E}+03$ & $2.23 E+04$ & $41.71 \%$ & $71.63 \%$ \\
\hline Total & 23 & $1.25 \mathrm{E}+04$ & $3.11 E+04$ & $40.10 \%$ & $100 \%$ \\
\hline
\end{tabular}


RPP-RPT-42968 Revision 0

HLW GLASS PRODUCTION ESTIMATE SUMMARY RESULTS

23 Batch Low wash efficiency

Case Description:

090818-7-SVF-MAR05 HLW Glass Batch Blend Results Summary Rev. C.xIsm

Waste feed:

09-08-13-2 SVF-MAR03 - Feed Vector to Macro Batch Calculator - Rev G.xIsm SP4 Unconstrained Case Feed Vector Batches - 23 Batch blending evaluation 090818-2-SVF-MAR04 Macro Batch to Process Stream Calculator Rev. D.xIsm WTP Process

Low wash eff $(80 \%)$ otherwise Base Case run Low wash efficiency, 23 Macro Batch blending

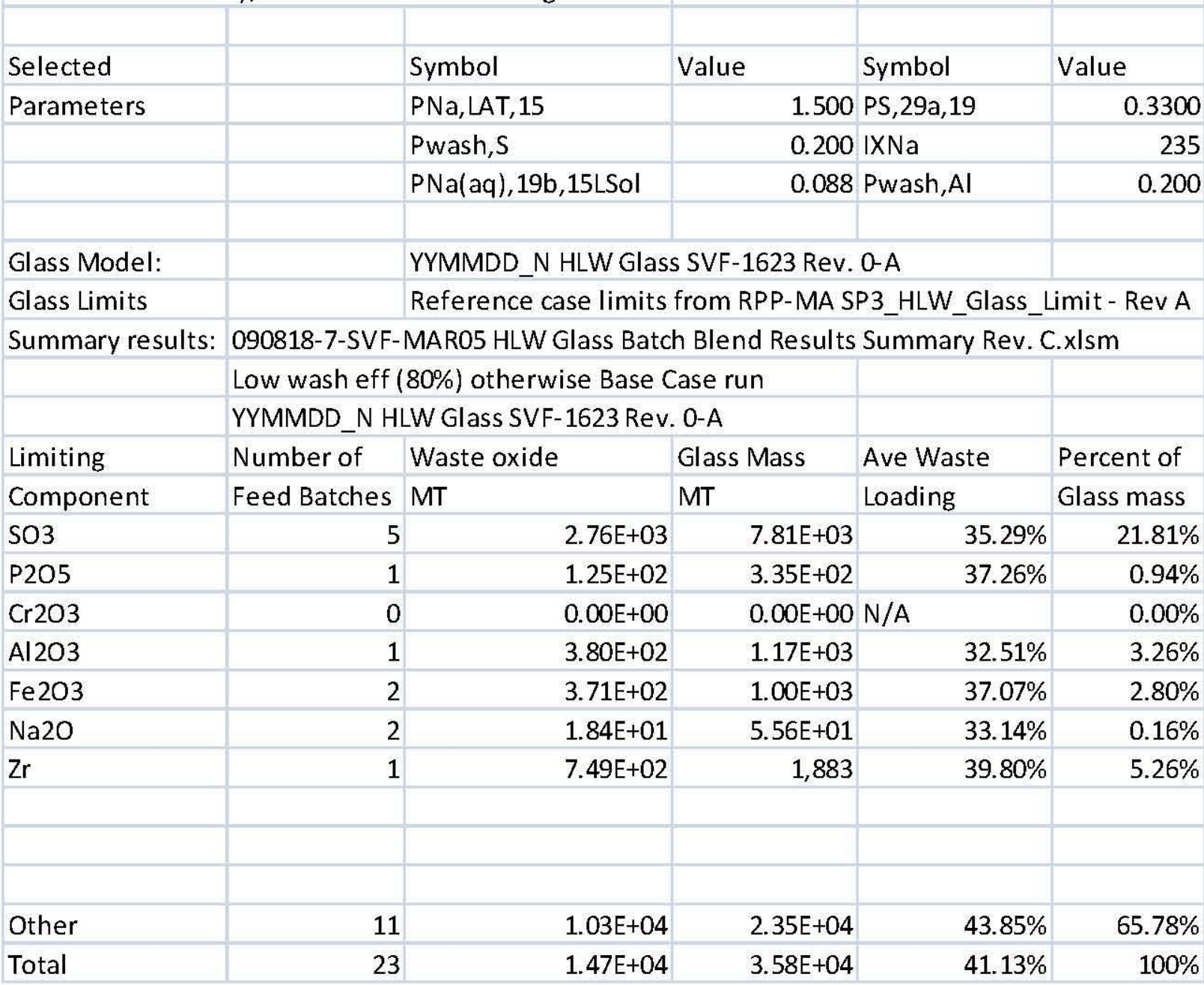


RPP-RPT-42968 Revision 0

HLW GLASS PRODUCTION ESTIMATE SUMMARY RESULTS

23 Batch $100 \%$ melter sulfate retention

Case Description:

090818-8-SVF-MAR05 HLW Glass Batch Blend Results Summary Rev. C.xIsm

Waste feed:

09-08-13-2 SVF-MAR03 - Feed Vector to Macro Batch Calculator - Rev G.xIsm SP4 Unconstrained Case Feed Vector Batches - 23 Batch blending evaluation 090818-3-SVF-MAR04 Macro Batch to Process Stream Calculator Rev. D.xIsm WTP Process

$100 \%$ HLW melter sulfate retention otherwise base case high melter sulfate retention, 23 Macro Batch blending

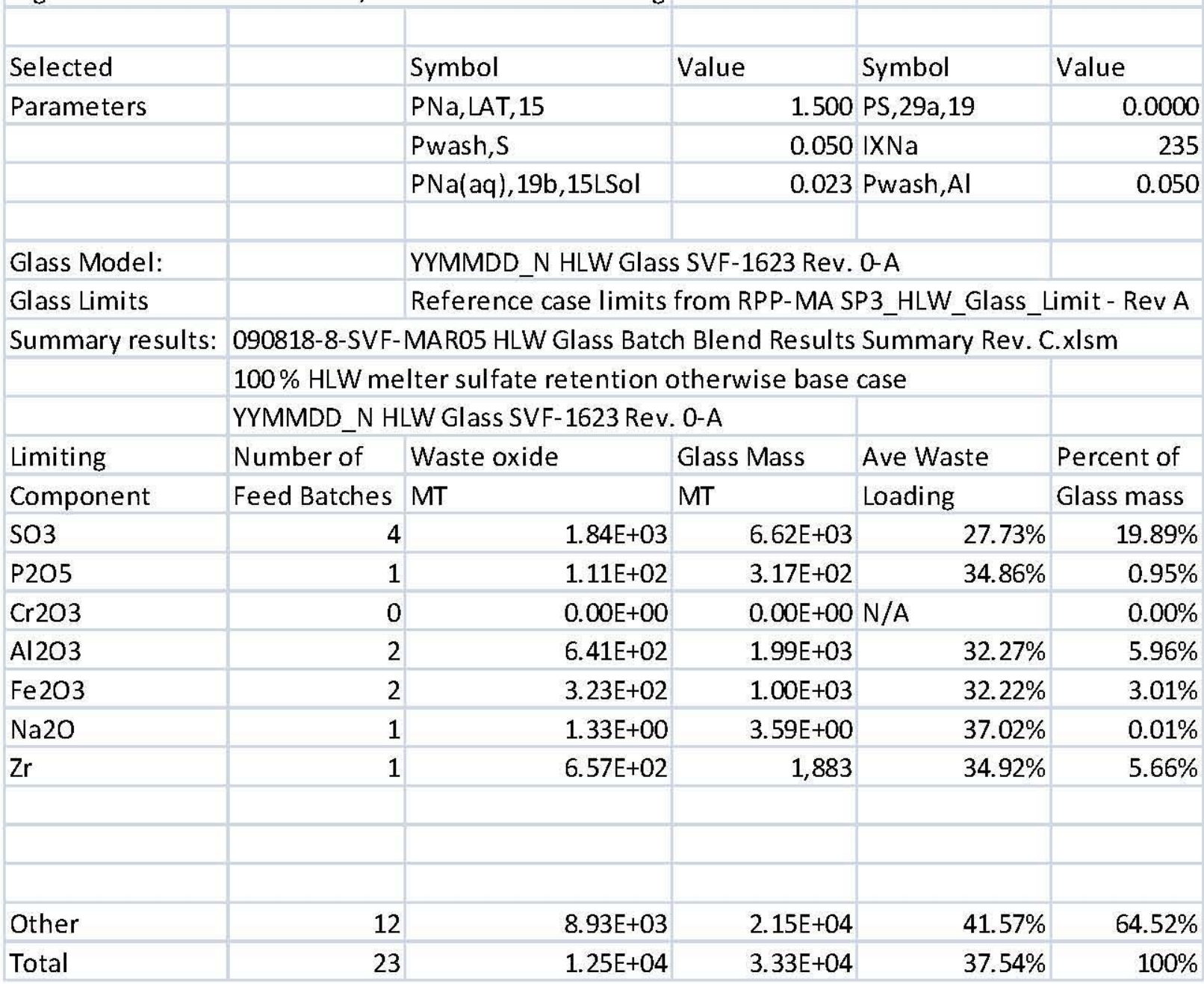


RPP-RPT-42968 Revision 0

\begin{tabular}{|c|c|c|c|c|c|}
\hline & \multicolumn{4}{|c|}{ HLW GLASS PRODUCTION ESTIMATE SUMMARY RESULTS } & \\
\hline \multicolumn{6}{|l|}{ Case Description: } \\
\hline \multicolumn{6}{|c|}{ 090818-9-SVF-MAR05 HLW Glass Batch Blend Results Summary Rev. C.xIsm } \\
\hline & & & & & \\
\hline & & & & & \\
\hline & & & & & \\
\hline \multicolumn{6}{|l|}{ Waste feed: } \\
\hline & & & & & \\
\hline \multicolumn{6}{|c|}{ 09-08-13-2 SVF-MAR03 - Feed Vector to Macro Batch Calculator - Rev G.xIsm } \\
\hline \multicolumn{6}{|c|}{ SP4 Unconstrained Case Feed Vector Batches - 23 Batch blending evaluation } \\
\hline \multicolumn{6}{|c|}{ 090818-4-SVF-MAR04 Macro Batch to Process Stream Calculator Rev. D.xIsm } \\
\hline \multicolumn{6}{|c|}{\begin{tabular}{|l|l|l|l|} 
WTP Process & & \\
\end{tabular}} \\
\hline \multicolumn{6}{|c|}{ Low wash eff ( $80 \%), 100 \%$ HLW melter sulfate retention } \\
\hline \multicolumn{6}{|c|}{ Low wash efficiency, high melter sulfate retention, 23 Macro Batch blending } \\
\hline Selected & & Symbol & Value & Symbol & Value \\
\hline \multirow[t]{3}{*}{ Parameters } & & PNa, LAT, 15 & 1.500 & PS, 29a, 19 & 0.0000 \\
\hline & & Pwash,S & 0.200 & IXNa & 235 \\
\hline & & $\mathrm{PNa}(\mathrm{aq}), 19 \mathrm{~b}, 15 \mathrm{LSol}$ & 0.088 & Pwash,Al & 0.200 \\
\hline Glass Model: & & \multicolumn{3}{|c|}{ YYMMDD_N HLW Glass SVF-1623 Rev. O-A } & \\
\hline Glass Limits & & \multicolumn{4}{|c|}{ Reference case limits from RPP-MA SP3_HLW_Glass_Limit - Rev A } \\
\hline \multirow[t]{3}{*}{ Summary results: } & \multicolumn{5}{|c|}{ 090818-9-SVF-MAR05 HLW Glass Batch Blend Results Summary Rev. C.xIsm } \\
\hline & \multicolumn{4}{|c|}{ Low wash eff $(80 \%), 100 \%$ HLW melter sulfate retention } & \\
\hline & \multicolumn{3}{|c|}{ YYMMDD_N HLW Glass SVF-1623 Rev. 0-A } & & \\
\hline Limiting & Number of & Waste oxide & Glass Mass & Ave Waste & Percent of \\
\hline Component & Feed Batches & MT & MT & Loading & Glass mass \\
\hline $\mathrm{SO} 3$ & 10 & $7.43 E+03$ & $2.38 \mathrm{E}+04$ & $31.30 \%$ & $57.24 \%$ \\
\hline P2O5 & 1 & 1. $25 \mathrm{E}+02$ & $3.35 E+02$ & $37.39 \%$ & $0.81 \%$ \\
\hline $\mathrm{Cr} 2 \mathrm{O} 3$ & 0 & $0.00 E+00$ & $0.00 E+00$ & N/A & $0.00 \%$ \\
\hline $\mathrm{Al} 2 \mathrm{O} 3$ & 1 & $3.81 E+02$ & 1.17E+03 & $32.61 \%$ & $2.82 \%$ \\
\hline $\mathrm{Fe} 2 \mathrm{O} 3$ & 2 & $3.72 E+02$ & $1.00 \mathrm{E}+03$ & $37.14 \%$ & $2.41 \%$ \\
\hline $\mathrm{Na} 2 \mathrm{O}$ & 2 & $1.84 \mathrm{E}+01$ & $5.55 \mathrm{E}+01$ & $33.17 \%$ & $0.13 \%$ \\
\hline $\mathrm{Zr}$ & 1 & $7.50 E+02$ & 1,883 & $39.84 \%$ & $4.54 \%$ \\
\hline & & & & & \\
\hline & & & & & \\
\hline Other & 6 & $5.70 E+03$ & 1. $33 \mathrm{E}+04$ & $42.89 \%$ & $32.05 \%$ \\
\hline Total & 23 & $1.48 \mathrm{E}+04$ & $4.15 E+04$ & $35.63 \%$ & $100 \%$ \\
\hline
\end{tabular}


RPP-RPT-42968 Revision 0

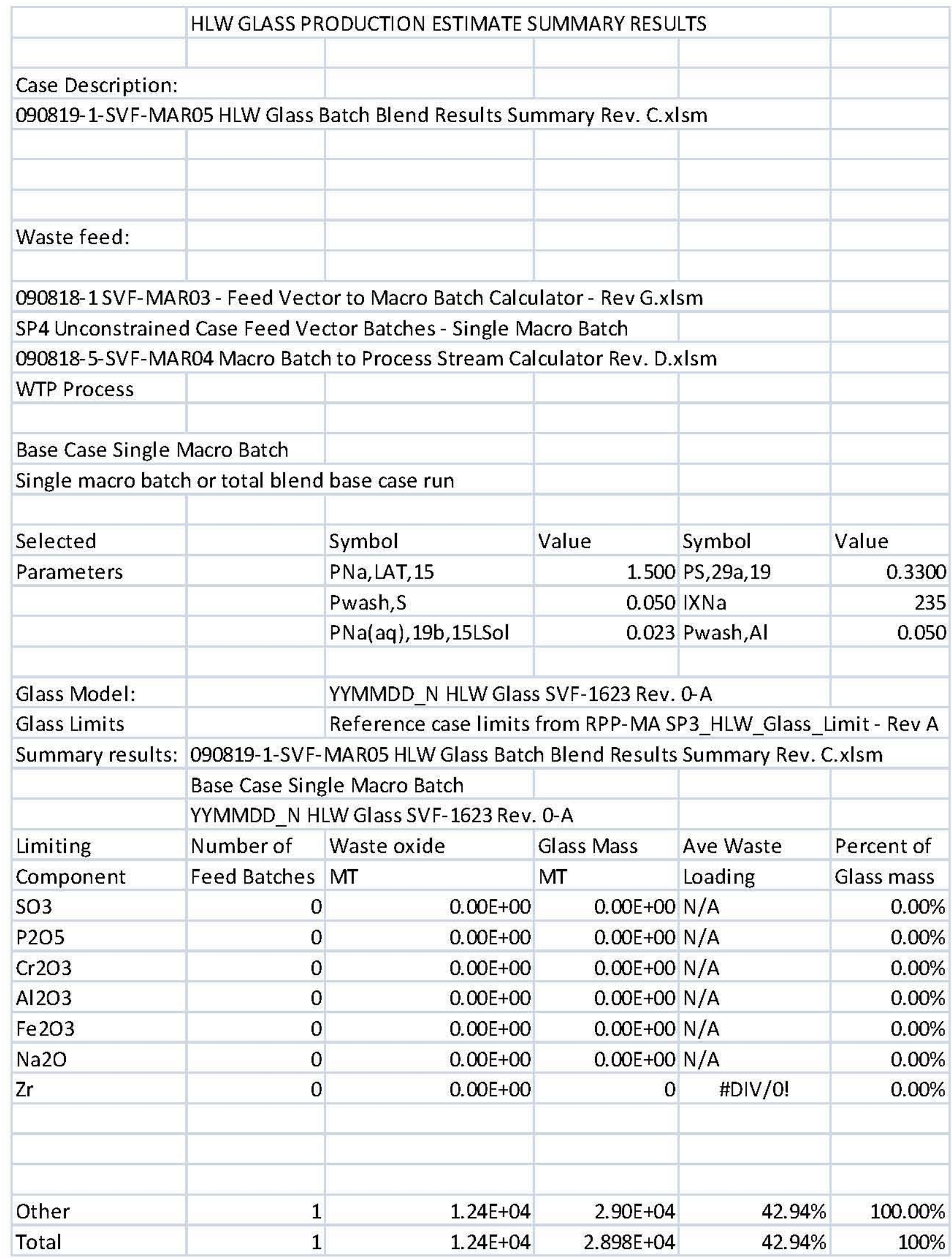


RPP-RPT-42968 Revision 0

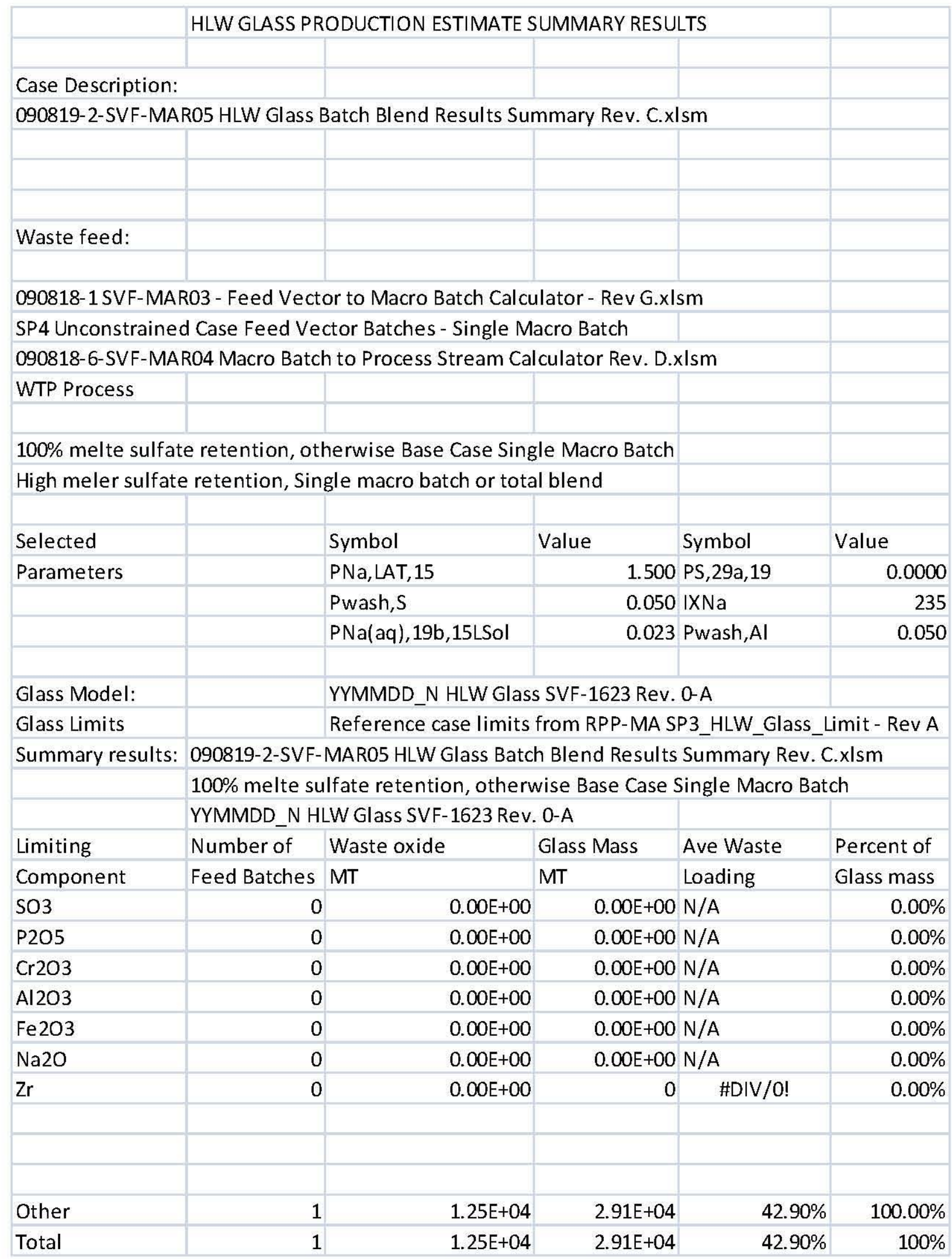


RPP-RPT-42968 Revision 0

HLW GLASS PRODUCTION ESTIMATE SUMMARY RESULTS

$40 \%$ Sulfate Retention, otherwise base case

Case Description:

090819-3-SVF-MAR05 HLW Glass Batch Blend Results Summary Rev. C.xIsm

Waste feed:

090813-1SVF-MAR03 - Feed Vector to Macro Batch Calculator - Rev G.xIsm

SP4 Unconstrained Case Feed Vector Batches - 116 macro batches

090819-1-SVF-MAR04 Macro Batch to Process Stream Calculator Rev. D.xIsm

WTP Process

$40 \% \mathrm{HLW}$ melter sulfate retention otherwise Base Case Run

Evaluate sensitivity to low melter sulfate retention 116 macro batch

\begin{tabular}{|c|c|c|c|c|}
\hline Selected & Symbol & Value & Symbol & Value \\
\hline Parameters & $\mathrm{PNa}, \mathrm{LAT}, 15$ & 1.500 & PS,29a,19 & 0.6000 \\
\hline & Pwash,S & 0.050 & IXNa & 235 \\
\hline & $\mathrm{PNa}(\mathrm{aq}), 19 \mathrm{~b}, 15 \mathrm{LSol}$ & 0.023 & Pwash, Al & 0.050 \\
\hline Glass Model: & \multicolumn{3}{|c|}{ YYMMDD_N HLW Glass SVF-1623 Rev. 0-A } & \\
\hline Glass Limits & \multicolumn{4}{|c|}{ Reference case limits from RPP-MA SP3_HLW_Glass_Limit - Rev A } \\
\hline
\end{tabular}

Summary results: 090819-3-SVF-MAR05 HLW Glass Batch Blend Results Summary Rev. C.xIsm

$40 \%$ HLW melter sulfate retention otherwise Base Case Run

YYMMDD_N HLW Glass SVF-1623 Rev. 0-A

\begin{tabular}{|c|c|c|c|c|c|}
\hline Limiting & Number of & Waste oxide & Glass Mass & Ave Waste & Percent of \\
\hline Component & Feed Batches & MT & MT & Loading & Glass mass \\
\hline SO3 & 8 & $5.90 E+02$ & 1. $79 \mathrm{E}+03$ & $32.98 \%$ & $4.78 \%$ \\
\hline P2O5 & 6 & 4. $69 \mathrm{E}+02$ & $1.65 E+03$ & $28.46 \%$ & $4.41 \%$ \\
\hline $\mathrm{Cr} 2 \mathrm{O} 3$ & 1 & 1.16E+02 & $2.53 E+02$ & $45.99 \%$ & $0.68 \%$ \\
\hline $\mathrm{Al} 2 \mathrm{O} 3$ & 14 & 3. $18 \mathrm{E}+03$ & 1. $25 \mathrm{E}+04$ & $25.47 \%$ & $33.38 \%$ \\
\hline $\mathrm{Fe} 2 \mathrm{O} 3$ & 4 & $3.57 E+02$ & $1.09 E+03$ & $32.66 \%$ & $2.92 \%$ \\
\hline $\mathrm{Na} 2 \mathrm{O}$ & 37 & $1.31 \mathrm{E}+03$ & $3.41 E+03$ & $38.38 \%$ & $9.12 \%$ \\
\hline $\mathrm{Zr}$ & 2 & 349.585319 & 2976.026909 & $11.75 \%$ & $7.95 \%$ \\
\hline & & & & & \\
\hline & & & & & \\
\hline & & & & & \\
\hline Other & 44 & $6.12 E+03$ & 1. $38 \mathrm{E}+04$ & $44.50 \%$ & $36.76 \%$ \\
\hline Total & 116 & 1. $25 \mathrm{E}+04$ & $3.74 E+04$ & $33.39 \%$ & $100 \%$ \\
\hline
\end{tabular}


RPP-RPT-42968 Revision 0

HLW GLASS PRODUCTION ESTIMATE SUMMARY RESULTS

$100 \%$ Sulfur Retention, low Washing efficiency

Case Description:

090819-4-SVF-MAR05 HLW Glass Batch Blend Results Summary Rev. C.xIsm

Waste feed:

090813-1 SVF-MAR03 - Feed Vector to Macro Batch Calculator - Rev G.xIsm

SP4 Unconstrained Case Feed Vector Batches - 116 macro batches

090819-2-SVF-MAR04 Macro Batch to Process Stream Calculator Rev. D.xIsm

WTP Process

$100 \%$ HLW melter sulfate retention, Low (80\%) wash efficiency

Evaluate sensitivity to $100 \%$ sulfate retention + wash efficiency

\begin{tabular}{|c|c|c|c|c|}
\hline Selected & Symbol & Value & Symbol & Value \\
\hline Parameters & PNa,LAT,15 & 1.500 & PS,29a,19 & 0.0000 \\
\hline & Pwash, S & 0.200 & IXNa & 235 \\
\hline & $\mathrm{PNa}(\mathrm{aq}), 19 \mathrm{~b}, 15 \mathrm{LSol}$ & 0.088 & Pwash,Al & 0.200 \\
\hline Glass Model: & \multicolumn{3}{|c|}{ YYMMDD_N HLW Glass SVF-1623 Rev. 0-A } & \\
\hline Glass Limits & \multicolumn{4}{|c|}{ Reference case limits from RPP-MA SP3_HLW_Glass_Limit - Rev A } \\
\hline
\end{tabular}

Summary results: 090819-4-SVF-MAR05 HLW Glass Batch Blend Results Summary Rev. C.xIsm $100 \%$ HLW melter sulfate retention, Low (80\%) wash efficiency

YYMMDD_N HLW Glass SVF-1623 Rev. 0-A

\begin{tabular}{|c|c|c|c|c|c|}
\hline Limiting & Number of & Waste oxide & Glass Mass & Ave Waste & Percent of \\
\hline Component & Feed Batches & MT & MT & Loading & Glass mass \\
\hline SO3 & 42 & $4.98 \mathrm{E}+03$ & $2.01 E+04$ & $24.80 \%$ & $39.54 \%$ \\
\hline P2O5 & 4 & $2.73 E+02$ & $9.02 E+02$ & $30.32 \%$ & $1.77 \%$ \\
\hline $\mathrm{Cr} 2 \mathrm{O} 3$ & 1 & 1. $49 \mathrm{E}+02$ & $3.93 E+02$ & $37.75 \%$ & $0.77 \%$ \\
\hline $\mathrm{Al} 2 \mathrm{O} 3$ & 12 & $3.68 \mathrm{E}+03$ & 1. $30 \mathrm{E}+04$ & $28.28 \%$ & $25.65 \%$ \\
\hline $\mathrm{Fe} 2 \mathrm{O} 3$ & 2 & $3.72 E+02$ & $1.00 \mathrm{E}+03$ & $37.15 \%$ & $1.97 \%$ \\
\hline $\mathrm{Na} 2 \mathrm{O}$ & 35 & $1.52 E+03$ & 4.18E+03 & $36.41 \%$ & $8.23 \%$ \\
\hline $\mathrm{Zr}$ & 2 & $3.50 E+02$ & 2,970 & $11.77 \%$ & $5.85 \%$ \\
\hline & & & & & \\
\hline & & & & & \\
\hline Other & 18 & $367 F+03$ & $824 \mathrm{~F}+02$ & $4452 \%$ & $16.22 \%$ \\
\hline Total & 116 & $1.50 E+04$ & $5.08 \mathrm{E}+04$ & $29.53 \%$ & $100 \%$ \\
\hline
\end{tabular}


RPP-RPT-42968 Revision 0

\begin{tabular}{|c|c|c|c|c|c|}
\hline & \multicolumn{4}{|c|}{ HLW GLASS PRODUCTION ESTIMATE SUMMARY RESULTS } & \\
\hline \multicolumn{2}{|c|}{21 Macro batch blend Base Case } & & & & \\
\hline \multicolumn{2}{|c|}{ Case Description: } & & & & \\
\hline \multicolumn{5}{|c|}{ 090820-1-SVF-MAR05 HLW Glass Batch Blend Results Summary Rev. C.xIsm } & \\
\hline & & & & & \\
\hline & & & & & \\
\hline \multirow[t]{2}{*}{ Waste feed: } & & & & & \\
\hline & & & & & \\
\hline \multicolumn{5}{|c|}{ 090820-1SVF-MAR03 - Feed Vector to Macro Batch Calculator - Rev G.xIsm } & \\
\hline \multicolumn{4}{|c|}{ SP4 Unconstrained Case Feed Vector Batches - 21 Macro Batch Blend } & & \\
\hline \multicolumn{5}{|c|}{ 090820-1-SVF-MAR04 Macro Batch to Process Stream Calculator Rev. D.xIsm } & \\
\hline WTP Process & & & & & \\
\hline \multicolumn{6}{|c|}{ Base Case Run 21 Macro Batch } \\
\hline \multicolumn{6}{|c|}{ Evaluate 21 Macro Batch Blending Case } \\
\hline & & & & & \\
\hline Selected & & Symbol & Value & Symbol & Value \\
\hline \multirow[t]{3}{*}{ Parameters } & & PNa, LAT, 15 & 1.500 & PS, 29a, 19 & 0.3300 \\
\hline & & Pwash,S & 0.050 & IXNa & 235 \\
\hline & & $\mathrm{PNa}(\mathrm{aq}), 19 \mathrm{~b}, 15 \mathrm{LSol}$ & 0.023 & Pwash,Al & 0.050 \\
\hline Glass Model: & & \multicolumn{3}{|c|}{ YYMMDD_N HLW Glass SVF-1623 Rev. 0-A } & \\
\hline Glass Limits & & \multicolumn{4}{|c|}{ Reference case limits from RPP-MA SP3_HLW_Glass_Limit - Rev A } \\
\hline \multirow{3}{*}{ Summary results: } & \multicolumn{5}{|c|}{ 090820-1-SVF-MAR05 HLW Glass Batch Blend Results Summary Rev. C.xIsm } \\
\hline & \multicolumn{2}{|c|}{ Base Case Run 21 Macro Batch } & & & \\
\hline & \multicolumn{3}{|c|}{ YYMMDD_N HLW Glass SVF-1623 Rev. 0-A } & & \\
\hline Limiting & Number of & Waste oxide & Glass Mass & Ave Waste & Percent of \\
\hline Component & Feed Batches & MT & MT & Loading & Glass mass \\
\hline $\mathrm{SO} 3$ & 3 & $9.90 \mathrm{E}+02$ & $2.52 E+03$ & $39.33 \%$ & $8.16 \%$ \\
\hline P2O5 & 0 & $0.00 \mathrm{E}+00$ & $0.00 \mathrm{E}+00$ & N/A & $0.00 \%$ \\
\hline $\mathrm{Cr} 2 \mathrm{O} 3$ & 0 & $0.00 \mathrm{E}+00$ & $0.00 \mathrm{E}+00$ & N/A & $0.00 \%$ \\
\hline $\mathrm{Al} 2 \mathrm{O} 3$ & 2 & $1.06 \mathrm{E}+03$ & $3.20 E+03$ & $33.26 \%$ & $10.36 \%$ \\
\hline $\mathrm{Fe} 2 \mathrm{O} 3$ & 2 & 3. $22 E+02$ & $1.00 \mathrm{E}+03$ & $32.19 \%$ & $3.24 \%$ \\
\hline $\mathrm{Na} 2 \mathrm{O}$ & 2 & $9.09 E+02$ & $1.90 \mathrm{E}+03$ & $47.73 \%$ & $6.17 \%$ \\
\hline $\mathrm{Zr}$ & 1 & $1.05 E+03$ & 2,842 & $36.91 \%$ & $9.21 \%$ \\
\hline & & & & & \\
\hline & & & & & \\
\hline Other & 11 & $8.13 E+03$ & $1.94 \mathrm{E}+04$ & $41.90 \%$ & $62.86 \%$ \\
\hline Total & 21 & $1.25 \mathrm{E}+04$ & 30868 & $40.38 \%$ & $100 \%$ \\
\hline
\end{tabular}




\section{RPP-RPT-42968 Revision 0}

\begin{tabular}{|c|c|c|c|c|c|}
\hline & \multicolumn{4}{|c|}{ HLW GLASS PRODUCTION ESTIMATE SUMMARY RESULTS } & \\
\hline \multicolumn{6}{|c|}{ Case Description: } \\
\hline \multicolumn{6}{|c|}{ 090831-1-SVF-MAR05 HLW Glass Batch Blend Results Summary Rev. C.xlsm } \\
\hline \multirow{2}{*}{\multicolumn{6}{|c|}{ Waste feed: }} \\
\hline & & & & & \\
\hline \multicolumn{6}{|c|}{ 090813-1 SVF-MAR03 - Feed Vector to Macro Batch Calculator - Rev G.xlsm } \\
\hline \multicolumn{6}{|c|}{ SP4 Unconstrained Case Feed Vector Batches - 116 macro batches } \\
\hline \multicolumn{6}{|c|}{ 090831-1-SVF-MAR04 Macro Batch to Process Stream Calculator Rev. D.xlsm } \\
\hline \multicolumn{6}{|c|}{\begin{tabular}{l|l|l|l} 
WTP Process & & & \\
\end{tabular}} \\
\hline \multicolumn{6}{|c|}{$90 \%$ 2nd stage wash efficiency, $100 \%$, melter sulfate retention } \\
\hline \multicolumn{6}{|c|}{$90 \%$ 2nd stage wash efficiency, $100 \%$, melter sulfate retention } \\
\hline & & & & & \\
\hline Selected & & Symbol & Value & Symbol & Value \\
\hline \multirow[t]{3}{*}{ Parameters } & & PNa,LAT, 15 & 1.500 & PS,29a,19 & 0.0000 \\
\hline & & Pwash,S & 0.100 & $\mathrm{IXNa}$ & 235 \\
\hline & & $\mathrm{PNa}(\mathrm{aq}), 19 \mathrm{~b}, 15 \mathrm{LSol}$ & 0.045 & Pwash, $\mathrm{Al}$ & 0.100 \\
\hline Glass Model: & & \multicolumn{3}{|c|}{ YYMMDD_N HLW Glass SVF-1623 Rev. 0-A } & \\
\hline Glass Limits & & \multicolumn{4}{|c|}{ Reference case limits from RPP-MA SP3_HLW_Glass_Limit - Rev A } \\
\hline \multirow[t]{3}{*}{$\begin{array}{l}\text { Summary } \\
\text { results: }\end{array}$} & \multicolumn{5}{|c|}{ 090831-1-SVF-MAR05 HLW Glass Batch Blend Results Summary Rev. C.xlsm } \\
\hline & \multicolumn{4}{|c|}{$90 \%$ 2nd stage wash efficiency, $100 \%$,melter sulfate retention } & \\
\hline & \multicolumn{3}{|c|}{ YYMMDD_N HLW Glass SVF-1623 Rev. 0-A } & & \\
\hline Limiting & Number of & Waste oxide & Glass Mass & Ave Waste & Percent of \\
\hline Component & Feed Batches & MT & MT & Loading & Glass mass \\
\hline $\mathrm{SO} 3$ & 35 & $3.33 \mathrm{E}+03$ & $1.39 \mathrm{E}+04$ & $23.96 \%$ & $30.80 \%$ \\
\hline $\mathrm{P} 2 \mathrm{O} 5$ & 4 & $2.53 \mathrm{E}+02$ & $8.78 \mathrm{E}+02$ & $28.81 \%$ & $1.95 \%$ \\
\hline $\mathrm{Cr} 2 \mathrm{O} 3$ & 1 & $1.27 \mathrm{E}+02$ & $3.00 \mathrm{E}+02$ & $42.46 \%$ & $0.67 \%$ \\
\hline $\mathrm{Al} 2 \mathrm{O} 3$ & 12 & $3.24 \mathrm{E}+03$ & $1.24 \mathrm{E}+04$ & $26.24 \%$ & $27.40 \%$ \\
\hline $\mathrm{Fe} 2 \mathrm{O} 3$ & 4 & $3.76 \mathrm{E}+02$ & $1.09 \mathrm{E}+03$ & $34.45 \%$ & $2.42 \%$ \\
\hline $\mathrm{Na} 2 \mathrm{O}$ & 32 & $1.26 \mathrm{E}+03$ & $3.41 \mathrm{E}+03$ & $37.03 \%$ & $7.56 \%$ \\
\hline $\mathrm{Zr}$ & 2 & $3.50 \mathrm{E}+02$ & $2.97 \mathrm{E}+03$ & $11.76 \%$ & $6.59 \%$ \\
\hline & & & & & \\
\hline Other & 26 & $4.44 \mathrm{E}+03$ & $1.02 \mathrm{E}+04$ & $43.53 \%$ & $22.62 \%$ \\
\hline Total & 116 & $1.34 \mathrm{E}+04$ & $4.51 \mathrm{E}+04$ & $29.67 \%$ & $100 \%$ \\
\hline
\end{tabular}


RPP-RPT-42968 Revision 0

\begin{tabular}{|c|c|c|c|c|c|}
\hline & \multicolumn{4}{|c|}{ HLW GLASS PRODUCTION ESTIMATE SUMMARY RESULTS } & \\
\hline \multicolumn{6}{|l|}{ Case Description: } \\
\hline \multicolumn{6}{|c|}{ 090831-2-SVF-MAR05 HLW Glass Batch Blend Results Summary Rev. C.xlsm } \\
\hline \multicolumn{6}{|l|}{ Waste feed: } \\
\hline \multicolumn{6}{|c|}{ 090813-1 SVF-MAR03 - Feed Vector to Macro Batch Calculator - Rev G.xIsm } \\
\hline \multicolumn{6}{|c|}{ SP4 Unconstrained Case Feed Vector Batches - 116 macro batches } \\
\hline \multicolumn{6}{|c|}{ 090831-2-SVF-MAR04 Macro Batch to Process Stream Calculator Rev. D.xIsm } \\
\hline \multicolumn{6}{|c|}{\begin{tabular}{l|l|l|l} 
WTP Process & & \\
\end{tabular}} \\
\hline \multicolumn{6}{|c|}{$90 \%$ 2nd stage wash eff, $67 \%$, melter sulfate retention } \\
\hline \multicolumn{6}{|c|}{$90 \%$ wash eff, otherwise Base Case Run 116 macro batch } \\
\hline & & & & & \\
\hline Selected & & Symbol & Value & Symbol & Value \\
\hline \multirow[t]{3}{*}{ Parameters } & & PNa, LAT,15 & 1.500 & $P S, 29 a, 19$ & 0.3300 \\
\hline & & Pwash, S & 0.100 & IXNa & 235 \\
\hline & & $\mathrm{PNa}(\mathrm{aq}), 19 \mathrm{~b}, 15 \mathrm{LSol}$ & 0.045 & Pwash,Al & 0.100 \\
\hline & & & & & \\
\hline Glass Model: & & \multirow{2}{*}{\multicolumn{4}{|c|}{ Reference case limits from RPP-MA SP3_HLW_Glass_Limit - Rev A }} \\
\hline Glass Limits & & & & & \\
\hline \multirow{3}{*}{ Summary results: } & \multicolumn{5}{|c|}{ 090831-2-SVF-MAR05 HLW Glass Batch Blend Results Summary Rev. C.xlsm } \\
\hline & \multicolumn{4}{|c|}{$90 \%$ 2nd stage wash eff, $67 \%$, melter sulfate retention } & \\
\hline & \multicolumn{3}{|c|}{ YYMMDD_N HLW Glass SVF-1623 Rev. 0-A } & & \\
\hline Limiting & Number of & Waste oxide & Glass Mass & Ave Waste & Percent of \\
\hline Component & Feed Batches & MT & MT & Loading & Glass mass \\
\hline $\mathrm{SO} 3$ & 21 & $1.91 \mathrm{E}+03$ & $6.98 \mathrm{E}+03$ & $27.31 \%$ & $\quad 16.99 \%$ \\
\hline P2O5 & 5 & $3.08 \mathrm{E}+02$ & $1.05 E+03$ & $29.43 \%$ & $2.55 \%$ \\
\hline $\mathrm{Cr} 2 \mathrm{O} 3$ & 1 & $1.27 \mathrm{E}+02$ & $3.00 E+02$ & $42.42 \%$ & $0.73 \%$ \\
\hline $\mathrm{Al} 2 \mathrm{O} 3$ & 14 & $3.42 E+03$ & $1.28 \mathrm{E}+04$ & $26.65 \%$ & $31.26 \%$ \\
\hline $\mathrm{Fe} 2 \mathrm{O} 3$ & 4 & $3.76 \mathrm{E}+02$ & $1.09 E+03$ & $34.40 \%$ & $2.66 \%$ \\
\hline $\mathrm{Na} 2 \mathrm{O}$ & 35 & $1.32 \mathrm{E}+03$ & $3.55 E+03$ & $37.22 \%$ & $8.64 \%$ \\
\hline $\mathrm{Zr}$ & 2 & $3.50 \mathrm{E}+02$ & 2,974 & $11.75 \%$ & $7.24 \%$ \\
\hline & & & & & \\
\hline & & & & & \\
\hline Other & 34 & $5.53 E+03$ & $1.23 E+04$ & $45.01 \%$ & $29.93 \%$ \\
\hline Total & 116 & $1.33 E+04$ & $4.11 E+04$ & $32.48 \%$ & $100 \%$ \\
\hline
\end{tabular}


RPP-RPT-42968 Revision 0

\begin{tabular}{|c|c|c|c|c|c|}
\hline & \multicolumn{4}{|c|}{ HLW GLASS PRODUCTION ESTIMATE SUMMARY RESULTS } & \\
\hline \multicolumn{6}{|l|}{ Case Description: } \\
\hline \multicolumn{6}{|c|}{ 091204-1-SVF-MAR05 HLW Glass Batch Blend Results Summary Rev. D.xIsm } \\
\hline \multicolumn{6}{|c|}{ Description: 116 macro batch base case } \\
\hline & & & & & \\
\hline \multirow{2}{*}{\multicolumn{6}{|c|}{ Waste feed: }} \\
\hline & & & & & \\
\hline \multicolumn{6}{|c|}{ 091204-1 SVF-1768 - Macro Batch Calculator - UC - Rev B.xlsm } \\
\hline \multicolumn{6}{|c|}{ SP4 Unconstrained Case Feed Vector Batches - 116 Macro Batch } \\
\hline \multirow{2}{*}{\multicolumn{6}{|c|}{$\begin{array}{l}\text { 091204-1-SVF-1767 Mission Analysis Process Stream Calculator Rev. A.xIsm } \\
\text { WTP Process }\end{array}$}} \\
\hline & & & & & \\
\hline \multicolumn{6}{|c|}{116 macro batch base case } \\
\hline \multicolumn{6}{|c|}{ rerun of 116 macro batch base case } \\
\hline Selected & & Symbol & Value & Symbol & Value \\
\hline \multirow[t]{3}{*}{ Parameters } & & PNa,LAT,15 & 1.500 & PS,29a,19 & 0.3300 \\
\hline & & Pwash,S & 0.050 & IXNa & 235 \\
\hline & & $\mathrm{PNa}(\mathrm{aq}), 19 \mathrm{~b}, 15 \mathrm{LSol}$ & 0.023 & Pwash,Al & 0.050 \\
\hline Glass Model: & & SVF-1623 & & & \\
\hline Glass Limits & & \multicolumn{4}{|c|}{ Reference case limits from RPP-MA SP3_HLW_Glass_Limit - Rev A } \\
\hline \multirow[t]{3}{*}{ Summary results: } & \multicolumn{5}{|c|}{ 091204-1-SVF-MAR05 HLW Glass Batch Blend Results Summary Rev. D.xIsm } \\
\hline & \multicolumn{2}{|c|}{116 macro batch base case } & & & \\
\hline & SVF-1623 & & & & \\
\hline Limiting & Number of & Waste oxide & Glass Mass & Ave Waste & Percent of \\
\hline Component & Feed Batches & MT & MT & Loading & Glass mass \\
\hline$\underline{\mathrm{SO} 3}$ & 18 & $1.56 \mathrm{E}+03$ & $5.80 \mathrm{E}+03$ & $26.82 \%$ & $14.77 \%$ \\
\hline P2O5 & 5 & $2.95 \mathrm{E}+02$ & $1.03 E+03$ & $28.61 \%$ & $2.63 \%$ \\
\hline $\mathrm{Cr} 2 \mathrm{O} 3$ & 1 & $1.17 \mathrm{E}+02$ & $2.53 \mathrm{E}+02$ & $46.00 \%$ & $0.65 \%$ \\
\hline $\mathrm{Al} 2 \mathrm{O} 3$ & 14 & $3.18 \mathrm{E}+03$ & 1. $25 \mathrm{E}+04$ & $25.50 \%$ & $31.82 \%$ \\
\hline $\mathrm{Fe} 2 \mathrm{O} 3$ & 4 & $3.57 E+02$ & $1.09 \mathrm{E}+03$ & $32.69 \%$ & $2.78 \%$ \\
\hline $\mathrm{Na} 2 \mathrm{O}$ & 35 & $1.26 \mathrm{E}+03$ & $3.31 E+03$ & $38.17 \%$ & $8.42 \%$ \\
\hline $\mathrm{Zr}$ & 2 & $3.50 E+02$ & 2,976 & $11.75 \%$ & $7.58 \%$ \\
\hline & & & & & \\
\hline & & & & & \\
\hline & & & & & \\
\hline Other & 37 & $5.40 E+03$ & $1.23 \mathrm{E}+04$ & $43.91 \%$ & $31.34 \%$ \\
\hline Total & 116 & $1.25 \mathrm{E}+04$ & $3.924 \mathrm{E}+04$ & $31.90 \%$ & $100 \%$ \\
\hline
\end{tabular}


RPP-RPT-42968 Revision 0

\begin{tabular}{|c|c|c|c|c|c|}
\hline & \multicolumn{4}{|c|}{ HLW GLASS PRODUCTION ESTIMATE SUMMARY RESULTS } & \\
\hline \multicolumn{6}{|l|}{ Case Description: } \\
\hline \multicolumn{6}{|c|}{ 091207-1-SVF-1817 Mission Analysis Glass Batch Blend Results Summary Rev. A.xIsm } \\
\hline \multicolumn{6}{|c|}{ Description: 56 Batch Base Case } \\
\hline & & & & & \\
\hline & & & & & \\
\hline \multicolumn{6}{|l|}{ Waste feed: } \\
\hline & & & & & \\
\hline \multicolumn{6}{|c|}{ 090911-1 SVF-1757 - Feed Vector to Macro Batch Calculator - Rev A.xIsx } \\
\hline \multicolumn{6}{|c|}{ SP4 Unconstrained Case Feed Vector Batches - 56 Macro Batch } \\
\hline \multicolumn{6}{|c|}{ 091204-2-SVF-1767 Mission Analysis Process Stream Calculator Rev. A.xlsm } \\
\hline \multicolumn{6}{|c|}{\begin{tabular}{l|l|l|l} 
WTP Process & & \\
\end{tabular}} \\
\hline \multicolumn{6}{|c|}{56 Macro Batch Blend Base Case } \\
\hline \multicolumn{6}{|c|}{56 Macro Batch Blend Base Case } \\
\hline & & & & & \\
\hline Selected & & Symbol & Value & Symbol & Value \\
\hline \multirow[t]{3}{*}{ Parameters } & & PNa,LAT, 15 & 1.500 & PS,29a,19 & 0.3300 \\
\hline & & Pwash,S & 0.050 & IXNa & 235 \\
\hline & & $\mathrm{PNa}(\mathrm{aq}), 19 \mathrm{~b}, 15 \mathrm{LSol}$ & 0.023 & Pwash,Al & 0.050 \\
\hline Glass Model: & & SVF-1623 & & & \\
\hline Glass Limits & & \multicolumn{4}{|c|}{ Reference case limits from RPP-MA SP3_HLW_Glass_Limit - Rev A } \\
\hline \multirow[t]{3}{*}{ Summary results: } & \multicolumn{5}{|c|}{ 091207-1-SVF-1817 Mission Analysis Glass Batch Blend Results Summary Rev. A.xl } \\
\hline & \multicolumn{2}{|c|}{56 Macro Batch Blend Base Case } & & & \\
\hline & SVF-1623 & & & & \\
\hline Limiting & Number of & Waste oxide & Glass Mass & Ave Waste & Percent of \\
\hline Component & Feed Batches & MT & MT & Loading & Glass mass \\
\hline $\mathrm{SO} 3$ & 10 & 1731 & 5544 & $31.23 \%$ & $15.25 \%$ \\
\hline P2O5 & 0 & 0 & 0 & N/A & $0.00 \%$ \\
\hline $\mathrm{Cr} 2 \mathrm{O} 3$ & 1 & 129 & 260 & $49.51 \%$ & $0.71 \%$ \\
\hline $\mathrm{Al} 2 \mathrm{O} 3$ & 9 & 2425 & 8980 & $27.00 \%$ & $24.70 \%$ \\
\hline $\mathrm{Fe} 2 \mathrm{O} 3$ & 4 & 374 & 1094 & $34.18 \%$ & $3.01 \%$ \\
\hline $\mathrm{Na} 2 \mathrm{O}$ & 5 & 1034 & 2645 & $39.07 \%$ & $7.28 \%$ \\
\hline $\mathrm{Zr}$ & 2 & 350 & 2974 & $11.75 \%$ & $8.18 \%$ \\
\hline & & & & & \\
\hline & & & & & \\
\hline Other & 25 & 6439 & 14856 & $43.34 \%$ & $40.87 \%$ \\
\hline Total & 56 & 12481 & 36353 & $34.33 \%$ & $100 \%$ \\
\hline
\end{tabular}


RPP-RPT-42968 Revision 0

\begin{tabular}{|c|c|c|c|c|c|}
\hline & \multicolumn{4}{|c|}{ HLW GLASS PRODUCTION ESTIMATE SUMMARY RESULTS } & \\
\hline \multicolumn{6}{|l|}{ Case Description: } \\
\hline \multicolumn{6}{|c|}{ 091208-1-SVF-1817 Mission Analysis Glass Batch Results Summary Rev. A.xIsm } \\
\hline \multicolumn{6}{|c|}{ Description: 56 macro batch blended to 112 macro batch using feed transfer tank blend } \\
\hline \multicolumn{6}{|c|}{\begin{tabular}{l|l|l|l|} 
Waste feed: & & \\
\end{tabular}} \\
\hline \multicolumn{6}{|c|}{ 091208-1-SVF-MAR15 Feed Tank Blending Blended Macro Batch Calculator Rev. A.xIsm } \\
\hline \multicolumn{6}{|c|}{ Feed tank $1 / 2$ Batch Blending 56 macro batches blended to give 112 blended macro batches } \\
\hline \multicolumn{6}{|c|}{ 091208-1-SVF-1767 Mission Analysis Process Stream Calculator Rev. A.xlsm } \\
\hline \multicolumn{6}{|c|}{\begin{tabular}{l|l|l|l|} 
WTP Process & &
\end{tabular}} \\
\hline \multicolumn{6}{|c|}{112 macro batch feed tank blending base case } \\
\hline \multicolumn{6}{|c|}{56 macro batches blended to 112 in feed tank } \\
\hline Selected & & Symbol & Value & Symbol & Value \\
\hline \multirow[t]{3}{*}{ Parameters } & & PNa,LAT,15 & 1.500 & PS,29a,19 & 0.3300 \\
\hline & & Pwash,S & 0.050 & IXNa & 235 \\
\hline & & $\mathrm{PNa}(\mathrm{aq}), 19 \mathrm{~b}, 15 \mathrm{LSol}$ & 0.023 & Pwash,Al & 0.050 \\
\hline Glass Model: & & SVF-1623 & & & \\
\hline Glass Limits & & \multicolumn{4}{|c|}{ Reference case limits from RPP-MA SP3_HLW_Glass_Limit - RevA } \\
\hline \multirow[t]{3}{*}{ Summary results: } & \multicolumn{5}{|c|}{ 091208-1-SVF-1817 Mission Analysis Glass Batch Results Summary Rev. A.xIsm } \\
\hline & \multicolumn{3}{|c|}{112 macro batch feed tank blending base case } & & \\
\hline & SVF-1623 & & & & \\
\hline Limiting & Number of & Waste oxide & Glass Mass & Ave Waste & Percent of \\
\hline Component & Feed Batches & MT & MT & Loading & Glass mass \\
\hline $\mathrm{SO} 3$ & 16 & $1.504 \mathrm{E}+03$ & $3.967 \mathrm{E}+03$ & $37.90 \%$ & $12.24 \%$ \\
\hline P2O5 & 0 & $0.000 E+00$ & $0.000 E+00$ & N/A & $0.00 \%$ \\
\hline $\mathrm{Cr} 2 \mathrm{O} 3$ & 1 & $5.225 E+01$ & $1.026 \mathrm{E}+02$ & $50.90 \%$ & $0.32 \%$ \\
\hline $\mathrm{Al} 2 \mathrm{O} 3$ & 14 & $1.966 \mathrm{E}+03$ & $6.335 E+03$ & $31.03 \%$ & $19.55 \%$ \\
\hline $\mathrm{Fe} 2 \mathrm{O} 3$ & 3 & $2.683 E+02$ & $8.091 E+02$ & $33.16 \%$ & $2.50 \%$ \\
\hline $\mathrm{Na} 2 \mathrm{O}$ & 8 & $9.272 E+02$ & $2.050 E+03$ & $45.24 \%$ & $6.32 \%$ \\
\hline $\mathrm{Zr}$ & 5 & $2.946 E+02$ & $2.552 E+03$ & $11.54 \%$ & $7.88 \%$ \\
\hline & & & & & \\
\hline & & & & & \\
\hline & & & & & \\
\hline Other & 65 & $7.454 \mathrm{E}+03$ & $1.659 E+04$ & $44.93 \%$ & $51.19 \%$ \\
\hline Total & 112 & 1. $247 E+04$ & $3.241 E+04$ & $38.47 \%$ & $100 \%$ \\
\hline
\end{tabular}


RPP-RPT-42968 Revision 0

APPENDIX B - BLENDING STUDY FEED VECTOR BATCHES AND SOURCE TANKS 
RPP-RPT-42968 Revision 0

\section{APPENDIX B- BLENDING STUDY FEED VECTOR BATCHES AND SOURCE TANKS}

A primary objective of the blending study analysis was to calculate the amount of high-level waste (HLW) glass resulting from blending the feed vectors into specific macro batches. This Appendix provides traceability between macro batches used for the various blending cases and the feed vector for the Unconstrained Case.

\section{B1.0 116 MACROBATCH CASE}

The 450 feed vectors from the System Plan (ORP-11242 Revision 4) Unconstrained Case, were converted into 116 macro batches in 090813-1 MAR03 - Feed Vector to Macro Batch Calculator - Rev G.xlsm. Feed vector batches with the same composition and/or same source tank identification were combined to yield the 116 macro batches.

Table B-1: Cross Reference for the 116 Macro Batches contains two columns, one column lists the macro batch number and the other column lists the feed vector batches combined to produce each 116 macro batch. Table B-2 shows the source tanks for the solids and liquids in each of the 116 macro batches.

\section{B2.0 56 MACROBATCH CASE}

The 450 feed vectors from the System Plan Unconstrained Case, were converted into 56 macro batches in 090911-1 SVF-1757 - Feed Vector to Macro Batch Calculator - Rev A.xlsm. This macro batch calculator run identifies the sludge/HLW batches and combines the sludge/HLW batches with low solids/LAW batches that are scheduled for delivery in the roughly the same time frame. This combination results in 56 macro batches.

Table B-3 provides cross references for the 56 Macro Batch case. It contains three columns, one column lists the corresponding 116 macro batch numbers that are included in each of the 56 macro batches, and the other column lists the feed vectors combined to produce each macro batch.

\section{B3.0 23 AND 21 MACROBATCH CASES}

The 450 feed vectors from the System Plan Unconstrained Case, were converted into 23 macrobatches in 09-08-13-2 SVF-MAR03 - Feed Vector to Macro Batch Calculator - Rev G.xlsm. This set of macro batches was developed by combining feed vector batches that appear potentially attractive blending candidates and which are currently planned to be delivered to the Waste Treatment and Immobilization Plant (WTP) within about two years of each other.

Table B-4 provides the cross reference for the 23 Macro Batch case. The three columns list batch number for the 23 macro batch case, the corresponding 116 macro batch numbers in each, and the feed vectors combined to produce each of the 23 macro batches.

The 450 feed vectors from the System Plan Unconstrained Case, were converted into 21 macro batches in 090820-1 SVF-MAR03 - Feed Vector to Macro Batch Calculator - Rev G.xlsm. Table B-5 provides the cross reference for the 21 Macro Batch case. The three columns list batch number for the 21 macro batch case, the corresponding 116 macro batch numbers, and the feed vectors combined to produce each of the 21 macro batches. 
RPP-RPT-42968 Revision 0

Table B-1. Cross Reference for the 116 Macro Batches.

\begin{tabular}{|c|c|c|c|c|c|}
\hline $\begin{array}{l}116 \text { Macro Batch } \\
\text { Number }\end{array}$ & Feed Vector Range & $\begin{array}{l}116 \text { Macro Batch Number } \\
\text { (cont.) }\end{array}$ & $\begin{array}{l}\text { Feed Vector Range } \\
\text { (cont.) }\end{array}$ & $\begin{array}{l}116 \text { Macro Batch Number } \\
\text { (cont.) }\end{array}$ & $\begin{array}{c}\text { Feed Vector Range } \\
\text { (cont.) }\end{array}$ \\
\hline 1 & $1-6$ & 40 & $163-169$ & 79 & $328-331,333-334$ \\
\hline 2 & $7-8,10$ & 41 & $170-176$ & 80 & 332 \\
\hline 3 & 9 & 42 & $177-178,180-183$ & 81 & 335 \\
\hline 4 & $11-15$ & 43 & 179 & 82 & $336-341,343$ \\
\hline 5 & $16-22$ & 44 & $184-190$ & 83 & 342 \\
\hline 6 & $23-37$ & 45 & $191-197$ & 84 & 344 \\
\hline 7 & $38-44$ & 46 & 198 & 85 & 345 \\
\hline 8 & $45-51$ & 47 & 199 & 86 & 346 \\
\hline 9 & $52,54-61$ & 48 & 200 & 87 & $347-352$ \\
\hline 10 & 53 & 49 & 201-202, 204-207 & 88 & 353 \\
\hline 11 & $62-65,67-68$ & 50 & 203 & 89 & $354-360$ \\
\hline 12 & 66 & 51 & $208-214$ & 90 & 361 \\
\hline 13 & $69-74$ & 52 & $215-221$ & 91 & 362 \\
\hline 14 & $75-76,78-82$ & 53 & 222 & 92 & 363 \\
\hline 15 & 77 & 54 & $223-228$ & 93 & $364-371$ \\
\hline 16 & $83,85-90$ & 55 & $229-232,234,236-237$ & 94 & $372-373,377-378,382-385$ \\
\hline 17 & 84 & 56 & 233 & 95 & 374 \\
\hline 18 & 91 & 57 & 235 & 96 & 375 \\
\hline 19 & 92 & 58 & $238-242,244-246$ & 97 & 376 \\
\hline 20 & $93-96,98-99$ & 59 & 243 & 98 & 379 \\
\hline 21 & 97 & 60 & $247-252$ & 99 & 380 \\
\hline 22 & 100 & 61 & $253-258,260$ & 100 & 381 \\
\hline 23 & 101 & 62 & 259 & 101 & $386-393$ \\
\hline 24 & 102 & 63 & $261-266$ & 102 & $394-401$ \\
\hline 25 & $103-107$ & 64 & 267 & 103 & $402-409$ \\
\hline 26 & $108-114$ & 65 & 268 & 104 & $410-417$ \\
\hline 27 & 115 & 66 & $269-275$ & 105 & 418 \\
\hline 28 & $116-122$ & 67 & $276-282$ & 106 & 419 \\
\hline 29 & $123-127,129$ & 68 & $283-288,290$ & 107 & 420 \\
\hline 30 & 128 & 69 & 289 & 108 & 421 \\
\hline 31 & $130-133,135-137$ & 70 & $291-296$ & 109 & $422-429$ \\
\hline 32 & 134 & 71 & $297-300,302-304$ & 110 & 430 \\
\hline 33 & 138 & 72 & 301 & 111 & $431-436$ \\
\hline 34 & $139-145$ & 73 & $305,307-311$ & 112 & $437-440$ \\
\hline 35 & $146-148,150-153$ & 74 & 306 & 113 & 441 \\
\hline 36 & 149 & 75 & $312-315,317-319$ & 114 & $442-448$ \\
\hline 37 & $154-155,157-160,162$ & 76 & 316 & 115 & 449 \\
\hline 38 & 156 & 77 & $320-323,325-327$ & 116 & 450 \\
\hline 39 & 161 & 78 & 324 & & \\
\hline
\end{tabular}


Table B-2. Trace-Back from Macro Batch Number to Source Tanks for the 116 Macro Batches.

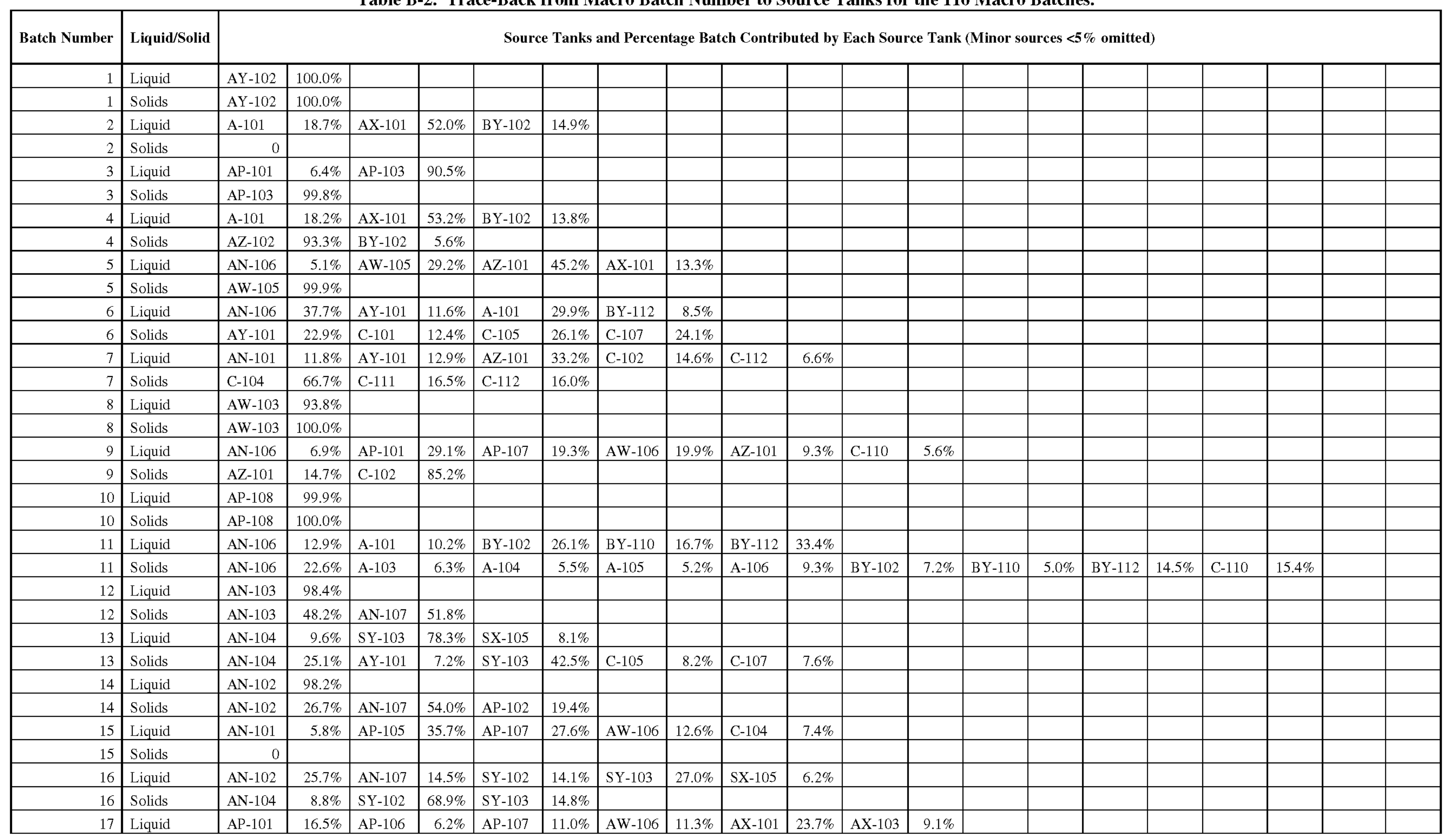


Table B-2. Trace-Back from Macro Batch Number to Source Tanks for the 116 Macro Batches.

\begin{tabular}{|c|c|c|c|c|c|c|c|c|c|c|c|c|c|c|c|c|c|c|c|}
\hline Batch Number & Liquid/Solid & & & & & Sour & e Tanks & and Perce & tage Ba & ch Contril & buted by & Each Sou & ce Tank & (Minor so & ources $<5 \%$ omitted & & & & \\
\hline 17 & Solids & AP-104 & $86.7 \%$ & AW-102 & $10.2 \%$ & & & & & & & & & & & & & & \\
\hline 18 & Liquid & AP-106 & $54.1 \%$ & A-103 & $19.7 \%$ & AX-101 & $9.8 \%$ & & & & & & & & & & & & \\
\hline 19 & Liquid & AW-106 & $66.1 \%$ & A-103 & $20.7 \%$ & & & & & & & & & & & & & & \\
\hline 19 & Solids & AW-106 & $99.7 \%$ & & & & & & & & & & & & & & & & \\
\hline 20 & Liquid & SY-102 & $6.6 \%$ & SX-105 & $54.8 \%$ & SX-112 & $15.0 \%$ & & & & & & & & & & & & \\
\hline 20 & Solids & SY-102 & $23.0 \%$ & SY-103 & $9.4 \%$ & C-102 & $12.6 \%$ & SX-105 & $8.8 \%$ & SX-110 & $8.4 \%$ & SX-112 & $34.1 \%$ & & & & & & \\
\hline 21 & Solids & 0 & & & & & & & & & & & & & & & & & \\
\hline 22 & Liquid & AN-101 & $74.7 \%$ & AP-103 & $18.2 \%$ & & & & & & & & & & & & & & \\
\hline 22 & Solids & AP-103 & $99.8 \%$ & & & & & & & & & & & & & & & & \\
\hline 23 & Liquid & AN-104 & $73.2 \%$ & BY-102 & $6.7 \%$ & BY-110 & $7.1 \%$ & BY-112 & $11.5 \%$ & & & & & & & & & & \\
\hline 23 & Solids & AN-104 & $18.8 \%$ & AN-106 & $7.9 \%$ & BY-102 & $11.3 \%$ & BY-110 & $12.0 \%$ & BY-112 & $30.4 \%$ & $\mathrm{C}-110$ & $5.4 \%$ & & & & & & \\
\hline 24 & Liquid & AN-104 & $95.0 \%$ & & & & & & & & & & & & & & & & \\
\hline 24 & Solids & AN-104 & $24.6 \%$ & AW-105 & $11.1 \%$ & AY-102 & $64.3 \%$ & & & & & & & & & & & & \\
\hline 25 & Liquid & AN-105 & $94.4 \%$ & & & & & & & & & & & & & & & & \\
\hline 25 & Solids & AN-104 & $15.7 \%$ & AN-105 & $37.5 \%$ & SY-103 & $26.5 \%$ & C-105 & $5.2 \%$ & & & & & & & & & & \\
\hline 27 & Liquid & AN-107 & $16.5 \%$ & AP-102 & $67.9 \%$ & & & & & & & & & & & & & & \\
\hline 27 & Solids & C-104 & $66.7 \%$ & $\mathrm{C}-111$ & $16.5 \%$ & C-112 & $16.0 \%$ & & & & & & & & & & & & \\
\hline 28 & Liquid & AN-103 & $16.9 \%$ & AN-105 & $65.5 \%$ & BY-101 & $6.3 \%$ & BY-111 & $5.9 \%$ & & & & & & & & & & \\
\hline 28 & Solids & AN-105 & $79.7 \%$ & BY-101 & $5.5 \%$ & BY-111 & $6.8 \%$ & & & & & & & & & & & & \\
\hline 29 & Liquid & AN-105 & $25.2 \%$ & SX-102 & $59.5 \%$ & SX-106 & $8.0 \%$ & & & & & & & & & & & & \\
\hline 29 & Solids & SX-102 & $9.7 \%$ & SX-111 & $76.1 \%$ & & & & & & & & & & & & & & \\
\hline 30 & \begin{tabular}{|l|} 
Liquid \\
\end{tabular} & AN-101 & $7.3 \%$ & AN-103 & $55.7 \%$ & AP-105 & $7.2 \%$ & A-101 & $8.9 \%$ & BY-110 & $6.3 \%$ & & & & & & & & \\
\hline 30 & Solids & AN-103 & $100.0 \%$ & & & & & & & & & & & & & & & & \\
\hline 31 & Liquid & AN-102 & $10.0 \%$ & SX-101 & $17.6 \%$ & SX-103 & $5.5 \%$ & SX-106 & $44.6 \%$ & SX-114 & $17.9 \%$ & & & & & & & & \\
\hline 31 & Solids & SX-101 & $6.4 \%$ & SX-103 & $19.8 \%$ & SX-110 & $6.4 \%$ & SX-114 & $50.7 \%$ & & & & & & & & & & \\
\hline 32 & Liquid & AN-102 & $13.5 \%$ & AN-107 & $67.7 \%$ & AP-102 & $17.0 \%$ & & & & & & & & & & & & \\
\hline 32 & Solids & AW-103 & $100.0 \%$ & & & & & & & & & & & & & & & & \\
\hline 33 & Liquid & AN-102 & $27.5 \%$ & AN-107 & $18.9 \%$ & BY-102 & $7.4 \%$ & BY-110 & $12.9 \%$ & BY-112 & $25.6 \%$ & & & & & & & & \\
\hline 33 & Solids & AN-106 & $9.1 \%$ & BY-102 & $8.8 \%$ & BY-110 & $15.1 \%$ & BY-112 & $46.7 \%$ & C-110 & $6.2 \%$ & & & & & & & & \\
\hline 34 & Liquid & BY-104 & $36.7 \%$ & BY-106 & $35.6 \%$ & BY-111 & $14.5 \%$ & & & & & & & & & & & & \\
\hline 34 & Solids & BY-101 & $10.8 \%$ & BY-103 & $31.4 \%$ & BY-109 & $27.2 \%$ & BY-111 & $21.1 \%$ & & & & & & & & & & \\
\hline 35 & Liquid & AP-108 & $5.4 \%$ & SX-102 & $17.5 \%$ & SX-103 & $7.7 \%$ & SX-106 & $7.3 \%$ & SX-107 & $10.1 \%$ & SX-109 & $44.0 \%$ & & & & & & \\
\hline 35 & \begin{tabular}{|l|} 
Solids \\
\end{tabular} & SX-107 & $34.2 \%$ & SX-109 & $34.7 \%$ & SX-111 & $11.9 \%$ & SX-114 & $7.3 \%$ & & & & & & & & & & \\
\hline 36 & Liquid & AW-101 & $98.2 \%$ & & & & & & & & & & & & & & & & \\
\hline
\end{tabular}


Table B-2. Trace-Back from Macro Batch Number to Source Tanks for the 116 Macro Batches.

\begin{tabular}{|c|c|c|c|c|c|c|c|c|c|c|c|c|c|c|c|c|c|c|c|c|c|}
\hline \multirow{2}{*}{$\begin{array}{r}\text { Batch Number } \\
36 \\
\end{array}$} & \multirow{2}{*}{\begin{tabular}{|l} 
Liquid/Solid \\
Solids \\
\end{tabular}} & \multicolumn{20}{|c|}{ Source Tanks and Percentage Batch Contributed by Each Source Tank (Minor sources <5\% omitted) } \\
\hline & & AW-101 & $100.0 \%$ & & & & & & & & & & & & & & & & & & \\
\hline 37 & Liquid & AP-102 & $17.9 \%$ & SX-104 & $34.2 \%$ & SX-109 & $30.2 \%$ & & & & & & & & & & & & & & \\
\hline 38 & Liquid & AN-101 & $10.4 \%$ & AP-102 & $5.8 \%$ & AP-105 & $10.1 \%$ & A-101 & $12.6 \%$ & AX-101 & $6.4 \%$ & BY-110 & $16.0 \%$ & BY-112 & $5.3 \%$ & & & & & & \\
\hline 38 & Solids & AP-105 & $26.7 \%$ & BY-109 & $9.2 \%$ & BY-110 & $42.9 \%$ & BY-112 & $14.0 \%$ & & & & & & & & & & & & \\
\hline 39 & Liquid & AP-105 & $9.0 \%$ & AP-106 & $5.6 \%$ & AP-107 & $6.9 \%$ & SY-103 & $5.1 \%$ & BY-101 & $8.9 \%$ & BY-102 & $10.0 \%$ & BY-109 & $8.1 \%$ & BY-110 & $7.1 \%$ & BY-112 & $5.3 \%$ & SX-105 & $15.4 \%$ \\
\hline 39 & Solids & BY-101 & $21.5 \%$ & BY-102 & $15.6 \%$ & BY-109 & $33.3 \%$ & BY-110 & $10.5 \%$ & BY-112 & $11.0 \%$ & & & & & & & & & & \\
\hline 40 & Solids & BX-107 & $50.7 \%$ & BX-109 & $32.5 \%$ & BY-107 & $16.0 \%$ & & & & & & & & & & & & & & \\
\hline 41 & Liquid & AW-101 & $8.7 \%$ & BX-107 & $5.2 \%$ & BY-105 & $8.1 \%$ & BY-107 & $12.0 \%$ & SX-104 & $37.5 \%$ & & & & & & & & & & \\
\hline 41 & Solids & BX-105 & $6.2 \%$ & BX-107 & $69.9 \%$ & BY-104 & $5.5 \%$ & BY-107 & $7.9 \%$ & BY-111 & $6.4 \%$ & & & & & & & & & & \\
\hline 42 & Liquid & S-106 & $32.3 \%$ & S-110 & $47.5 \%$ & SX-104 & $14.8 \%$ & & & & & & & & & & & & & & \\
\hline 42 & Solids & S-110 & $19.9 \%$ & SX-104 & $61.3 \%$ & SX-109 & $6.6 \%$ & & & & & & & & & & & & & & \\
\hline 43 & Liquid & AP-106 & $5.2 \%$ & AW-106 & $6.9 \%$ & BY-101 & $5.6 \%$ & BY-103 & $22.8 \%$ & BY-109 & $20.0 \%$ & SX-105 & $14.2 \%$ & & & & & & & & \\
\hline 43 & Solids & 0 & & & & & & & & & & & & & & & & & & & \\
\hline 44 & Liquid & AW-101 & $31.0 \%$ & BY-105 & $14.9 \%$ & S-106 & $26.2 \%$ & SX-104 & $5.4 \%$ & & & & & & & & & & & & \\
\hline 44 & Solids & AW-101 & $15.5 \%$ & BX-103 & $22.7 \%$ & BX-104 & $27.3 \%$ & BX-106 & $5.2 \%$ & BX-107 & $11.3 \%$ & BY-105 & $10.7 \%$ & & & & & & & & \\
\hline 45 & Liquid & BY-105 & $33.0 \%$ & S-106 & $9.7 \%$ & \begin{tabular}{|l|l|} 
S-110 \\
\end{tabular} & $19.8 \%$ & & & & & & & & & & & & & & \\
\hline 46 & Liquid & AP-104 & $8.0 \%$ & AW-102 & $9.7 \%$ & BY-101 & $5.7 \%$ & BY-103 & $12.1 \%$ & SX-103 & $28.6 \%$ & SX-105 & $6.4 \%$ & & & & & & & & \\
\hline 46 & Solids & AN-104 & $8.8 \%$ & SY-102 & $68.9 \%$ & SY-103 & $14.8 \%$ & & & & & & & & & & & & & & \\
\hline 47 & Liquid & AN-105 & $9.3 \%$ & BY-101 & $10.9 \%$ & BY-103 & $12.3 \%$ & BY-111 & $7.6 \%$ & SX-101 & $34.5 \%$ & SX-103 & $18.1 \%$ & & & & & & & & \\
\hline 47 & Solids & AN-105 & $81.4 \%$ & BY-101 & $5.6 \%$ & BY-111 & $6.9 \%$ & & & & & & & & & & & & & & \\
\hline 48 & Liquid & AW-104 & $11.5 \%$ & S-103 & $8.5 \%$ & S-108 & $72.2 \%$ & & & & & & & & & & & & & & \\
\hline 48 & Solids & AW-104 & $100.0 \%$ & & & & & & & & & & & & & & & & & & \\
\hline 49 & Liquid & B-109 & $7.5 \%$ & BX-110 & $12.1 \%$ & BY-105 & $24.7 \%$ & BY-108 & $27.3 \%$ & S-103 & $6.9 \%$ & & & & & & & & & & \\
\hline 49 & Solids & BX-104 & $8.0 \%$ & BX-105 & $23.8 \%$ & BX-112 & $18.2 \%$ & BY-105 & $25.6 \%$ & BY-108 & $6.5 \%$ & & & & & & & & & & \\
\hline 50 & Liquid & AN-101 & $19.7 \%$ & BY-101 & $22.7 \%$ & BY-103 & $18.4 \%$ & BY-111 & $18.4 \%$ & SX-101 & $6.8 \%$ & & & & & & & & & & \\
\hline 50 & Solids & BY-101 & $29.8 \%$ & BY-103 & $24.0 \%$ & BY-109 & $9.2 \%$ & BY-111 & $20.2 \%$ & SX-112 & $5.6 \%$ & & & & & & & & & & \\
\hline 51 & Liquid & AW-104 & $16.8 \%$ & B-108 & $8.0 \%$ & B-109 & $10.5 \%$ & BX-110 & $26.5 \%$ & BY-105 & $6.8 \%$ & BY-108 & $8.4 \%$ & & & & & & & & \\
\hline 51 & Solids & B-109 & $54.6 \%$ & BX-101 & $11.7 \%$ & BX-110 & $21.1 \%$ & & & & & & & & & & & & & & \\
\hline 52 & Liquid & AW-104 & $54.1 \%$ & S-108 & $7.5 \%$ & S-109 & $28.9 \%$ & & & & & & & & & & & & & & \\
\hline 52 & Solids & AW-104 & $100.0 \%$ & & & & & & & & & & & & & & & & & & \\
\hline 53 & Liquid & BY-101 & $15.5 \%$ & BY-104 & $8.2 \%$ & BY-106 & $10.2 \%$ & BY-111 & $21.1 \%$ & SX-101 & $24.5 \%$ & SX-103 & $6.2 \%$ & & & & & & & & \\
\hline 53 & Solids & BY-101 & $56.8 \%$ & BY-103 & $7.5 \%$ & BY-111 & $26.8 \%$ & & & & & & & & & & & & & & \\
\hline 54 & Liquid & S-101 & $21.3 \%$ & S-107 & $5.8 \%$ & S-108 & $58.2 \%$ & S-110 & $6.1 \%$ & & & & & & & & & & & & \\
\hline 54 & Solids & S-101 & $44.2 \%$ & S-107 & $26.5 \%$ & S-108 & $12.9 \%$ & S-110 & $6.3 \%$ & & & & & & & & & & & & \\
\hline 55 & Liquid & S-101 & $39.4 \%$ & S-103 & $22.0 \%$ & S-108 & $7.1 \%$ & S-110 & $16.1 \%$ & & & & & & & & & & & & \\
\hline
\end{tabular}


Table B-2. Trace-Back from Macro Batch Number to Source Tanks for the 116 Macro Batches.

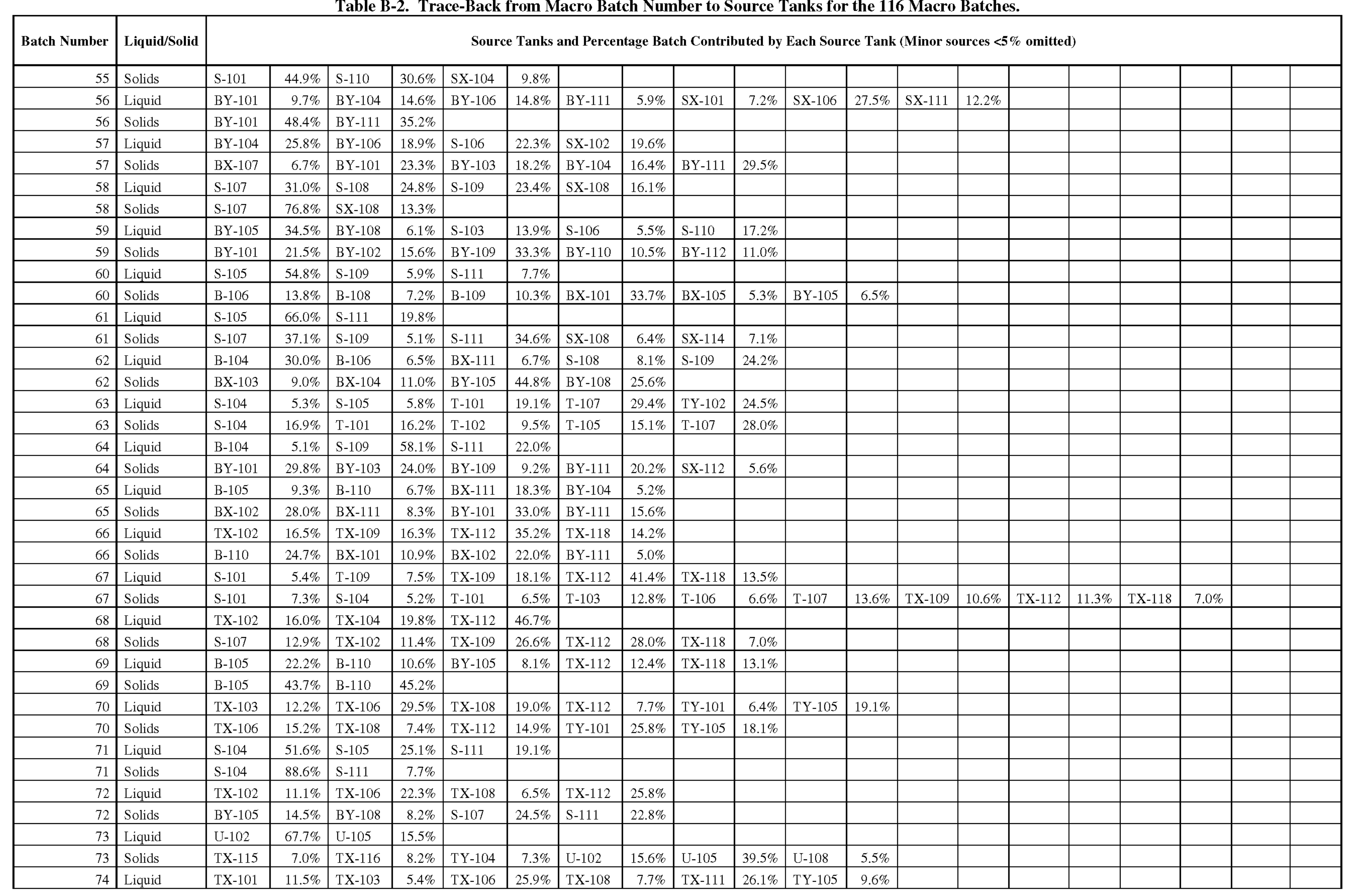


Table B-2. Trace-Back from Macro Batch Number to Source Tanks for the 116 Macro Batches.

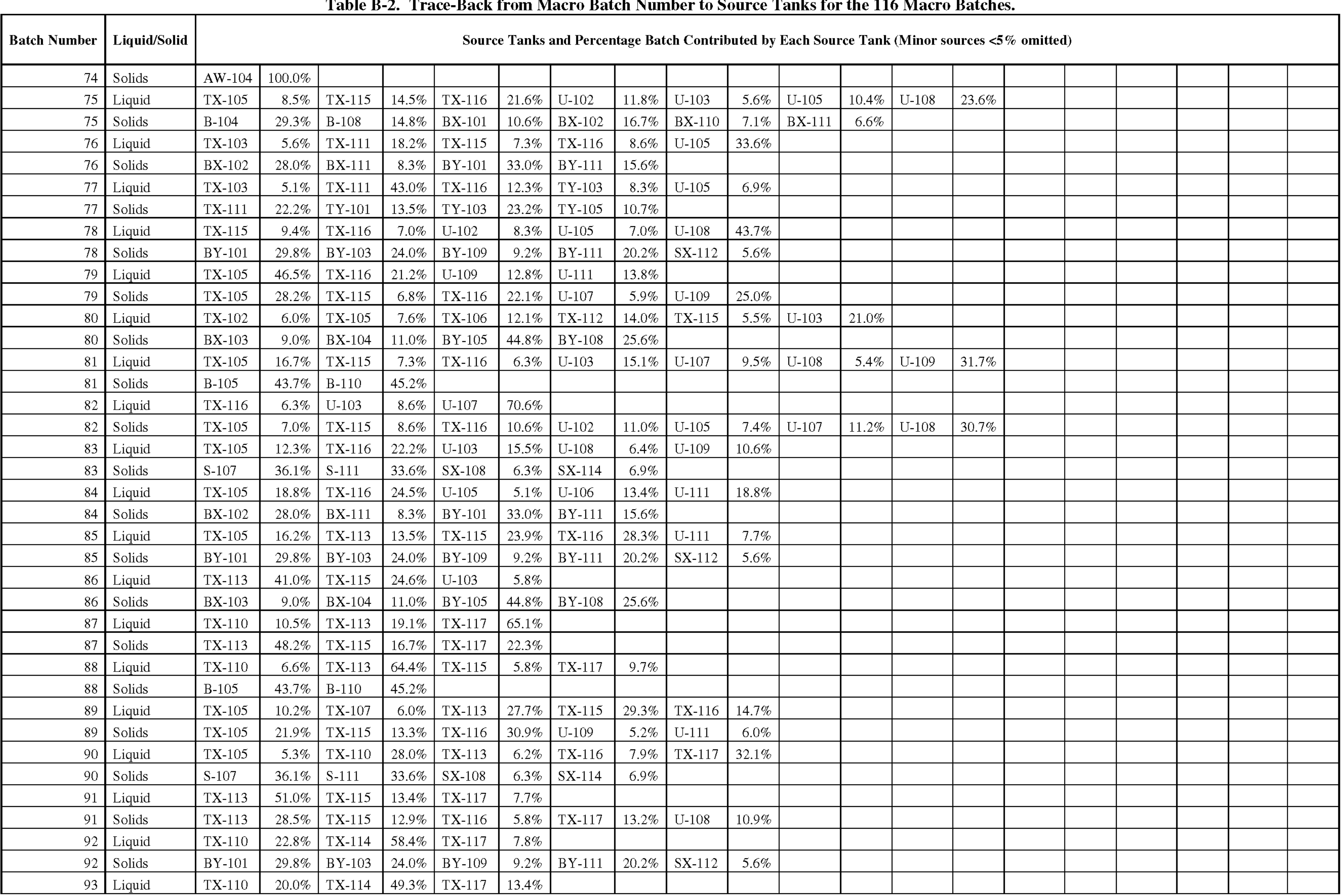


Table B-2. Trace-Back from Macro Batch Number to Source Tanks for the 116 Macro Batches.

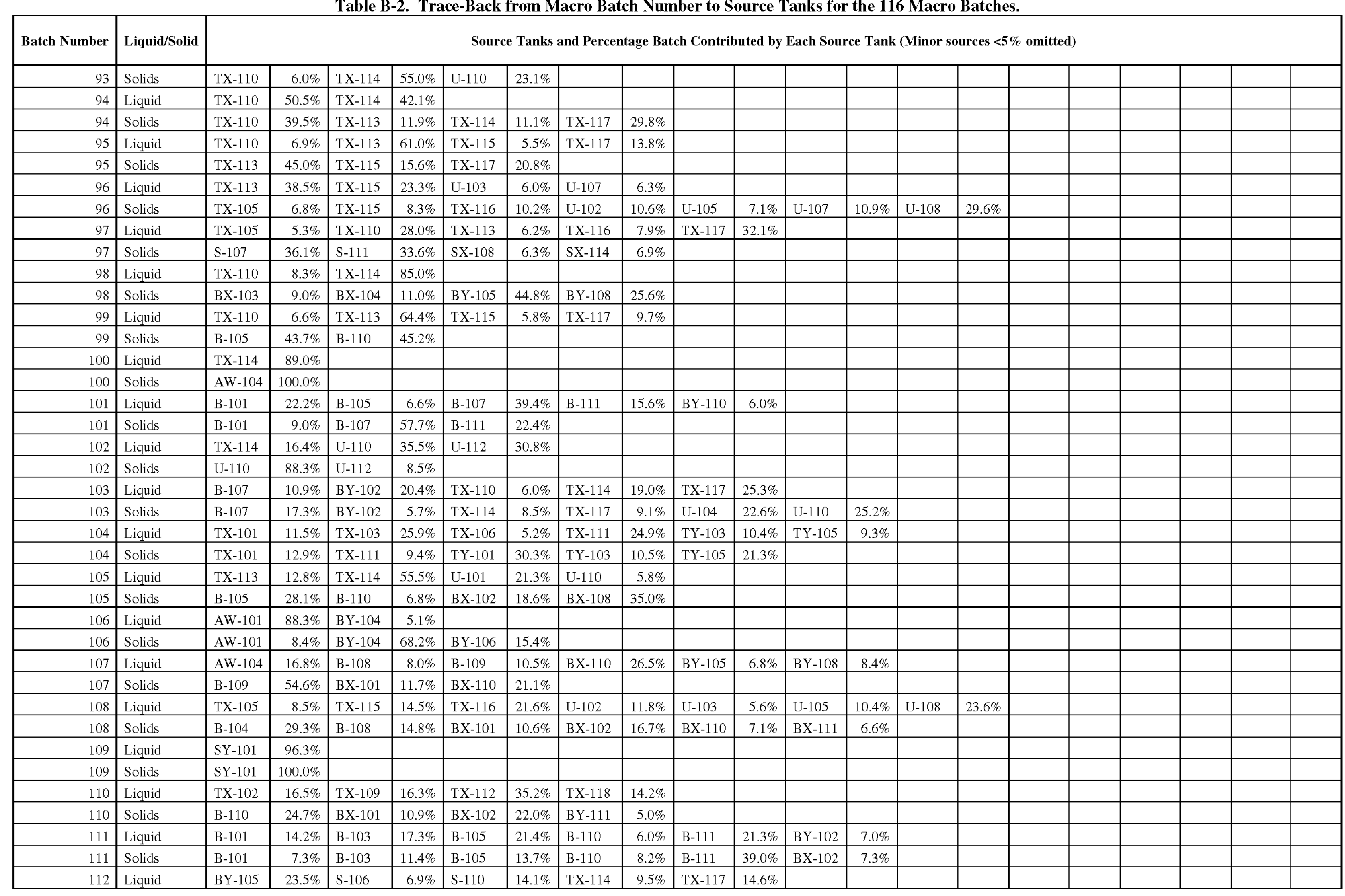


Table B-2. Trace-Back from Macro Batch Number to Source Tanks for the 116 Macro Batches.

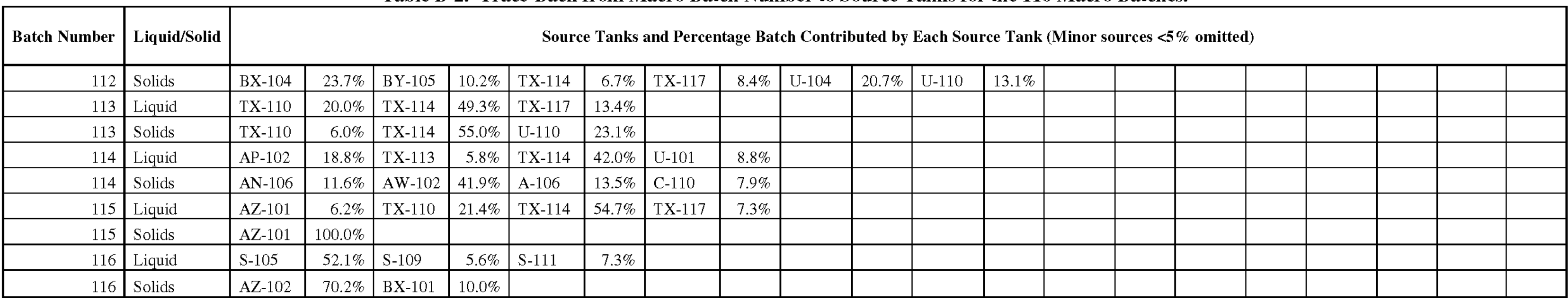


RPP-RPT-42968 Revision 0

Table B-3. Cross References for the 56 Macro Batch Case.

\begin{tabular}{|l|l|l|l|l|l|}
\hline $\begin{array}{c}\text { 56 Macrobatch } \\
\text { Number }\end{array}$ & $\begin{array}{c}\mathbf{1 1 6} \\
\text { Macrobatch } \\
\text { Number }\end{array}$ & Feed Vector Range & $\begin{array}{c}\mathbf{5 6} \text { Macrobatch } \\
\text { Number (cont.) }\end{array}$ & $\begin{array}{c}\mathbf{1 1 6} \text { Macrobatch } \\
\text { Number (cont.) }\end{array}$ & Feed Vector Range (cont.) \\
\hline 1 & $1-2$ & $1-6,7-8,10$ & 29 & $57-58$ & $235,238-242,244-246$ \\
\hline 2 & $3-4$ & $9,11-15$ & 30 & $59-60$ & $243,247-252$ \\
\hline 3 & 5 & $16-22$ & 31 & $61-62$ & $253-260$ \\
\hline 4 & 6 & $23-37$ & 32 & $63-65$ & $261-268$ \\
\hline 5 & 7 & $38-44$ & 33 & $66-67$ & $269-282$ \\
\hline 6 & 8,10 & $45-51,53$ & 34 & $68-69$ & $283-290$ \\
\hline 7 & 9 & $52,54-61,66$ & 35 & 70,72 & $291-296,301$ \\
\hline 8 & 11 & $62-65,67-68,77$ & 36 & 71 & $297-300,302-304,306$ \\
\hline 9 & 13 & $69-74,84$ & 37 & 73 & $305,307-311,316$ \\
\hline 10 & 14 & $75-76,78-82,91$ & 38 & 75 & $312-315,317-319,324$ \\
\hline 11 & 16,21 & $83,85-90,97$ & 39 & 77,80 & $320-323,325-327,332$ \\
\hline 12 & $19-20,22-23$ & $92-96,98-101$ & 40 & 79 & $328-331,333-335$ \\
\hline 13 & $24-26$ & $102-114$ & 41 & $82-84$ & $336-341,342-344$ \\
\hline 14 & $27-28$ & $115-122$ & 42 & $85-87$ & $345-352$ \\
\hline 15 & $29-30$ & $123-129$ & 43 & $88-89$ & $353-360$ \\
\hline 16 & $31-32$ & $130-137$ & 44 & $90-93$ & $361-371$ \\
\hline 17 & $33-34$ & $138-145$ & 45 & $94-96$ & $372-375,377-378,382-385$ \\
\hline 18 & $35-36$ & $146-153$ & 46 & 97,101 & $376,386-393$ \\
\hline 19 & $37-38$ & $154-160,162$ & 47 & 98,102 & $379,394-401$ \\
\hline 20 & $39-40$ & $161,163-169$ & 48 & 104 & $380,410-417$ \\
\hline 21 & 41,43 & $170-176,179$ & 49 & 105 & 381,418 \\
\hline 22 & 42 & $177-178,180-183,198$ & 50 & 103,106 & $402-409,419$ \\
\hline 23 & 44 & $184-190,199$ & 51 & $107-108$ & $420-421$ \\
\hline 24 & 45,48 & $191-197,200$ & 52 & $109-110$ & $422-430$ \\
\hline 25 & $49-50$ & $201-207$ & 53 & $111-112$ & $431-440$ \\
\hline 26 & $51-52$ & $208-221$ & 54 & $113-114$ & $441-448$ \\
\hline 27 & $53-54$ & $222-228$ & 55 & 115 & 449 \\
\hline 28 & $55-56$ & $229-234,236-237$ & 56 & 116 & 450 \\
\hline & & & & \\
\hline
\end{tabular}


Table B-4. Cross References for the 23 Macro Batch Case.

\begin{tabular}{|c|c|c|}
\hline $\begin{array}{l}23 \text { Macrobatch } \\
\text { Number }\end{array}$ & 116 Macrobatch Number & Feed Vector Range \\
\hline 1 & 1 & $1-6$ \\
\hline 2 & 2 & $7-8,10$ \\
\hline 3 & 3 & 9 \\
\hline 4 & 4 & $11-15$ \\
\hline 5 & $5-7$ & $16-44$ \\
\hline 6 & $8,10,12-13$ & $45-51,53,66,69-74$ \\
\hline 7 & $9,11,14-18$ & $52,54-65,67-68,75-91$ \\
\hline 8 & $19-22,24,25$ & $92-100,102-107$ \\
\hline 9 & $23,26,27$ & $101,108-115$ \\
\hline 10 & $28-34$ & $116-145$ \\
\hline 11 & $35-41$ & $146-176$ \\
\hline 12 & $42-52$ & $177-221$ \\
\hline 13 & $53,54,60$ & $222-228,247-252$ \\
\hline 14 & $55,57,63-65$ & $229-232,234-237,261-268$ \\
\hline 15 & 56,62 & 233,259 \\
\hline 16 & $58,59,66,67$ & $238-246,269-282$ \\
\hline 17 & $61,68-70$ & $253-258,260,283-296$ \\
\hline 18 & $71-79$ & 297-331, 333-334 \\
\hline 19 & $80-87$ & $332,335-352$ \\
\hline 20 & $88-93$ & $353-371$ \\
\hline 21 & $94-98,102$ & $372-379,394-401$ \\
\hline 22 & $94,99-101,103-106$ & $380-393,402-419$ \\
\hline 23 & $107-116$ & $420-450$ \\
\hline
\end{tabular}


Table B-5. Cross References for the 21 Macro Batch Case.

\begin{tabular}{|c|c|c|}
\hline 21 Macrobatch Number & 116 Macrobatch Number & Feed Vector Range \\
\hline 1 & 1 & $1-6$ \\
\hline 2 & 2 & $7-8,10$ \\
\hline 3 & 3 & 9 \\
\hline 4 & 4 & $11-15$ \\
\hline 5 & $5-6$ & $16-37$ \\
\hline 6 & $7-10$ & $38-61$ \\
\hline 7 & $11-18$ & $62-91$ \\
\hline 8 & $19-22,24,25$ & $92-100,102-107$ \\
\hline 9 & $23,26,27$ & $101,108-115$ \\
\hline 10 & $28-34$ & $116-145$ \\
\hline 11 & $35-41$ & $146-176$ \\
\hline 12 & $42-50$ & $177-207$ \\
\hline 13 & $51-56$ & $208-234,236-237$ \\
\hline 14 & $57-63$ & $235,238-266$ \\
\hline 15 & $64-71$ & $267-300,302-304$ \\
\hline 16 & $72-80$ & $301,305-334$ \\
\hline 17 & $81-87$ & $335-352$ \\
\hline 18 & $88-92$ & $353-363$ \\
\hline 19 & $93-102$ & $364-401$ \\
\hline 20 & $103-106$ & $402-419$ \\
\hline 21 & $107-116$ & $420-450$ \\
\hline
\end{tabular}

